\title{
Literatur und Religion als Rito- und Mythopoetik. Überblicksartikel zu einem neuen Ansatz in der Klassischen Philologie
}

\section{Einführung}

Nachdem man sich am Übergang zum dritten Jahrtausend endgültig vom Glauben an die Aufklärung und die damit verbundene alleinseligmachende Rationalität verabschiedet hat, können andere Vorstellungen und Ansätze, die durchaus bereits in vormodernen Kunst- und Literaturformen, obgleich in anderer diskursiver Formation, virulent waren, auch für das aktuelle Denken Einfluß gewinnen. ${ }^{1}$ Hier denke ich vor allem an die Religion und an religiöse Äußerungsformen wie Mythos, Performativität und Ritualität. Während lange Zeit als Dogma galt, daß sich der griechische Geist "vom Mythos zum Logos" entwickelt habe, setzt sich allmählich allgemein die Erkenntnis durch, daß beide Bereiche sich gegenseitig bedingen und man zum Teil sogar von einer gegenwendigen Entwicklung sprechen kann. ${ }^{2}$

Die postulierte Entwicklung von religiösen, kultischen Anfängen hin zu rein säkularen Spiel- und Literaturformen hat sich also ihrerseits als moderne mythische Erzählung erwiesen. Gerade im frühen Griechenland, aber auch in Ägypten und im Vorderen Orient, gibt es keine moderne Aufspaltung in einen säkularen Bereich der Öffentlichkeit und Politik auf der einen, in eine Sphäre der Religion auf der anderen Seite. In einer weitgehend oral geprägten traditionellen Gesellschaft bilden Mythos und Ritual den wichtigsten Bezugspunkt, das heißt den Makrotext, nach dem die Menschen ihr Leben und Denken ausrichten. ${ }^{3}$ Die künstlerischen Äußerungsformen sind dementsprechend nicht l'art pour l'art, sondern einge-

${ }^{1}$ Der vorliegende Überblicksartikel basiert zum Teil auf meinem grundlegenden Lexikonartikel (Bierl 2002a). Vgl. allgemein Kuschel 1997; Auerochs 2002. Ebenfalls zu Griechenland, zudem mit Blick auf das moderne Griechenland, vgl, Alexiou 2002 und Yatromanolakis/Roilos 2003; 2004. Zu Rom vgl. Feeney 1998; Barchiesi/Rüpke/Stephens 2004.

2 Nestle 1940; dagegen nun Most 1999; Buxton 1999; vgl. zudem Kulenkampff 1993. $\mathrm{Zu}$ einer Bedeutungsuntersuchung von Mythos und Logos vgl. Nesselrath 1999.

3 Nagy 1990, 30-33, 66-68; Bierl 2001, passim und Index s. v. 'Mythos' und 'Ritual'; ähnlich auch Aloni 1998, 18-19. 
bettet in traditionelle Mentalitäten und Vorstellungen. Der Sänger, Aöde und Rhapsode, Schriftsteller oder Dichter fingiert seine Handlungen, also die Narration oder das theatrale Spiel, nicht völlig voraussetzungslos aus einem Nichts, sondern gründet sie auf verfügbare Diskurse der Lebenswelt. Daraus folgt zwangsläufig, daß gerade der Mythos, das Ritual und heortologische Abläufe für die damalige poetische Konstruktion entscheidende inhaltliche Muster darstellen.

Es geht hier also um eine grundlegende Methode, die sich das Ziel steckt, religiöse Performanz sowie religionswissenschaftliche Aspekte und Themen für die Interpretation von literarischen Texten umfassend fruchtbar zu machen. Dabei wird die produktive und dynamische Interdependenz von Literatur und religiösen Äußerungsformen betont. Unter anderem stellt sich die Frage, wie diese als heuristisches Instrumentarium dienen können, um die Struktur und den Sinn von literarischen Formen historisch adäquat zu erfassen. Im folgenden werden die Grundlagen einer rituellmythischen Poetik mit Fokussierung auf die altgriechische Literatur erarbeitet. Dieser Forschungsansatz ordnet sich in idealtypischer Weise in die neue kulturwissenschaftliche Ausrichtung der Geisteswissenschaften ein, in der gerade in den letzten Jahren Fragen der Ritualität, Ikonizität und Performativität sowie die Vernetzung aller einer Gesellschaft zugrundeliegenden kulturellen Diskurse im Vordergrund stehen. ${ }^{4}$

Mythen und Riten können offenbar aufgrund ihres sozialen Energiepotentials Performanzen und Erzählungen hervorbringen. In einer solchen rituellen Mythopoesie entsteht in Wucherungen und Neukombinationen von kulturellen Teilgeflechten ein komplexes Gewebe, der 'Text', der in markierter und kunstvoller Form zu Literatur werden kann. ${ }^{5}$

\section{Voraussetzungen, Abgrenzungen und die Problematisierung der Begriffe 'Literatur' und 'Religion'}

Aus diesen Prämissen wird deutlich, daß es hier nicht um die alte Frage von postulierten religiösen Ursprüngen im Sinne einer entwicklungsgeschichtlichen Abfolge gehen soll. Eine solche Suche war bis vor etwa dreißig Jahren nahezu ausschließlich der Gegenstand der Forschung in

\footnotetext{
${ }^{4}$ Bachmann-Medick 1996; Neumann/Weigel 2000.

5 Neumann 2000.
} 
diesem Themenkomplex. Der genetische Zusammenhang von Ritual und Literatur wird zwar in den antiken und anderen Literaturen allgemein weitgehend vorausgesetzt, kann aber nicht historisch exakt rekonstruiert werden. Dies gilt insbesondere für die Situation im frühen Griechenland. Entscheidend ist das Faktum, daß es hier im Gegensatz zur von der Aufklärung geprägten Moderne keine Trennung in eine säkulare Literatur und eine religiöse Sphäre gibt, sondern Religion in ihren Manifestationen von Ritual und Mythos überall mit der Lebenswelt - unter anderem mit der Politik ${ }^{6}$ - sowie mit deren kulturell-symbolischen Schöpfungen interagiert. Für den hier zu erörternden Zugang ist ein Verständnis grundlegend, das Literatur nicht als autonomes Artefakt eines von den gesellschaftlichen Faktoren losgelösten Künstlers, sondern als sozio-kulturelles Phänomen betrachtet. Dabei rückt also der pragmatische Kontext ins Zentrum, ohne daß man freilich dem Autor eigene Intentionen absprechen wollte. Allerdings muß zudem innerhalb der sich über mehr als ein Jahrtausend erstreckenden Epoche, in der die antike Literatur blühte, differenziert werden. Die Frühphase der archaischen und frühen klassischen Zeit Griechenlands zeichnet sich durch die Mündlichkeit der Vermittlung in einem okkasionellen Rahmen aus. Ritual und Mythos stellen hier zentrale Kategorien einer ursprünglichen, lokal begrenzten Polis dar, die sich weitgehend über diese definiert. Gattungen sind hierbei nicht nur formale, sondern vor allem funktionale literarische Bezugsgrößen, die sich aus der Gelegenheit der Aufführung ergeben. ${ }^{7}$ Die Theorie und die Anfänge des hier thematisierten Ansatzes haben sich vor allem im Bereich der Gräzistik entwickelt, weshalb das Fach im vorliegenden Band im Mittelpunkt stehen soll. Die Verankerung einer solchen 'Literatur' in einer mythisch-rituellen Lebenswelt, das heißt ihr 'Sitz im Leben', läßt sich besonders gut anhand der frühgriechischen Lyrik und des Dramas zeigen, das in seiner Einbettung in Kulten zu Ehren des Dionysos stets im Zentrum ritualbestimmter Betrachtung stand. Aber selbst in dieser Phase lassen sich neben dem funktionalen Gebrauchswert, beispielsweise der Hymnik, überall bereits literarische Gattungstraditionen und intertextuelle Phänomene beobachten. Ein literarischer Text erschließt sich also nie ausschließlich nur in bezug auf einen präexistenten Kontext, sondern Text und Kontext können

\footnotetext{
${ }^{6}$ Connor 1988; Sourvinou-Inwood 1990.

${ }^{7} \mathrm{Vgl}$. Nagy 1994/95; Warning 1976.
} 
durchaus in einem dynamisch-antagonistischen Verhältnis stehen. ${ }^{8}$ Nach dem epochalen Einschnitt, den der Übergang zur Schriftlichkeit markiert, wandelt sich das Phänomen qualitativ, doch kann auch im Hellenismus und in der römischen Zeit weiterhin von einem produktiven Nebeneinander von Literatur und Religion gesprochen werden. Selbst für diese spätere Entwicklungsstufe zeichnet sich im Einklang mit einer Neubewertung der römischen Religion ${ }^{9}$ ein kreatives und dynamisches Verhältnis der beiden kulturell-symbolischen Äußerungssysteme ab. ${ }^{10}$ Die Vorstellung, daß Rom angeblich ein mythenloses Volk ohne jegliche Imagination gewesen sei, während die Griechen im Mythos kreativ, ursprünglich und authentisch gedacht hätten, beruht auf einem romantischen Vorurteil. ${ }^{11}$ Selbstverständlich war auch Rom in der Lage, sich auf der Basis fremder griechischer und indigener mythischer Geschichten seiner eigenen Grundlagen zu versichern und imaginär zu spiegeln. ${ }^{12}$ Diese Beziehung gegenseitiger Befruchtung in sich überlagernden Kulturen in einem Prozeß von Rezeption und Überbieten (aemulatio) bestimmte dann die europäische Geistesgeschichte über das Mittelalter und die Renaissance bis hin zu Aufklärung und Gegenwart. Mythisch-rituelle Themen der Antike werden hierbei mehr und mehr zu symbolgeladenen literarischen Motiven, mittels derer man allgemein-humane und gesellschaftspolitische Konflikte immer neu bearbeiten kann. Neuerdings wird der anthropologische Zusammenhang von Ritual und Literatur selbst für die Moderne wieder reflektiert. ${ }^{13}$ Die beiden Bereichen innewohnende narrative Struktur, die Mimesis, die Ästhetik der Präsentation und nicht zuletzt die affirmative Funktion stehen dabei im Mittelpunkt. ${ }^{14}$

Literatur und Religion basieren auf symbolisch-kulturellen Zeichen, die aus realen und imaginären Substraten gespeist werden. Im Geflecht solcher über Sprache, Bilder und Symbole hergestellter Diskurse verortet der Mensch seine Stellung zur Umwelt und drückt in ästhetisch markierter Form sein Denken und Weltverständnis aus. Poesie wird zu einem auf wirkliche und fiktive Gegenstände bezogenen kulturell-ästhetischen 'Pro-

\footnotetext{
${ }^{8}$ Vgl. Feeney 1998, 141.

${ }^{9}$ Vgl. Beard 1993; Graf 1993a.

${ }^{10}$ Feeney 1998; 2004.

$11 \mathrm{Vgl}$. Graf 1993a; $1993 \mathrm{~b}$.

12 Feeney 1998; Wiseman 2004.

13 Braungart 1996; 1998.

14 Braungart 1996; 2004 und hier in Band 2.
} 
dukt' intellektueller Reflexion. Das Fiktive erhält so eine Eigendynamik: Es verselbständigt sich in der produktiven Aneignung, Überbietung, ja sogar Hinterfragung und Aufhebung der zugrundeliegenden mythischrituellen Strukturen zunehmend zum kreativen Expressionsmedium. ${ }^{15}$ In den antiken mediterranen Kulturen bildet sich eine situationsabstrakte Literatur, die auf Fiktionalität, Intertextualität und Rezeption beruht, erst allmählich heraus. ${ }^{16}$ Gerade die Entwicklung im griechischen Bereich stellt einen solchen graduellen Übergang in aller Deutlichkeit vor Augen. Es lohnt sich daher ganz besonders, die diesbezügliche Situation exemplarisch anhand der griechischen Kultur zu beleuchten, zumal diese in ihrer Deutung als das "nächste Fremde" zum Ursprung und Modell, ${ }^{17}$ von dem aus man sich sowohl orientiert als auch kontrastiv abhebt, für sämtliche spätere europäisch-westliche Literatur avanciert ist. In der archaischen und klassischen Zeit stehen viele Texte immer noch in einem pragmatischen, ortsabhängigen, rituellen oder gesellschaftlich funktionalen Kontext. Gedichte von Sappho oder Pindar wie auch das attische Drama sind nicht als autonome Literatur komponiert, sondern werden erst von späteren Generationen als solche gedeutet und rezipiert. ${ }^{18}$ Gewebe kulturell-symbolischer Produktion, also Texte, ursprünglich gedacht zur Aufführung oder Rezitation in bestimmten funktionalen Zusammenhängen (am aristokratischen Hof, im Symposion, Mädchenkreis, Dionysoskult und Poliskontext), besitzen bereits das Potential zur Literatur, werden aber erst im Zuge literaturgeschichtlicher Betrachtung zu 'Literatur' erklärt. Entscheidend für diesen Perspektivenwechsel ist unter anderem auch die 'Schule' im weitesten Sinne. Beispielsweise wird der panhellenische und kanonische Text Homers ebenso wie das attische Drama zum obligatorischen Lektürestoff. Dabei übersieht man schnell, daß diese Literaturprodukte eigentlich zur Aufführung bestimmt sind, in ihrer narrativen Struktur und im Bildreservoir parasitär auf den bis dato zentralen Diskursen von Mythos und Ritual beruhen, sich diese aneignen und durch Kombination und Variation ihrer Elemente Neues schaffen. Und selbst nach dem epochalen Einschnitt des Hellenismus ist Literatur größtenteils weiterhin

${ }^{15}$ Hierzu gab B. v. Jagows Vortrag an unserer Konferenz interessante Anregungen.

16 Vgl. für die Situation in Ägypten Loprieno 1996. Zum Literaturbegriff der Ägyptologie vgl. Burkard/Thissen 2003, 14-28. Zum Zusammenhang von Literatur und Religion in Ägypten vgl. Baines 1996 und Loprieno in diesem Band.

${ }^{17}$ Hölscher 1965 , bes. 81 .

${ }^{18} \mathrm{Zu}$ den Zusammenhängen bei Sappho vgl. Bierl 2003. 
Mythopoesie, freies Spiel mit vertrauten oder nun gesuchten Formen und Varianten von Kult, Ritual und Mythos, die strukturbildend wirken. Dies hat nicht unbedingt mit einem Säkularisierungsprozeß zu tun, wie man durch eine vorschnelle Analogie mit neuzeitlichen Vorgängen annehmen könnte, ${ }^{19}$ da eine vollkommene Loslösung der Gesellschaft vom Sakralen noch undenkbar ist. Bei dem Begriff 'Religion' sollte man zudem moderne oder christliche Assoziationen vermeiden. Religion ist in dieser Verwendung nicht als innige und individuelle 'Rückbindung' an einen Gott zu verstehen. "Religion' ist ein anachronistischer, totalisierender Begriff, den die Griechen so nicht kannten." 20 Die Griechen agieren lokal begrenzt und drücken sich in den verschiedenen Zentren jeweils kollektiv aus. Sie vollziehen Handlungen in Riten und denken in Mythen. Landläufig bezeichnet man diese symbolischen Ausdrucksformen im Dialog mit den Göttern als 'Religion', und ich will aus Gründen einer allgemein verständlichen Terminologie hier daran festhalten. Allerdings ist aus dem Gesagten deutlich geworden, daß sowohl 'Literatur' als auch 'Religion' durchaus problematische Begrifflichkeiten für diese Fragestellung darstellen, also vom Inhalt her zu relativieren und zu hinterfragen sind.

Aufgrund idealistischer Traditionen hat es diese hier vorgestellte heuristische Methode in Deutschland ungleich schwerer als in anderen Kulturkreisen, insbesondere im anglo-amerikanischen Raum. Denn gerade im Falle der USA gründet ein aufgeklärter Staat ebenfalls auf einem mythisch-historischen, religiösen Substrat. In den Zeiten der Anfänge hat man sich dabei vor allem auf Diskurse der Antike bezogen. ${ }^{21}$

Für die hier präsentierte Betrachtungsweise sprechen allgemein die geisteswissenschaftlichen Trends der letzten Jahrzehnte mit den einzelnen 'Wenden', dem linguistischen, dem interpretativen, dem ikonischen und zuletzt dem performativen turn. ${ }^{22}$ Auffällig ist vor allem ein Trend zur Literaturwissenschaft als Kulturwissenschaft mit einer stark anthropologisch-ethnologischen Ausrichtung. Diese wirkte sich vor allem auf dem Gebiet der griechischen Religion aus, zumal die Religionswissenschaft als relativ modernes Gebiet ihre Methoden umgekehrt aus den geisteswissen2002 .

19 Vgl. Ruh 1980; 1998; Meuthen 1993; Tervooren 1993; Kuschel 1997; Auerochs

${ }^{20}$ Kurke 2005, 82 .

21 Vgl. Richardson 1978; Reinhold 1984.

22 Bachmann-Medick 1996, 7-30; zum Performativen vgl. Fischer-Lichte 1998a; 1998b; 1999; Fischer-Lichte/Wulf 2001; Wirth 2002; Fischer-Lichte 2004. 
schaftlichen und soziologischen Disziplinen schöpfte. ${ }^{23}$ Gerade durch die Sensibilisierung für das Performative rückt man zunehmend davon ab, kulturelle Begebenheiten nur als Texte zu sehen, wie es in der Anthropologie lange Zeit üblich war. Damit hatte man unbewußt oder bewußt nur das Primat der Textlichkeit anerkannt, das sich in den philologisch ausgerichteten Geisteswissenschaften etabliert hat. Wie die neue Forschung zeigt, ist aber selbst ein Ritual keine feste, objektivierbare Einheit oder allgemeingültige Gegebenheit, die schriftlich tradierbar in allen Kulturen anerkannt wird. Demzufolge ist es nach $\mathrm{C}$. Bell vernünftiger, von ritueller Handlung oder performativer Ritualisierung zu sprechen, mit der bei den Akteuren über am Körper ausgelebte Wirkungen Sinn gestiftet werden kann. ${ }^{24}$ Dieser Sinn wird dann im Mythos in autoritative Erzählungen gegossen, die schließlich in die Literatur Eingang finden. In dem Ernstnehmen des religiös-kulturellen Kontexts im Hinblick auf die literarische Struktur grenzt sich diese Richtung von der rein textimmanenten, formalistischen Methode der Klassischen Philologie ab, die ihr Pendant im New Criticism hatte, und knüpft damit eher an altertumswissenschaftliche Ansätze an, wie sie als erster K. O. Müller (1797-1840) vertrat. ${ }^{25}$ Es soll im folgenden nicht um die historische Thematik der Literatur als möglichen Wissensspeichers des kulturellen Gedächtnisses - auch wenn Mythos und Ritual etwa in Katalogdichtungen wie Hesiods Theogonie zentrale Bereiche davon darstellen - oder als Quelle für Religionsgeschichte gehen. Ebensowenig steht die Erforschung der individuellen Religion bei einem bestimmten Autor oder die ästhetisch-religionsphänomenologische Suche nach dem Wesen der Religion zur Debatte, sondern der hier verfolgte Ansatz prüft die Frage, wie sich religiöse Äußerungsformen und textliche Strukturen gegenseitig beeinflussen. Dabei fließen traditionelle philologische Vorgehensweisen sowie moderne Methoden ein, wie zum Beispiel die Linguistik, Semiologie, Narratologie, Foucaultsche Diskursanalyse, Ethnologie, historische Anthropologie, Bildwissenschaft, Soziologie und die Performance- und Gender-Studies. Dem stereotyp geäußerten Vorwurf des Reduktionismus auf ein einziges Verfahren oder ein einzelnes mythisch-rituelles Schema kann damit begegnet werden.

${ }^{23}$ Kohl 1988, 243.

${ }^{24}$ Bell 1992, 69-117.

${ }^{25}$ Calder/Schlesier 1998 


\section{Wissenschaftsgeschichte, Personen und Positionen}

Bei genauerer Betrachtung ist die Richtung nicht so neu wie es erscheint. ${ }^{26}$ Die wissenschaftsgeschichtliche Tradition spiegelt bekanntlich zugleich die Trends der Geisteswissenschaften wider. K. O. Müller (1797-1840) liest zuerst Homer unter mythisch-ritualistischen Aspekten, unter anderem als Reflex von lokalen Kultsagen. ${ }^{27}$ Im Gefolge der indoeuropäisch ausgerichteten Forschungen, vor allem von F. M. Müller (1823-1900), feiert die Naturmythologie auf diesem Gebiet 'fröhliche Urständ', was selbst Wilamowitz dazu verleitet, "Odysseus als gesunkenen Sonnengott" zu deuten. ${ }^{28}$ H. Usener (1834-1905) verbindet Mythos und Ritus bei Homer zum ersten Mal systematischer, wobei er lokale Heroenkulte aus entsprechenden Ritualen herleitet und bestimmte Teile des Epos direkt aus dem Kult erklärt. In Nachfolge des Grimm-Schülers W. Mannhardt (18311880) führt er dabei das Paradigma der Jahreszeiten- und Fruchtbarkeitskulte ein, ${ }^{29}$ allerdings ohne damit große Wirkung zu erzielen. Beispielsweise leitet er die Thersites-Szene der Ilias aus dem ionischen Pharmakosritual ab und deutet sie als Austreibung des Winters durch den "Sommergott" Achill. ${ }^{30}$ Parallel zu Usener und seinem Schwiegersohn A. Dieterich (1866-1908) entsteht allerdings in England die viel einflußreichere mythand-ritual-Schule der Cambridge Ritualists um Sir J. G. Frazer (18541941), W. R. Smith (1846-1894), J. E. Harrison (1850-1928), G. Murray (1866-1957) und F. M. Cornford (1874-1943). ${ }^{31}$ Frazers Golden Bough (1890) macht das Fruchtbarkeitsparadigma in Verbindung mit dem Jahresfest und Königsritual allgemein bekannt. Harrison, Murray und Cornford stellen daraufhin die ritualistische Erforschung des griechischen Dramas in den Mittelpunkt, das bei der Entwicklung dieses Zugangs zentral bleiben soll. Tragödie und Komödie werden in ihrer institutionellen Verankerung im Dionysoskult auf der Grundlage eines festen Schemas (pattern) gedeutet, wobei in Anlehnung an F. Nietzsche (1844-1900) die späten, doch etwas idiosynkratischen Bakchen des Euripides zum Musterdrama avan-

26 Vgl. u. a. Kohl 1988; Schlesier 1994.

27 Müller 1825, 348-371; Graf 1991, 336-337, zum folgenden 335-340.

28 Wilamowitz-Moellendorff 1884, 267-285. Vgl. mit Zitat Graf 1991, 339.

${ }^{29} \mathrm{Vgl}$. auch Usener 1904.

30 Usener 1897, 239-259, bes. 255. Vgl. Graf 1991, 340-341.

31 Vgl. Ackerman 1987; 1991; Arlen 1990; Calder 1991; Versnel 1993, 15-88; Csapo 2005, 132-180. Zum Leben von Harrison nun Beard 2000 und Robinson 2002. 
cieren. ${ }^{32} \mathrm{Im}$ berühmten "Excursus on the Ritual Forms Preserved in Greek Tragedy" zu Harrisons Themis (1912) erstellt Murray zum ersten Mal eine ritualistische Handlungssequenz. ${ }^{33}$ In dem Konstrukt eines tänzerisch ausagierten sacer ludus um die Verfolgung, Tötung, Zerstückelung und Wiedergeburt eines Jahresgottes mit dem frei erfundenen Kunstterminus

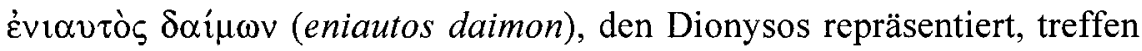
das zeitgenössische romantische Bestreben nach der Ergründung von Ursprüngen - ein historisch immer weiter zurückreichender Ansatz macht diese im Totenkult, Animismus und schließlich Totemismus aus -, sozialevolutionäres Denken im Sinne C. Darwins (1809-1882) und Vorstellungen Nietzsches zusammen. Murrays Schema (Agon, Pathos, Botenbericht über einen Todesfall, Threnos, Anagnorisis, Rettung, Wiederauferstehung) verbindet das jahreszeitliche Vegetationsmuster, die auf eine falsche Interpretation von Hdt. 5.67.5 zurückgehenden Mysterien-Vorstellungen eines 'leidenden Gottes' in der Person des Doppelgängers Pentheus ${ }^{34}$ und Nietzsches einflußreiches Konzept, daß alle tragischen Helden nur "Masken jenes ursprünglichen Helden Dionysus" seien. ${ }^{35}$ Cornford konstruiert auf der nämlichen Grundlage im Jahre 1914 seine stereotype Plot-Formel für die Komödie, ${ }^{36}$ wobei nach seiner Überzeugung die Bauformen Parodos, Agon, Parabase, Opfer, Fest und die mit einem Komos begangene Hochzeit den rituellen Kern eines im bäuerlichen Brauchtum verankerten Spiels bilden. ${ }^{37}$ Beide mystisch-religionsgeschichtlichen Vorschläge stoßen auf heftige Kritik der etablierten Fachwelt. $^{38}$

Insbesondere zeigen sie eine Tendenz zum Zirkulären, indem aus dem als sekundär angesehenen Mythos ("ritual misunderstood") der Bakchen, also einer späten Tragödie, ein Urritus abgeleitet wird, auf den die anderen literarischen Handlungen gespannt werden wie auf ein Prokrustesbett. Das

32 Nietzsche 1872.

${ }^{33}$ Murray 1912.

34 Vgl. Henrichs 1986, 394 mit Anm. 92; Bierl 1991, 7 mit Anm. 13; 1999, 586-587.

35 Nietzsche 1872, 67. Diese Überlegungen lassen sich erneut auf K. O. Müller zurückführen; vgl. Schlesier 1995; 1998, bes. 415-421.

36 Cornford 1914.

${ }^{37}$ Henderson 1993, xviii-xix.

38 Pickard-Cambridge 1927, 185-206, 329-349; Bierl/Calder/Fowler 1991, 111-115 (= Wilamowitz' Briefe an Murray Nr. 55-56). 
Jagen nach Ursprüngen erweist sich als "aboriginal fallacy", ${ }^{39}$ da gilt: "origin is not to be identified with meaning." 40 Zudem wird ein solcher Ursprung nach jeweils zeitbedingten Kategorien postuliert. Die in Jane Harrisons Themis (1912) ausgemachten sozialen 'Ur-Sprünge' lassen nur den Riß zwischen Anspruch und Wirklichkeit bezüglich einer verlorenen Utopie erkennen, der im Ritual mimetisch überspielt wird. In ihrer sozialevolutionistischen Theorie, die bei Morgan, Engels und Marx Anleihen nimmt, erscheint dieser nur mehr zu erahnende aurea-aetas-Urzustand freilich auch als Zielvorgabe für die Zukunft. ${ }^{41}$ Bemerkenswert ist hier neben der genetischen Suche der Ansatz zu einem strukturellen Handlungssequenzmodell. Vom Durkheimschen Schlüsseltheorem des Sozialen findet Harrison in Themis unter Aufnahme anthropologischer Literatur zum Initiationsritual. ${ }^{42}$ Aufgrund der interdisziplinären, die Sozialwissenschaften einbeziehenden ethnologischen und performativen Tendenzen der Religions- und Ritualwissenschaft, die gleichberechtigt die drei großen Paradigmen von Fruchtbarkeit, Neujahr, Initiation nebeneinander verwendet, ${ }^{43}$ kann man in Folge problemlos an diese Traditionen anknüpfen, die damals ihrer Zeit weit voraus sind und gerade deshalb auf breite Ablehnung stoßen. Dies hat unter anderem mit der Ausweitung der ritualmyth-Schule im eigentlichen Sinne zu tun ${ }^{44}$ die auf altorientalischen Modellen fußend das Frazersche Königsritual mit dem Vegetationskult vermengt. ${ }^{45}$ Nach den Übertreibungen der Cambridger Schule und der gesamten Richtung, die jenes hermeneutische Schema über die gesamte Weltliteratur legt, werden religionswissenschaftlich geleitete Deutungen von Literatur über viele Jahrzehnte, die selbst von säkularisierter und technologischer Aufbruchsstimmung gekennzeichnet sind, zunächst ad acta gelegt - auch von Murray und Harrison selbst. Lediglich Einzelgänger wie der marxistische Altertumswissenschaftler G. Thomson (19031987) oder E. R. Dodds (1893-1979), Schüler und Nachfolger von Murray auf dem Regius Chair zu Oxford, gehen im Bereich der Tragödie unbeirrt

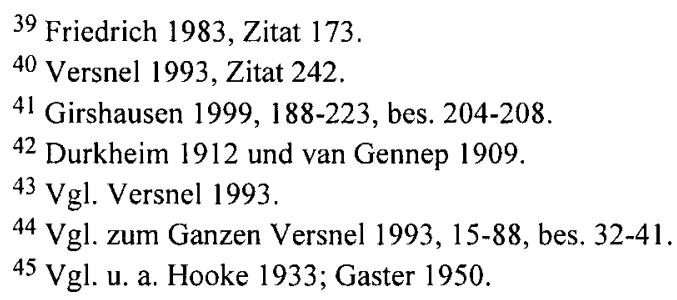


auf den Pfaden von Harrison und Murray weiter. ${ }^{46}$ Eine Generation später, Mitte der 1960er Jahre, lebt die Richtung erneut auf, nun freilich unter veränderten Vorzeichen. Entscheidend für die hier vorgestellte Methode werden die Arbeiten von W. Burkert und R. Seaford, ${ }^{47}$ die ganz bewußt an Harrison anknüpfen. ${ }^{48}$ Zeitgleich mit Burkert entwickelt in Frankreich J.-P. Vernant in Anschluß an die innovativen Ansätze L. Gernets (18821962) eine strukturalistisch-anthropologische Richtung. ${ }^{49}$ Mit seiner Pariser Schule übt er zusammen mit M. Detienne und P. Vidal-Naquet großen Einfluß vor allem auf die romanische Welt und die USA aus. Dionysos deutet man als 'das Andere'. Ritual wird eng auf die Polis bezogen, wobei diese Forschergruppe ein besonderes Augenmerk auf das Opfer, den pharmakos und die Initiation legt. Vor allem erfolgt aber eine eigene Übertragung dieser Ansätze auf die Interpretation der Tragödie..$^{50}$

Insgesamt läßt sich also konstatieren, daß die religionswissenschaftlichen Paradigmen Fruchtbarkeit, Neujahr und Initiation und die Themen Opfer, Mysterien und Heroenkult gerade seit den Cambridge Ritualists in theoretischer Hinsicht eng miteinander verwoben sind. Daher bietet sich für den Transfer auf die griechische Literatur ein polyparadigmatischer Ansatz an, wie ihn beispielsweise H. Versnel vertritt. ${ }^{51}$ Nur zu Darstellungszwecken wird die eigentliche Einheit im folgenden auseinandergenommen.

46 Thomson 1957 (Initiation und Mysterium); Dodds 1944 (Fortsetzung der ritualistischen Bakchen-Deutung in seinem berühmten Kommentar). Vgl. den späten Nachfolger im bereits veralteten Vegetationsparadigma Guépin 1968. Mystisches Ursprungsdenken leitet desgleichen die Überlegungen der Cambridge Ritualists und ihrer Nachfolger bezüglich der frühen Philosophie, die hier ebenfalls zur Literatur gerechnet wird. Cornford gibt die entscheidenden Anstöße zu einer evolutionistischen Sichtweise von religiösen Ursprüngen zur Emanzipation des Logos. Besonders die Vorsokratiker assoziiert man mit Mysterienvorstellungen; vgl. Cornford 1912; 1952; Thomson 1953; 1968.

47 Burkert 1966b; 1972 (mit Aufnahme der Opfertheorie sowie paläolithischer und ethologischer Modelle in Anlehnung an K. Meuli [1891-1968] und unter dem Einfluß von R. Merkelbach); Seaford 1981; 1984 (ritualistischer Cyclops-Kommentar); 1994a; 1994b; 1996 (ritualistischer Bakchen-Kommentar).

48 Versnel 1993, 74-79.

${ }^{49}$ Zur strukturalistischen Mytheninterpretation insgesamt vgl. Csapo 2005, 181-261.

50 Vernant/Vidal-Naquet 1972/1986; vgl. u. a. Goldhill 1997, 333-336; Segal 1981; 1982; Zeitlin 1991.

51 Versnel 1993, bes. 12. 


\section{Modelle und Themenkomplexe in der Literatur}

Als performatives, mimetisches, semiotisch besonders aufgeladenes, politisches und mündlich vermitteltes Genre mit ritueller Einbettung, das über den Mythos und das Ritual in einer Aufführung zentrale Werte und Begriffe einer traditionell ausgerichteten Bürgerschaft in Frage stellt, ist das Drama in seiner Struktur als Handlung gerade nach der geschilderten Wende in den Geisteswissenschaften der zentrale Schauplatz des hier thematisierten Ansatzes. Daher soll das griechische Theater als hauptsächliches Exempel dienen, wobei die Entwicklungen in den anderen literarischen Gattungen und Gebieten punktuell eingeblendet werden. Für die Applikation auf die Fragestellung, wie die symbolischen Äußerungsmedien Ritual und Mythos funktionieren, ${ }^{52}$ ist die Handlungsstruktur entscheidend.

\subsection{Vorverständnis und Voraussetzung}

\section{Das Verhältnis von Ritual und Mythos}

Schon Harrison deutet drei Varianten an, wie sich beide erst von der Religionswissenschaft erfundenen Kategorien zueinander verhalten: ${ }^{53}$ a) der Mythos geht sekundär aus dem Ritus hervor; ${ }^{54}$ b) der Mythos ist das Szenario eines dramatischen Rituals; ${ }^{55}$ c) Mythos und Ritus entwickeln sich pari passu, müssen also nicht exakt aufeinander abgestimmt sein. ${ }^{56}$ Auf diesem Weg geht Burkert mit dem Paradigma der Initiation weiter. ${ }^{57}$ Er sieht sowohl das Ritual als auch den Mythos neuerdings als Handlungsprogramme, die einen unmittelbaren biologischen Sinn besitzen, aber im Laufe der Menschheitsgeschichte viele Transformationen erfahren haben. ${ }^{58}$ Als sprachliche oder praxisbezogene kommunikative Äußerungen

52 Calame 1990, 29-54.

${ }^{53} \mathrm{Vgl}$. Versnel 1993, 29.

54 So die Cambridge Ritualists, u. a. Harrison 1912, 29 sowie Seaford 1981, 252; 1996, 35.

55 So die myth-and-ritual-Schule im eigentlichen Sinn anhand des Frazerschen Jahreskönigs- und Neujahrsmodells; vgl. Harrison 1912, 331-334; Leach 1982; Nagy 1990, 30-33, 378, 388 und passim; Seaford 1981, bes. 252-253; 1996, 43.

56 Harrison 1912, 16.

57 Burkert 1966a.

58 Burkert 1979, 1-58; 1996. 
bewahren sie nur noch Reflexe der ursprünglichen Aufgabe in der Natur. Literatur ist demnach nichts anderes als eine weitere Umformung von Mythen und Ritualen, nun in künstlerischer Form. Vor zu simplen Funktionalisierungen der Riten sollte Abstand genommen werden. Sehr oft wird sich der Ritus nur syntaktisch als Handlungsprogramm erklären lassen können, ${ }^{59}$ ohne durch einen Mythos eine tiefere Bedeutung zu erhalten. Mancher Mythos wird erst in späterer Zeit im Sinne einer Aitiologie hinzuerfunden worden sein. Viele rituelle Abläufe sind dagegen relativ freie, nicht verstandene Handlungskonstellationen, auf die der Dichter seine eigene Handlung in aristotelischer Terminologie (z. B. Arist. Po. 1450a4-5) als $\mu \hat{v} \theta 0 \varsigma$ (mythos) ablegen kann. Ferner sollte man von der Vorannahme Abstand nehmen, Handlung vollziehe sich in der Antike ausschließlich nach streng aristotelischen Kategorien im Sinne einer 'geschlossenen Illusion', wie dies im naturalistischen Theater der Fall ist, dessen Handlungsbegriff bekanntlich den Denkgewohnheiten der Aufklärung entspricht. Neben referentiell-mimetischen Vorgaben herrschen gerade auch im volkstümlichen Theater und anderen rituellen Inszenierungen nichtreferentielle, prädramatische Formen der Präsentation vor, die eine gebrochene, zum Rahmen hin offene Perzeptionsweise bevorzugen. ${ }^{60}$ Außerdem muß man nach Gattungen differenzieren, die als diskursive Kodifikationen konventionelle Sprechakte darstellen und gewissermaßen als Prinzipien dynamischer Produktion funktional mit der jeweiligen Okkasion in Beziehung stehen. ${ }^{61}$ Beispielsweise basiert die Tragödie auf variablen Mythen, wobei der direkte Bezug zum Ritual schwächer ausgebildet ist, während die Komödie den $\mu \hat{v} \theta$ os (mythos) zu erfinden hat (vgl. Antiphanes fr. 189 Kassel-Austin), dafür eher Riten vereinnahmt und frei kombiniert. Der 'Mythos' als komische Handlung wird auf dieser Grundlage also auf phantastische Weise kreiert. ${ }^{62}$ In der performativen Ritual-Analyse gehen Ritual und Theater eine besonders enge Symbiose ein. ${ }^{63}$

\footnotetext{
${ }^{59}$ Etwa nach Burkert 1996 aus dem Verlangen, etwas zu bekommen ('to get').

${ }^{60}$ Bierl 2001, passim, Index s. $v$

61 Todorov 1978, 23-25, 44-60; Nagy 1990, 362-363; 1994/95.

62 Bierl 2002b.

${ }^{63} \mathrm{Vgl}$. z. B. Tambiah 1985.
} 


\section{Bild und Metapher im Verhältnis zu Mythos und Ritual}

Mit dem iconic turn hat man auch in den Altertumswissenschaften begonnen, sich mit der Verbindung von Bild und Text zu beschäftigen. Die traditionelle, sehr stark auf Mündlichkeit beruhende griechische Kultur basiert sprachlich noch sehr viel stärker auf Bildlichkeit als heutige Literaturen. Die so fremde Zivilisation der Hellenen darf also nicht in humanistischer Manier einfach weitgehend dem heutigen Diskurs gleichgesetzt werden. Gerade um das spezifisch Andere zu verstehen, muß man das ikonische Substrat der griechischen Denkmuster erkennen lernen.

Bild und Sprache sind nicht völlig getrennte Systeme, die ab und $\mathrm{zu}$ miteinander in eine Beziehung treten, sondern sind im Gegenteil eng

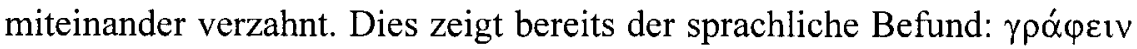
(graphein) steht im Griechischen sowohl für Schreiben als auch für Zeichnen und Malen. Beide Techniken kollektiver Repräsentation sind ikonische Spuren des kulturellen Gedächtnisses. Einen festen Bereich davon bilden die Metapher und die tropische Sprechweise insgesamt. Seit geraumer Zeit betrachtet man die Metapher nicht als rhetorisches Mittel, womit ein Begriff durch einen anderen ersetzt wird, sondern als Interaktion, in dem Sinne, daß der bildlich geladene Träger (vehicle) ein Raster liefert, um den abstrakteren Anteil (tenor) zu veranschaulichen und lebendig vor Augen zu führen. In der Metapher manifestiert sich eine Schnittmenge zwischen Sprache und Bild. Feststehende Bilder und visuelle Konstellationen bestimmen eine Kultur und ihre Denkweise, insbesondere die traditioneller Gesellschaften. ${ }^{64}$ In dichter Folge können sie ganze Texte als Gewebe organisieren, wobei sich ein solches Geflecht in paradigmatisch-metaphorischer und syntagmatisch-metonymischer Weise ausbreitet. Wenige Schlüsselbilder sind in der Lage, im "Spiel der Tropen" ganze Texte zu generieren und zu strukturieren. ${ }^{65} \mathrm{Je}$ fremder eine Kultur, umso schwieriger gestaltet sich das Dechiffrieren ihrer Bildlichkeit. Bildszenarien und dichterische Texte können sich also als mentale Denkstrukturen gegenseitig erhellen.

Eine traditionelle Gesellschaft wie das archaische Griechenland, das von der Mündlichkeit der Rezeption geprägt ist, definiert sich bekanntlich weitgehend über Mythos und Ritual, die wiederum beide von einer spezifischen Bildlichkeit gespeist sind. Gerade Metaphern stellen oft das Gefäß

\footnotetext{
64 Vgl. Ferrari 1997; 2002, bes. Kap. 3, 61-86.

65 Vgl. Fernandez 1977; 1986; 1991.
} 
für Mythen und Riten dar. ${ }^{66}$ Aus rituell-mythischen Szenarien und Tableaus entstehen Erzählungen und narrative sowie performative Abläufe. Bild, Performanz, Lebenswelt, mentale Konzepte und Vorstellungen interagieren also in griechischen Texten. ${ }^{67}$

Für die künstlerische Produktion kann zudem der Zusammenhang zwischen literarischer Metapher und dem Ritual - sowie sekundär dem Mythos - herangezogen werden. Die moderne Sozialanthropologie hat gezeigt, daß eine Metapher ein Ritual erzeugen kann, indem es weitere Metaphern in Bewegung setzt, die durch Ähnlichkeit und/oder Kontiguität aktiviert werden. ${ }^{68}$ Ritual kann man als performatives, spektakuläres, multimedial inszeniertes Verhalten verstehen, mit dem Ziel, die Außenwelt unter Kontrolle zu bringen und die Beziehung zwischen Subjekt und Objekt zu überdenken. ${ }^{69}$ Es basiert auf Lebenszyklen und ganz fundamentalen Alltagshandlungen, wie z. B. Essen, Trinken, Kleidung und Waschen. ${ }^{70}$ Auf Metaphern als Kombinationsinstrumenten, deren Hintergrund solche einfachen konventionellen und rituellen Aktionen bilden, konstruieren wir unser komplexes Denken. ${ }^{71}$ Vor allem sind Metaphern und Ritual handlungsbezogen. Rituale bedeuten nach James Fernandez "the acting out of metaphoric predications upon inchoate pronouns which are in need of movement." 72 Wörtlich genommene Metaphern können in ihrer bildhaften Qualität in Handlung umgesetzt werden. Aristophanes hat beispielsweise seinen komischen Plot oft auf solchen tropologischen Verfahrensweisen hergestellt. Er bringt Metaphern in eine narrative Anordnung und verknüpft sie mit schon bestehenden Ritualen zu einem Ritual der Kunst. Dabei fühlt er sich frei, die rituellen Elemente neu zu formieren, Einzelteile zu verdoppeln oder sogar neue Rituale selbst zu erfinden.

\subsection{Rituelle Perspektive}

In der Forschung gibt es hierzu zwei grundsätzliche Ansatzweisen: a) das Drama - oder ein anderes in der Okkasion aufgehendes Werk - ist insge-

\footnotetext{
$66 \mathrm{Vgl}$. Alexiou 2002, bes. 317-319.

$67 \mathrm{Vgl}$. Alexiou 2002.

${ }^{68}$ Fernandez 1977; 1986; 1991.

${ }^{69}$ Vgl. u. a. Fernandez 1977; Seaford 1994a, xi-xii; Alexiou 2002, 317-348.

${ }^{70} \mathrm{Vgl}$. Alexiou 2002, 319-324.

71 Vgl. u. a. Lakoff/Johnson 1980; Lakoff/Turner 1989.

${ }^{72}$ Fernandez 1977, bes. 3-27, Zitat 23.
} 
samt Ritual; b) das Drama verwendet das Ritual oder rituelle Abläufe lediglich zur Konstruktion einer Handlung.

$\mathrm{Zu}$ a): Hier kann man wiederum zumindest für die frühe Phase differenzieren, ob aa) die gesamte Aufführung in der Einbettung in einen 'Sitz im Leben' ein Ritual darstellt, ${ }^{73}$ oder ob ab) nach der myth-ritual-Theorie im eigentlichen Sinne auch die Handlung den entsprechenden Mythos inszeniert, die Akteure also intra-fiktional rituell agieren, indem der gespielte Mythos das Szenario der rituellen Okkasion darstellt; ${ }^{74}$ dieser Ansatz funktioniert letztlich nur für die Bakchen des Euripides, ist aber selbst hier problematisch, da er die poetisch-symbolische Weiterverarbeitung, die Aneignungen, das gegenlesende Hinterfragen und Überbieten außer acht läßt.

$\mathrm{Zu} \mathrm{b):} \mathrm{Ein} \mathrm{Autor} \mathrm{kann} \mathrm{einzelne} \mathrm{Ritualkomplexe} \mathrm{(beispielsweise} \mathrm{die}$ Mädcheninitiation als Mädchentragödie, die Dendrophorie, die Suche) zur Konstruktion der Handlung heranziehen..$^{75}$ Hierbei ist unter anderem die narrativ-strukturalistische Erzählforschung von V. Propp (1972) von Bedeutung. ${ }^{76}$ Einzelne Motive oder Motivketten, Kultabläufe, Feste oder Ritualkomplexe können von ihrem Wirklichkeitsbezug gelöst werden, frei auseinandergenommen und wieder zusammengesetzt werden, zuletzt mit den Mitteln der Selektion, Addition und Kombination in ihrer spektakulären Zeichen- und Bildhaftigkeit für die literarische 'Geschichte' funktionalisiert werden. ${ }^{77}$ Die Verbindung von Ritual und Tragödie hat in besonderer Weise das Interesse der Forschung auf sich gezogen. ${ }^{78}$ Insgesamt besteht also die Möglichkeit, daß ein Text aus einer assoziativ gestalteten rituellen Substruktur gespeist wird, zumal diese Riten die pragmatische Lebenswelt bestimmen.

73 U. a. Aronen 1992; Auffarth 1991; Bierl 1991; Brelich 1975; des Bouvrie 1993; Riu 1999.

74 Calame II 1977; Nagy 1990, 345-350 (für Alkman); 1990, 30-33, 388 und passim; Seaford 1981, bes. 252-253; 1996, bes. 43 .

${ }^{75}$ Krummen 1990 (für Pindar in der okkasionellen Einbettung).

76 Burkert 1979, 1-34.

${ }^{77}$ Bowie 1993a, 1-17; Easterling 1988; Krummen 1998.

78 Cartledge 1997; Easterling 1988; 1997; Krummen 1998; Lloyd-Jones 1998; Graf 2007. 


\subsubsection{Außenstruktur}

Rahmung - die Gottheit und ihr Mythos sind auf der Inhaltsebene bestimmend

Der Anlaß eines Götterfestes und der dazugehörige Mythos können eng mit dem Inhalt eines Liedes oder einer Aufführung in Beziehung stehen. Das Fest der Aotis, zu dem Alkmans Großes Partheneion (fr. 1 PageDavies) gesungen und getanzt wird, sowie Vorstellungen bezüglich der zentralen Gottheit der Morgenröte liegen beispielsweise unmittelbar der Bild- und Handlungsebene als Substrat zugrunde. Wiederum kann hierfür das attische Drama exemplarisch herangezogen werden. Da es bekanntlich an Festen zu Ehren des Dionysos aufgeführt wurde, hat man einen direkten strukturellen Zusammenhang zwischen dem Inhalt und der rituellen Einbettung gesucht. ${ }^{79}$ Einige sehen diesen Konnex in einer allgemeinen anthropologischen Beziehung, ${ }^{80}$ andere postulieren einen deutlichen Gegensatz zwischen der äußeren, eher affirmativen Rahmung und dem destruktiven Gehalt der Tragödie. ${ }^{81}$ Wieder andere betrachten die Ausnahme und die dionysische Lizenz als Grund der Verkehrung und Verzerrung der Normen auf der Inhaltsebene. ${ }^{82} \mathrm{R}$. Seaford postuliert im Vorkommen des Dionysos und des Dionysischen ein politisches Modell, das auf der Inhaltsebene die Zerstörung des königlichen Haushalts zum Ziel der Herausbildung einer kollektivistischen Polisordnung präsentiert. ${ }^{83} \mathrm{C}$. SourvinouInwood (2003) sieht ebenfalls einen direkten Zusammenhang von der rituellen "Matrix" des umrahmenden Dionysoskults, der die gastliche Aufnahme des ankommenden Gottes in kollektiven Begehungen feiere, mit den Inhalten und Strukturen einer rekonstruierten Prototragödie, die diesen $\xi_{\varepsilon v \imath \sigma \mu o ́}$ (xenismos) im Mythos reaktualisiere. Auch bei Aischylos fänden sich in der Dominanz des Chorischen noch deutliche Spuren davon, während sich die Tragödie des Sophokles und Euripides kaum mehr einem solchen Schlüsselmythos unterordnen lasse, aber weiterhin auf der rituellen Grundlage von einem durch und durch religiösen Diskurs geprägt sei,

79 Dagegen, besonders gegen Seafords ritualistischen Ansatz, mehr als skeptisch Friedrich 1996; 2000; 2001; übertrieben sind die negativen Schlußfolgerungen von Scullion 2002.

${ }^{80}$ U. a. Aronen 1992; Bierl 1991; Brelich 1975; des Bouvrie 1993.

81 Z. B. Goldhill 1987.

82 U. a. Hoffman 1989.

${ }^{83}$ Seaford 1993; 1994a; vgl. Girard 1972 und unten 'Opfer und Opfertheorie'. 
der insbesondere das Verhältnis zwischen Göttern und Menschen ergründe und problematisiere. X. Riu (1999) sieht für die Komödie das Dionysische wirksam, das er aus einer strukturalistisch-soziologischen Lektüre der Bakchen à la façon der Pariser Schule ableitet und mit dem alten Cornfordschen Schema überblendet. ${ }^{84}$ In der Aufnahme des Dionysos als Prinzip des Anderen in die Polis werde die Auflösung der Ordnung durchgespielt. ${ }^{85}$ Das Dionysische ist freilich nicht nur Szenarium der Gewalt und Brutalität, sondern steht auch für positive politische Werte, insbesondere für die der Kollektivität einer kohärenten Polis. ${ }^{86}$ Gerade im Satyrspiel und in der Komödie ist es als Zeichen des liminalen Anderen zudem Ausdrucksmittel der ebenso das dionysische Rahmenritual beherrschenden Atmosphäre von Freude, Heiterkeit, Ausgelassenheit und berauschter Stimmung bei Wein. ${ }^{87}$ Neuerdings wird überdies die selbstreflexive, metatheatrale Verbindung zwischen Dionysos als Gott des Theaters, dionysischen Zeichen und performativen Theaterkonstituenten betont. ${ }^{88}$ Insbesondere der Verweis auf den bestimmenden Chor, den Tanz und die Musik wird unterstrichen. ${ }^{89}$

\section{Fest, Ausnahmefest, verkehrte Welt, Theatralität und rite de passage}

Die diversen Zeichen der Andersartigkeit sind nicht unbedingt auf das für das Drama belegte dionysische Rahmenritual zurückzuführen, sondern lassen sich allgemeiner mit den Konzepten der Festlichkeit, des Spiels, der verkehrten Welt und mit denjenigen von Ausnahmeritualen der Lizenz

${ }^{84}$ Vgl. Cornford 1914.

${ }^{85} \mathrm{Vgl}$. Seaford 1996 mit der Rezension von Bierl 1999 und insgesamt Riu 1999 mit der Rezension von Bierl 2002c.

${ }^{86}$ Bierl 1991, bes. 18-20, 45-110, bes. 49-54; Isler-Kerényi 2001.

$87 \mathrm{Vgl}$. Peirce 1993.

${ }^{88}$ Segal 1982, 215-271; vgl. Segals Bemerkungen im Nachwort (369-378, bes. 370 375) zur erweiterten zweiten Auflage (1997) und seine Antwort ( $B M C R$ 98.5.26) auf Seafords kritische Rezension (BMCR 98.3.10); Bierl 1991, 111-218; 2001, bes. 37-86; Kaimio et al. 2001; Dobrov 2001. Vgl. nun die als Megarezension abgefaßte Habilitation von Radke 2003. Ihre massive Pauschalkritik an diesem Ansatz kann nicht überzeugen, weil sie meinen Versuch, die Frage auf eine neue Grundlage zu stellen (Bierl 2001, bes. 37-86), und Kaimio et al. 2001 schlichtweg ignoriert.

${ }^{89} \mathrm{Vgl}$. Segal 1982, 242-247; Bierl 1991, u. a. 35-36, 83-84, 99, 106-107, 129, 155 , 164, 190-191, 224 und 242-243 (Stellenangaben zum Chortanz in Verbindung mit Dionysos); ferner Henrichs 1994/95; 1996a; 1996b. Vgl. zur Komödie Bierl 2001; Calame 2004. 
erklären. ${ }^{90}$ Die Anbindung an Dionysos muß nicht notwendigerweise und direkt erfolgt sein, sondern kann aufgrund einer allgemeinen Konfiguration von Zeichen geschehen sein, die eine Auflösung der Ordnung versinnbildlichen. Damit wird dann Dionysos als Gott des Anderen assoziiert. Im Hintergrund stehen ethnologische Vorstellungen von brauchtümlichen Festen und theatralen Formen, in denen die Gesellschaft kurzfristig die etablierte Ordnung verläßt und in Phantasien eine Anderwelt im Rückfall auf Atavismen experimentell durchspielt, um dadurch im Kontrast die bestehenden Werte und Normen letztendlich zu bestätigen. ${ }^{91}$ Je nach Gattung und Okkasion unterscheiden sich solche Situationen massiv. Die Tragödie basiert auf dem Heroenmythos und setzt die Verkehrung nach oben durch, ${ }^{92}$ während die Alte Komödie solchen volkstümlichen und rituellen Spielweisen näher steht ${ }^{93}$ In diesem Zusammenhang muß ein spezifisches Theatralitätsgefüge berücksichtigt werden: Hierbei wird die Welt der performativen Formen im Längsschnitt vom reinen Nicht-Theater zum Kunsttheater der mimetischen Repräsentation über die Zwischenschritte der spektakulären Inszenierung im Alltag, auf der Straße und am Marktplatz, und eines grotesken, ganz anderen Theaters betrachtet. Letzteres geriert sich wie die Alte Komödie als Anti-Theater, wobei es mittels eines Sturzes in primordiale Kulturstufen eine nichtmimetische Anderwelt der Dystopie und Utopie im Funktionellen - unter Mißachtung des Substantiellen - inszeniert. ${ }^{94}$ Solche karnevalesken Formen der verkehrten Welt wurden neuerdings mit M. Bachtin (1895-1975) verbunden. ${ }^{95}$ Allerdings können sie in der Antike am besten vom pragmatischen Bezug auf bestimmte Ausnahmefeste abgeleitet werden. Die Zeichen einer solchen temporären Auflösung der Ordnung (u. a. Tod, Obszönität, Wildheit, tierisches Verhalten, Tanz, Utopie, Alt-Neu, Absetzung der Götter, Sklavenfreiheit, Gewalt) sind so unspezifisch, daß sie sich mit den drei großen religionswissenschaftlichen Paradigmen - ich meine die Initiation, das

${ }^{90}$ Hoffman 1989; Farioli 2001.

91 Vgl. Auffarth 1991 (für Homer: Verbindung des altorientalischen Königsrituals mit Initiationsriten); Bierl 2002b (für die Alte Komödie).

92 Brelich 1975; Baudy 1993a.

93 Brelich 1975; Bierl 2001.

94 Münz 1998, bes. 99-101, 282; vgl. Bierl 2002b.

95 Zur verkehrten Welt vgl. Babcock 1978; Goldhill 1991, 167-222, bes. 176-188; Kenner 1970. Zur Verbindung mit Bachtin vgl. u. a. Rösler 1986; Goldhill 1991, 176188; Möllendorff 1995. 
Neujahrsfest und die Fruchtbarkeit (in der festlichen Übergangsphase) erklären lassen. Der dionysische Zusammenhang wurde zum Teil heortologisch durch eine referentielle Verbindung mit den ausnahmeartigen Anthesterien gesucht. ${ }^{96}$ Derartige Bezüge können selbstverständlich von der Rahmung her auch den Inhalt des Spiels als 'Mythos' beeinflussen. Allerdings sind die Inszenierungen inhaltlich meist nichtreferentielles, freies Spiel von Ganzkörpermasken, die ein solches Zeichenspektrum der Alterität in freier Phantasie produzieren. Für die Theatralität eines Festes und vieler Rituale ist einerseits A. van Genneps (1873-1957) Dreischritt des rite de passage (Trennung - Übergang - Rückkehr) von Bedeutung, den auch V. Turner in seinem ethnologischen Konzept des "social drama" benutzt. ${ }^{97}$ Dieses Konzept wird besonders für die archaische Frühphase angewandt. Alkmans Großes Partheneion oder die Tragödie verarbeiten rituell Prozesse, welche die ganze versammelte Bürgerschaft transformieren. In der Theater-Anthropologie wird jüngst die Nähe von Ritual und Theater als performance betont. ${ }^{98}$ Entscheidend ist in einem solchen rite de passage die Übergangsphase, die Turner als das Liminale bezeichnete. Auf das Theater überträgt er entsprechend die Vorstellung des antistrukturellen Liminoiden, ${ }^{99}$ in dem Akteure und Zuschauer eine Erfahrung des "Betwixt and Between" durchleben. ${ }^{100}$ Das Übergangsriten-Modell der Anthropologie wird jüngst als hermeneutisches Kriterium auf zahlreiche Texte angewandt. ${ }^{101}$ Allerdings ist es zu allgemein, zumal ein solcher Dreischritt überall in Erscheinung tritt und selbst aus Aristoteles' mimetischem Theater abgeleitet werden kann. Er kann daher anderen Expressionsweisen des Nichtreferentiellen nicht gerecht werden. Die Formen der Verspottung und des Obszönen sowie die Herabsetzung im volkstümlichen

96 U. a. Auffarth 1994; Bierl 1994a; Craik 1987.

97 Van Gennep 1909; Turner 1967; 1974; Padilla 1999.

98 Turner 1989; Schechner 1990; Hüttler 1999; Bierl 2001, 14 und passim; Köpping 2003 und Köpping (im Druck).

99 Turner 1974, 15-16.

100 Turner 1967, 93-111.

${ }^{101}$ Es ist natürlich eng mit dem Deutungsparadigma der Initiation verwoben (siehe unten 'Initiation'). Padilla 1999 (mit Beiträgen zur Tragödie und zum Roman); Segal 1982, 158-214 (E. Ba.); Aronen 1992 (Drama allgemein); Padilla 1992 (Ar. Ra.); Paradiso 1987 (Ar. Pl.); Bierl 2001; Segal 1994b, Kap. 1-4, 3-84 (Hom. Od.); Habinek 1990; Dowden 1999 (Roman); für die moderne Literatur vgl. z. B. Elsbree 1991 mit der Kritik von Braungart 1996, 163-164. 
Spiel der Komödie werden daher wohl am besten durch einen interkulturellen Vergleich erklärt. ${ }^{102}$

Das Konzept der verkehrten Welt hat nicht nur Einfluß auf die frühe griechische Dichtung (Homer, Iambos, Tragödie, Alte Komödie), sondern lebt auch als literarisches Motiv fort. ${ }^{103}$ In Rom zeitigt es große Wirkung, hier vor allem im Saturnalienmodell. ${ }^{104}$ Da Senecas Apocolocyntosis zahlreiche saturnalische Anspielungen in der Komposition aufweist, könnte der Text tatsächlich anläßlich der Saturnalien aufgeführt worden sein. ${ }^{105}$ Freilich könnte Seneca das römische Ausnahmefest nur als literarisch vermittelte Referenz zum Zwecke der ludischen Verspottung der Kaiserfamilie eingesetzt haben. ${ }^{106}$

\subsubsection{Zwischen Innen und Außen - der Chor}

Der dramatische Chor vermittelt als shifter zwischen der extrafiktionalen Dimension des 'Hier und Jetzt' (énonciation) und der internen Handlung des 'Da und Dort'. ${ }^{107}$ Als singende Tanzformation übt er eine genuin rituelle Funktion aus. ${ }^{108}$ Gerade hier kann der performative turn und die entsprechende performative Ritualanalyse in Verbindung mit der Sprechakttheorie J. L. Austins adäquat für die Deutung eingesetzt werden. ${ }^{109} \mathrm{Als}$ rituelles Kollektiv, das von seiner Genese her eng mit Feiern der Fruchtbarkeit, der Jahresbegehung und vor allem mit Pubertätsweihen in Verbindung steht, wurde der Chor in eine dramatische Handlung integriert. Hier tendiert er dazu, durch anderweitige rituelle Formen (Hikesie, Libation, Klage, Gebet an die aktuellen Polisgötter etc.) die Handlung spektakulär zu untermalen und dynamisch in die Ebene der aktuellen Aufführung

102 Apte 1985; Rösler 1993 (zu den Thesmophorien).

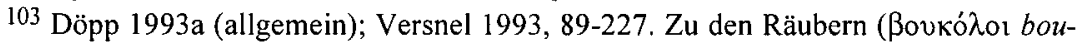
koloi) des Romans als Ausdruck der verkehrten Welt vgl. Bertrand 1988.

104 Döpp 1993b (Überblick mit weiter Anwendung von Plautus über Catull carm. 14 bis Petron und Apuleius); Lefèvre 1988; Versnel 1998 (römische Komödie); Teuber 1993 (Apul. Met.); Nauta 1987 (Sen. Apoc.).

105 Nauta 1987.

106 Mazzoli 1982.

$107 \mathrm{Zu}$ Problemen der énonciation vgl. Calame 1995; 2005.

108 Zum Chortanz als Ritual vgl. Burkert 1977, 167-169; Lonsdale 1993. Ingesamt Bierl 2001. Zum Chor im Satyrspiel vgl. nun Bierl 2006.

109 Tambiah 1985 und Austin 1972. 
zu wechseln, was den Effekt der communitas erhöht. ${ }^{110}$ Auch auf der Mikroebene der markierten, von der Alltagssprache feierlich abgehobenen Ausdrucksweise und durch die am Körper ausagierte Rhythmik wird der in einer lebendigen Chorkultur aufgewachsene Zuschauer selbst nahezu Teilnehmer eines synästhetisch präsentierten Spektakels, das symbolische Inhalte in performativer Fusion vermittelt. ${ }^{111}$ Dadurch steht der Chor in direkter Nähe zu den nicht eingebetteten Aufführungen der Chorlyrik und der Gebrauchslieder. ${ }^{112}$ Als traditioneller Ort der Erziehung Jugendlicher dient er der Vorbereitung auf den Erwachsenenstatus und ist eng mit der sogenannten Initiation verbunden. ${ }^{113}$ Neuerdings wird der dramatische Chor in pragmatisch-institutioneller Hinsicht mit dem Ephebendienst in Beziehung gesetzt. ${ }^{114}$ Ferner werden in der Einbindung seiner genuinen Funktionen in ein fiktionales Spiel diese initiatorischen Bezüge in transformierter und vermittelter Form wachgehalten. Der komische Chor ist noch weniger in die Handlung integriert als der tragische und schließt deutlich an volkstümliche nichtmimetisch-prädramatische Darstellungsformen an, wobei das narrative Element des Mythos hier nahezu entfällt. Der zugrundeliegende Komos kann ebenfalls als Reaktualisierung der Transitionsphase auf dem Weg zum Erwachsenendasein gedeutet werden. ${ }^{115}$

\subsubsection{Binnenstruktur auf der Inhaltsebene}

Im folgenden angesprochene Themen kommen nie in direkter Reinform vor, sondern sie sind immer schon vermittelt und literarisch weiterverarbeitet. Natürlich können sie ebenfalls in der pragmatischen Dimension vorhanden sein, woraus man zum Teil genetische Rückschlüsse gezogen hat. ${ }^{116}$

110 U. a. Turner 1974, 274 und Index s. $v$.

111 Bierl 2001; Gödde 2000a; 2000b.

112 Calame 1977.

113 Siehe unten 'Initiation'.

114 Winkler 1990; Graf 1998, 25-27.

115 Bierl 2001.

116 So z. B. für die Bukolik Reitzenstein 1893, 193-228; Merkelbach 1956; Baudy 1993b. 


\section{Initiation}

Angeregt durch Harrison, Burkert, Vernant und A. Brelich hält in den 1970/80er Jahren das soziologische Paradigma der Initiation als dernier cri Einzug in die Interpretation vor allem der frühgriechischen und dramatischen Literatur. ${ }^{117}$ Insgesamt wird der Ansatz mit der breiteren Thematik des rite de passage verknüpft. ${ }^{118}$ Zudem ist dabei Vernants Erkenntnis bedeutsam, daß die weibliche Wahrnehmung der Hochzeit der männlichen Erfahrung des Ephebenkriegsdienstes entspreche. ${ }^{119}$ Das Paradigma wird stark von ethnologischen Vergleichsstudien beeinflußt. Selbst wenn es in Griechenland keine Entsprechung zu tribalen Initiationen gibt und die Ephebie nicht für die Frühzeit belegt ist, so finden sich doch überall Reste initiatorischer Bräuche aus einer übergreifenden indoeuropäischen Tradition, ${ }^{120}$ vor allem in Kreta und Sparta; ${ }^{121}$ Überbleibsel kann man auch in Athen entdecken. ${ }^{122}$ Ungeachtet möglicher survivals wird der kritische Übergang von der Jugend zum Erwachsenenstatus in allen Kulturen thematisiert. Was antike Götter in diesem Kontext angeht, hat man insbesondere Artemis und Apollon damit verbunden und für die Interpretation fruchtbar gemacht. ${ }^{123}$ Die sich aus der geringen Eindeutigkeit der Zeichen der Marginalität und Liminalität ergebende Schwierigkeit eines solchen Unterfangens wurde von $\mathrm{H}$. S. Versnel thematisiert, ${ }^{124}$ besteht doch eine Gefahr darin, das Schema zu undifferenziert auf alle Texte anzuwenden,

117 Allgemein Moreau 1992 und Padilla 1999. Die Anwendung erfolgte vor allem bei Homer: Auffarth 1991; Hölscher 1988, 251-258 (zur Od.); Bremmer 1978 (zu homerischen Helden); Graf 1991, 358-360 (zusammenfassend mit weiterer Literatur); ferner in der Lyrik: insbesondere bei Alkman (Calame II 1977) und Sappho (Merkelbach 1957; Bierl 2003); in der Tragödie: Vidal-Naquet 1968; Zeitlin 1978; Bremmer 1992; Seaford 1981, 263-268; Segal 1982, 158-214 (für Pentheus in E. Ba.); Krummen 1993, 208-212; Bierl 1994b; Lada-Richards 1997; in der Komödie: Thiercy 1986, 305-327; Bowie 1993a, 45-58, 78-101; Lada-Richards 1999, 45-78; Bierl 2001, bes. 225-276 und Index s. v.; zu Alkman in Ar. Lys. vgl. nun Bierl 2007. Zum Roman: Dowden 1999; Lalanne 2006 und Bierl hier in Band 2.

118 Padilla 1999.

119 Vernant 1987, 27-50, bes. 31-32.

120 Bremmer 1980; Waldner 2000, bes. 33-50.

121 Zu Kreta vgl. Leitao 1995; Waldner 2000, 222-242. Zu Sparta Jeanmaire 1939.

122 Z. B. die Arrhephorien-Bräuche; vgl. Burkert 1966a.

$123 \mathrm{Zu}$ Artemis vgl. Sourvinou-Inwood 1988; zu Apollon vgl. Bierl 1994b; Versnel 1993, 289-334 (zu Mars und Apollon); zu Dionysos vgl. Jeanmaire 1951, 56-57; Waldner 2000, 146-150; zur Anwendung auf die Interpretation von tragischen Texten vgl. u. a. Wolff 1992; Bierl 1994b.

124 Versnel 1993, 60-74. 
zumal nahezu jede traditionelle Erzählung und alle Märchen die Dreierkomposition des Übergangsrituals als Struktur menschlicher Erfahrungen besitzen. Hier gibt es den methodischen Vorschlag, von Initiation nur dann zu sprechen, wenn auch auf pragmatischer Ebene ein Kultbezug und eine institutionelle Gebundenheit bestehen. ${ }^{125}$ Versuche, das Modell beispielsweise auf das hellenistische Epos des Apollonios, auf Vergil und den Roman auszudehnen, ${ }^{126}$ obwohl die rituelle Verankerung fehlt, würden dann hinfällig. Meines Erachtens bleibt die Anwendung des Initiationsschemas durchaus auch in diesen Fällen legitim, wenn eine präzise hermeneutische Methodologie dafür vorliegt. Natürlich können initiatorische Themen literarisch tradiert werden. ${ }^{127}$ Ferner überlappen sich die signifiants mit dem Neujahrsparadigma. ${ }^{128} \mathrm{G}$. J. Baudy verknüpft die Initiation in zahlreichen Arbeiten mit dem Vegetationsparadigma. ${ }^{129}$ Entscheidend ist die Analyse einer spezifischen symbolischen Bildhaftigkeit von Motiven in den Texten, wie etwa Narbe, Jagd, Wolf, Bogen, Chlamys, Haartracht, Verkleidung, Geschlechterrollen-Indifferenz, Statusverkehrung, Weben, Wollarbeit, Tanz, Mädchentragödie, Tod und Wiedergeburt, Tod und Hochzeit etc., und die performative Umsetzung des in der narrativen Struktur angelegten initiatorischen Geschehens. Für die Aufdeckung der weiblichen Initiation haben sich die Gender Studies mit der Erforschung der Geschlechterrolle als fruchtbar erwiesen. ${ }^{130}$ In der Literatur wird dieser Motivkomplex häufig durch die Reaktualisierung und die Umkehrung des Initiationsablaufs verarbeitet. ${ }^{131}$ Vorzeitig das Ende des Paradigmas Initiation auszurufen, wie dies neuerdings von mancher Seite geschieht, ${ }^{132}$ erscheint verfehlt. In der entsprechend wissenschaftsgeleiteten Applikation bietet es nach wie vor geeignete Wege zur Erfassung von Literatur, da viele antike Texte eine damit in Einklang zu bringende Struktur aufweisen und Themen wie Krieg und Hochzeit für die jungen Menschen in einer

125 Graf 1991, 359.

$126 \mathrm{Zu}$ Apollonios vgl. Hunter 1988; zu Vergil vgl. Thomas 1989; zum Roman vgl. García Gual 1992; Dowden 1999; Lalanne 2006 und Bierl hier in Band 2.

127 Z. B. von Homer und durch die Heldensage (Iason, Aeneas).

128 Vgl. die Kombination bei Auffarth 1991; Versnel 1993, 57, 59, 80-83.

${ }^{129}$ U. a. Baudy 1986; 1991; 1992; 1993 b; 1996.

130 Bierl 2001, bes. 225-276.

131 Zur Reaktualisierung vgl. Bierl 2001, u. a. 267, 276-287, 313, 318 Anm. 48, 341 Anm. 105; zur Umkehrung vgl. Bowie 1993a, 78-101, 102-112.

132 Vgl. die massive Skepsis gegen das Paradigma durch Dodd/Faraone 2003. 
traditionellen Gesellschaft omnipräsent sind. Der entsprechend zu untersuchende Text und die historischen Gegebenheiten eröffnen die jeweils adäquate Vorgehensweise.

\section{Mysterien}

Eine Untergattung der tribalen Pubertätsweihen stellen die Geheimkulte der griechischen Mysterien dar. ${ }^{133}$ Ursprünglich mit dem reduktionistischen pattern der Cambridge Ritualists verwoben, werden sie von $\mathrm{R}$. Seaford (1981) zunächst für die Bakchen wiederentdeckt, der sie als Dramatisierung des Aition der thebanischen Dionysosweihen sowie als Quelle des Tragödienursprungs aus bakchischen Mysterien interpretiert. ${ }^{134}$ Selbst wenn man die Ursprünge nie eindeutig klären wird, gab dieser Aufsatz einem ganzen Forschungszweig Anstoß, eleusinische und bakchische Geheimkulte als strukturelles Referenzmodell in den Texten nachzuweisen, worauf überdies Aristoteles in der Poetik mit seiner zentralen Begrifflichkeit zu rekurrieren scheint. ${ }^{135}$ So werden vor allem der Verweis auf rituelle Terminologie, aber auch die Rätselhaftigkeit der metaphorischandeutungsreichen Sprache, die Beschäftigung mit Pathos, die Lust am Leiden, die Erregung der Affekte in Raserei ( $\beta \alpha \kappa \chi \varepsilon i ́ \alpha$ bakcheia), die metaphorische Stilisierung von Heldinnen zu Bakchen, ${ }^{136}$ die Reinigung

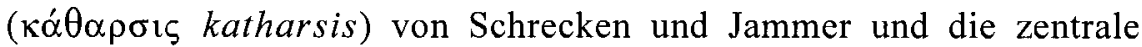
Kategorie der Rettung damit in Verbindung gebracht. ${ }^{137}$ Neben den in Pubertätsweihen wurzelnden Mysterien fließen laut Seaford unter anderem Jagd- und Opferbräuche, Klage-, Trauer- und Hochzeitsriten, das Pharmakosritual und Vegetationsbräuche ein. ${ }^{138}$ Die Mysterienbezüge werden vor allem mit den Neufunden von Goldblättchen unterstrichen, die das Vorhandensein bakchischer Mysterien belegen. ${ }^{139}$ Neuerdings wird der hervor.

133 Nach Thomson 1957, 101-136 und Seaford 1981, 263-265 gehen sie sogar daraus

134 Seaford 1981; ähnlich schon vorher gedeutet von Jeanmaire 1951, 301-316 und Guépin 1968.

$135 \mathrm{Zu}$ den eleusinischen Zusammenhängen in E. Ion vgl. Zeitlin 1989.

$136 \mathrm{Vgl}$. Schlesier 1993.

137 Schlesier 1995, 412-415 sieht Mysterienbezüge u. a. in E. Hipp., Hec., Supp., $H F, T r ., E l$.; Seaford 1994b bei Sophokles; zu S. OC vgl. Calame 1998.

138 Seaford 1994a; 1996.

${ }^{139} \mathrm{Vgl}$. Schlesier 1995, 389-397; Seaford 1996, 41; Riedweg 1998. 
strukturelle Zusammenhang ebenso für die Komödie thematisiert. ${ }^{140}$ Fundamentale Verbindungen zum Drama können zudem im Moment der Mimesis und in der performativen Präsentation des unterlegten Mythos in Eleusis ausgemacht werden. Unteritalische Mysterienkulte scheinen die Denk- und Darstellungsweise von Parmenides und Empedokles beeinflußt zu haben. ${ }^{141}$ Desgleichen scheint Heraklit von orphischen Einweihungsvorstellungen nicht unberührt zu sein. ${ }^{142} \mathrm{Im}$ Falle Platons kann man in einigen Dialogen, vor allem im Symposion und Phaidros, nachweisen, wie die Mysterienterminologie die narrative Struktur bestimmt. ${ }^{143}$

\section{Mysterien und Roman}

Im Anschluß an K. Kerényi (1897-1973) formuliert R. Merkelbach die Theorie, die griechischen Romane (außer demjenigen des Chariton) seien Mysterientexte der im ausgehenden Altertum florierenden Einweihungskulte der Isis, des Mithras, des Dionysos und des Sonnengottes. Ihr eigentlicher Sinn sei nur den Eingeweihten verständlich, die hinter dem "Oberflächensinn" einer einfachen literarischen Erzählung in jeder Episode dechiffrierbare Anspielungen auf mystische Geheimnisse erkennen könnten. ${ }^{144}$ Ähnlich wie im Falle der mythisch-rituellen Tragödiendeutung liegt eine Tendenz zum Zirkulären vor: Mysterienreligion wird aus dem Roman 'gefiltert' und dann als strukturierender Unterbau desselben nachgewiesen. Dieser Weg wird heute weitgehend abgelehnt. Gerade um Apu-

140 Faraone 1997; Auffarth 1999; Lada-Richards 1999, bes. 45-122; Riu 1999, bes. 92-94, 102-103, 136-139, 141.

${ }^{141}$ Kingsley 1995; 2000; 2003; zu Empedokles u. a. Riedweg 1995; Bierl (in Vorbereitung).

142 Seaford 1986, 14-20; Schefer 2000 (mit älterer Literatur 46 Anm. 1), die Heraklits Fragmente allerdings in überzogener Weise als "echten Mysterienlogos" (73) deutet.

143 Vgl. Riedweg 1987, 1-69, der für einen metaphorischen Bezug plädiert. Schefer 1996; Schefer 2001 übertreibt, wenn sie diese Verweise als Belege für einen wirklichen Mysteriensinn interpretiert, die auf reale Kulterfahrungen von Apollon-Einweihungen zurückgehen. Zur strukturellen Verwendung von athenischem Fest- und Kultmaterial bei Platon vgl. auch Krummen hier in Band 2.

144 Kerényi 1927; Merkelbach 1962; 1988; 1994; 1995. Zum "Oberflächensinn" vgl. u. a. Merkelbach 1962, 90. Über die mythische Figur des Daphnis wollte Wojaczek 1969 im Anschluß an Merkelbachs (1962, 192-224) Longus-Interpretation schließlich sogar die Bukolik mit der dionysischen Mysterientradition der Bukoloi verbinden und in der Nachfolge von R. Reitzenstein (1893, 204-228, bes. 204-208) den dionysischen Ursprung erweisen, was methodisch ebenso fragwürdig bleibt. Zur Kritik vgl. Geyer 1977, 179. 183; Baudy 1993b, 286. 
leius' Metamorphosen ist trotz des überaus deutlichen Isis-Bezugs besonders im elften Buch eine heftige Kontroverse entbrannt. J. Winkler erschütterte die rein religiöse Position gründlich, indem er diesen Roman als "a philosophical comedy about religious knowledge" charakterisierte; ${ }^{145}$ S. J. Harrison betrachtete das Vorkommen isiatischer Züge dann in ähnlicher Weise als Parodie auf ernste religiöse Texte, wobei solches platonisch-mystisches Wissen in der Manier der Zweiten Sophistik zu Unterhaltungszwecken demonstrativ zur Schau gestellt werde. ${ }^{146}$ Das von Merkelbach herangezogene Material mit angeblich mystischem Sinnpotential deutet man daher nun nach der communis opinio als gattungsspezifische Versatzstücke der literarischen Komposition. Die immer wieder nahezu stereotyp aufgeführten Widerlegungen der Merkelbachschen These von M. Berti und A. Geyer sind allerdings religionswissenschaftlich wenig fundiert, diejenigen von $\mathrm{R}$. Turcan bleiben, wiewohl sie sehr detailliert sind, dennoch insgesamt unbefriedigend. ${ }^{147} \mathrm{R}$. Beck gelingt ein Vermittlungsversuch, indem er zeigt, daß sich die Thesen von Winkler und Merkelbach gegenseitig erhellen und daß die Romane die Beschäftigung mit Rettung, $\tau \varepsilon \lambda \varepsilon \tau \eta ́($ telete) und den $\delta \rho \omega ́ \mu \varepsilon v \alpha($ dromena) mit den Mysterien gemeinsam haben. ${ }^{148}$ Im Streit der Positionen kann man heute in der Terminologie Winklers ausgleichend konstatieren, daß die Isis-Initiation auf der Erzähler (actor)-Ebene ernst gemeint ist, die Ironie durch den Autor (auctor) zustande kommt. ${ }^{149}$ Insgesamt sprechen Merkelbach und seine Gegner am eigentlichen Problem vorbei. Ebenso wie im Fall der Tragödie oder der Bukolik stellen die Mysterien auch für den Roman wohl kaum den Ur-

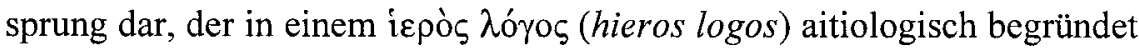
wird, ${ }^{150}$ sondern nur eines von vielen möglichen rituellen Referenzmodellen, ${ }^{151}$ über die der Autor frei verfügt, ohne sie deshalb zwangsläufig parodieren zu müssen. Zweifelsohne fällt der Höhepunkt dieser Prosagattung mit der Blüte der Mysterienreligion zusammen, weshalb das Denken der Romanschreiber von diesem kulturellen Element,

145 Winkler $1985,124$.

146 Harrison 1996, 514-515 und 1999, xxxviii.

147 Berti 1967; Geyer 1977; Turcan 1963; 1989.

148 Beck 1982; 1996. Auch sonst sucht man neuerdings im Falle des Apuleius wieder vorsichtig Anschluß an Merkelbach; vgl. z. B. Münstermann 1995.

149 So Riess 2001, 330-337.

150 Merkelbach 1962, 333.

151 So auch Winkler 1985; Harrison 1999, xxxviii. 
insbesondere von der eskapistischen Suche nach Heil ( $\sigma \omega \tau \eta p i ́ \alpha$ soteria), geprägt ist. Die Gattung ist vom intertextuellen Einlesen unterschiedlicher Prä- und Subtexte bestimmt, überdies durch die nichtsäkularisierte Lebenswelt des Autors, so daß, selbst wenn keine institutionelle, genetische oder kultische Verbindung mit den Mysterien gegeben ist, Rituelles und Mythisches einfließen und den Grundstock dessen ausmachen, aus dem der Romancier seine Handlung frei konstruiert. Daß Initiationen als Passageriten mit dem Aufbau vieler volkstümlicher Erzählungen strukturelle Ähnlichkeiten aufweisen, ${ }^{152}$ kommt ihm dabei entgegen. Es stellt Merkelbachs großes Verdienst dar, auf dieses religiöse Substrat aufmerksam gemacht zu haben. Neuerdings versucht man schließlich den Roman aus der christlichen Wundererzählung heraus zu erhellen. ${ }^{153}$

\section{Neujahrsfest und Königsritual}

Bereits Harrison (1912) ist an der engen Verflechtung zwischen der Initiation und dem Jahresfest interessiert. Wieder ist es Burkert, der diesen Strang aufnimmt und den Zusammenhang thematisiert: "In den Initiationsriten erneuert sich das Leben der Gemeinschaft, in den daraus erwachsenen Neujahrsriten erneuert sich die Ordnung der Polis." $154 \mathrm{Zu}$ Recht hat man das auffällige Schwanken führender Religionshistoriker zwischen beiden Kategorien auf eine funktionale und formale Ähnlichkeit beider Paradigmen zurückgeführt. Denn hier wie dort gibt es einen deutlichen rite de passage und ähnliche signifiants als die Erzählung charakterisierende Elemente: häufig spielen im Zustand der Marginalität für den Protagonisten eine Flut, ein Monster, Statusverkehrungen, eine Reise in die Unterwelt oder gar Todeserfahrung eine Rolle. ${ }^{155} \mathrm{C}$. Auffarth wendet das Schema des Jahresfests kombiniert mit dem Königsritual, der jährlich rituell begangenen temporären Absetzung und Wiedereinsetzung des Herrschers, auf der Grundlage altorientalischer Vorbilder auf Homers Odyssee an und zeigt, wie der Zustand der Marginalität als verkehrte Welt dem experimentellen Durchspielen alternativer Möglichkeiten dienen

152 Ruiz-Montero 1988 nach der Erzählanalyse von Propp 1972. Vgl. auch Bierl hier in Band 2.

${ }^{153}$ Bowersock 1994.

154 Burkert 1966a, Zitat 25. Zum Neujahrsfest allgemein vgl. zudem Burkert 1972, 153-273; Versnel 1993, 89-135, 136-227, 228-288.

155 Versnel 1993, 80-83. 
kann. Gleichzeitig sieht er bei Telemach und Odysseus das Initiationsschema in Form einer Reaktualisierung ihres Übergangsstatus am Werk. ${ }^{156}$ Auffarth überträgt das altorientalische Schema darüber hinaus auf die Vögel des Aristophanes, indem er in den ausnahmeartigen Anthesterien ein solches Jahresfest erkennt. ${ }^{157}$ Burkerts Aufsatz über das Jahresfest auf Lemnos inspiriert die Deutung der Lysistrate und der Ritter des Aristophanes; ${ }^{158}$ die Ekklesiazusen werden zudem in Verbindung mit den Skiren und Panathenäen gesehen, welche den Festzyklus des attischen Jahresübergangs mitbestimmen. ${ }^{159}$

\section{Fruchtbarkeit und Vegetationsfest}

Während die beiden anderen großen Erklärungsmuster der Initiation und des Jahresfestes unter Einbeziehung von modernen soziologischen und anthropologischen Perspektiven ganz auf der Höhe der Zeit sind, scheint das Fruchtbarkeitsparadigma seit den 1950er und 1960er Jahren auch unter dem einflußreichen Diktum von Burkert ganz außer Mode gekommen zu sein, obwohl der bäuerliche Hintergrund als ökonomische Basis gerade in der archaischen und klassischen Zeit die Lebenswelt weitgehend bestimmt. In der religionshistorischen Analyse und im Transfer auf die Literatur wird dieser Ansatz heute besonders von G. J. Baudy in Kombination mit der Initiation - zum Teil in Kombination mit Mysterien und dem Jahresfest und unter Berücksichtigung heortologischer Abläufe, vor allem im Zusammenhang mit der Saatgutprüfung, verwendet. ${ }^{160}$ Meines Erachtens ist eine Rückkehr zu W. Mannhardt (1831-1880), Frazer oder Cornford durchaus lohnenswert, ${ }^{161}$ allerdings auf dem Niveau heutiger Methoden. Es soll daher weder um Fruchtbarkeitsmagie noch um die Auffindung von

156 Auffarth 1991.

157 Auffarth 1994. Vgl. ferner Craik 1987; Zannini Quirini 1987 (im Interpretationsschlüssel von Brelich 1975); Riu 1999, 250. Zum Plutos vgl. Bierl 1994a.

158 Burkert 1970; zur Deutung der Lysistrate vgl. Martin 1987; Bowie 1993a, 178204; zu den Rittern vgl. Bowie 1993a, 66-74.

159 Bowie 1993a, 254-267.

160 U. a. Baudy 1986, bes. 49-91 (Adonisgärten und Pl. Phdr.); 1991 (Kallimachos, Demeterhymnos); 1992 (Arrhephorienritus); 1993b (Theoc. Id. 7 und ritualistische Deutung der Bukolik); 1996 (Hdt. 2.121-123); 2004 (zu den Thebais-Epen und A. Th.).

${ }^{161}$ Mannhardt 1865; 1868; 1875/1877; 1884; Frazer 1890; Cornford 1914. Über das Pharmakosritual der Thargelien ist eine Verbindung zum eher soziologischen Denken im Modell des Opfers gewährleistet. 
Jahresdämonen, sondern um die Symbolwirkung brauchtümlicher Abläufe im Kalender der Polis gehen. Die diversen kultischen Handlungen, die fast ausschließlich den grundlegenden Lebensbereich des Nahrungserwerbs reflektieren, besitzen nämlich eine sinnbildliche Zeichenkraft. ${ }^{162}$ Der Raum, die Zeit und die beteiligten Objekte verdienten demnach eine genauere Behandlung in den symbolischen Prozessen, die im Zusammenhang mit den Ritualen entstehen. Aristophanes scheint sich besonders für die Anwendung des agrikulturellen Interpretationsmodells anzubieten (auch in Verbindung mit den Mysterien von Eleusis), zumal viele seiner Komödien voll von Fruchtbarkeitsmotiven sind (Ach., Pax, Ra., Pl.). In diesem Zusammenhang hat in der Aristophanesforschung neuerdings wenigstens das Anodos-Schema, also die Hervorholung einer unterirdischen Göttin als symbolischer Ausdruck einer nahezu utopischen Rückkehr zur Fruchtbarkeit, Reichtum und Gesundheit Anwendung gefunden. 163

\section{Allgemeine Riten}

Ein weiterer Forschungszweig untersucht, wie Autoren, vor allem Dramatiker, Riten des Alltags aufgrund der herausragenden Bild- und Zeichenhaftigkeit in ihre Handlung einbetten und welche Funktionen diese in der poetischen Konstruktion des jeweiligen Plots besitzen. Selbstverständlich ist das Vorkommen solcher Riten historisch über die zugrundeliegende Präsenz all dieser Formen in rituellen Gebrauchsliedern vermittelt, aus denen zum Teil die archaische Chorlyrik schöpft. Insbesondere die Choreuten, aber auch andere Schauspieler werden im Theater häufig als rituelle Akteure gekennzeichnet, um das Publikum in den Bereich zwischen Wirklichkeit und Fiktion zu ziehen. ${ }^{164}$ Oft erhalten Dramen ihre Titel vom rituellen Tun der Akteure. ${ }^{165}$ Zudem werden Hochzeitsriten und ihre Verbindung mit Todeserfahrungen, ${ }^{166}$ Hikesie- und Supplikations-

162 Vgl. Calame 1990, 289-396; Schmitt Pantel 1992, bes. 117-252.

${ }^{163}$ In Th. (Bierl 2001, 139 mit Anm. 85); in Ra. (Lada-Richards 1999, 81-84, 106108, 114); in Pax (Bowie 1993a, 143-146).

164 Vgl. Easterling 1988; Kranz 1933, 127-137; Krummen 1998; Lloyd-Jones 1998.

165 Vgl. z. B. Hiketides, Choephoroi, Psychagogoi. Für die Alte Komödie vgl. Bierl 2001, 97 Anm. 202.

$166 \mathrm{Vgl}$. Seaford 1987. 
szenen, ${ }^{167}$ Opferhandlungen, Libationen, ${ }^{168}$ Reinigungen, Segnungen, ${ }^{169}$ Beschwörungen, Verfluchungen, ${ }^{170}$ Jagdriten, ${ }^{171}$ Heilungen, Gebet und Gebetsreihen, ${ }^{172}$ Eide, magische Binderituale, ${ }^{173}$ Bestattungsbräuche, ${ }^{174}$ Klagen und Threnoi, ${ }^{175}$ Tanz, ${ }^{176}$ Komoi, ${ }^{177}$ Agone, Prozessionen, Aischro-

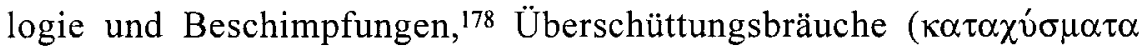
katachysmata) etc. in ein theatrales Spektakel transformiert. ${ }^{179}$ Theater, das selbst im rituellen Kontext aufgeführt wird, integriert diese Riten meist in Chorpartien als direkt am Körper ausagierte lebensweltliche Handlung, wobei performativ gewissermaßen 'Ritual im Ritual' entsteht. Diese Konstruktion von mythos auf der Basis ritueller Abläufe erhöht die emotionale Ergriffenheit und wirkt gemeinschaftsstiftend; das dynamischoszillierende Ineinandergreifen von intra- und extrafiktional-pragmatischer Ebene gerade durch den Chor als internen Zuschauer erzeugt communitas und Kohäsion der im Spektakel anwesenden Polis. Die von der Realität entfernten, auch gattungs- und okkasionsbedingten Verzerrungen sowie die freie, auf den Prinzipien der Addition und Selektion basierende Kombination schaffen erst die theatrale Handlung, die in gewisser Weise selbst als fiktionales Ritual die Wirkung des realen Rituals übernehmen soll. ${ }^{180}$ Nicht zufällig können im Theater fiktive Rituale inszeniert werden, die keine Verankerung in der Lebenswirklichkeit besitzen, wie etwa die Todesbeschwörungsriten in den Persern des Aischylos. Indem also Dramatiker, und später beispielsweise Romanschriftsteller, über allerlei Rituale der Lebenswelt als performatives Material kreativ verfügen, schaffen sie immer neue poetische Möglichkeiten. Folglich richtet die For-

${ }^{167}$ Burian 1972; Henrichs 1993b; Gödde 2000b.

168 Jouanna 1992.

${ }^{169} \mathrm{Zu}$ Segnungen vgl. Auffarth 1991, 524-558.

170 Stehle 2005.

171 Vidal-Naquet 1968; 1969 (Verbindung zum Opfer).

172 Pulleyn 1997; Stehle 2004.

173 Faraone 1985.

174 Easterling 1988, 91-99; Henrichs 1993b; Hame 2004.

175 Alexiou 1974; Foley 1993; Segal 1994a; Gödde 2000a. Unter dramaturgischstruktureller Betrachtung Schauer 2002.

176 Henrichs 1996a; 1996b; Bierl 2001, Index s. $v$.

177 Bierl 2001, Index s. v.; Pappas 1987.

178 Degani 1987; Halliwell 1991, 288-290; Rösler 1993; Treu 1999.

179 Vgl. Easterling 1988; Krummen 1998; Gödde 2000a; $2000 \mathrm{~b}$.

180 Bierl 2001. 
schung ihr Augenmerk nicht nur darauf, wie Dichter durch Einverleibung von Riten sowie durch Ankündigung und spätere Ausführung einen Plot konstruieren, sondern wie sie sogar Erwartungen beim Publikum wecken, die später enttäuscht werden, und die festen Ablaufmuster für ihre Zwecke regelrecht manipulieren. ${ }^{181}$ Das dem Ritual, insbesondere dem Opfer inhärente Krisenpotential kann für den dramatischen Effekt genutzt werden, indem man die hier umspielte Gewalt zur fiktionalen Wirklichkeit werden läßt. Dies bedeutet letzten Endes die mimetische Perversion des Rituals, das eigentlich dazu da ist, Bedrohungen der Zivilisation performativ zu bewältigen. Die Komödie arbeitet mit vergleichbaren Mitteln, selbst wenn sie entsprechend der Gattungsgesetzlichkeit dazu tendiert, das kreative Umgehen für ihre Ziele des Lachens und des Auslebens sämtlicher sonst unterdrückter Triebe einzusetzen. Dementsprechend kommt das permanente Übergreifen in die pragmatisch-rituelle Einbettung des dionysischen Festrahmens hinzu. ${ }^{182}$ Rituelle Handlungsblöcke und ähnliche Techniken der Manipulation bestimmen natürlich überdies andere Gattungen, wie das Epos und die Lyrik. ${ }^{183}$

Selbst die hellenistische Literatur ist davon - freilich in anderer Weise - gekennzeichnet. Im sogenannten mimetischen Gedicht wird der Ablauf heiliger Handlungen artifizieller oder besonders exotischer Art, beispielsweise bei Kallimachos, in das im situationsunabhängigen Kontext der Schriftlichkeit stehende poetische Produkt hereingenommen. ${ }^{184}$ In der Bukolik, u. a. in Theoc. Id. 5, 7 und 8, werden Wettgesänge zwischen Hirten von der Welt des Brauchtums in die Struktur von Literatur übertragen. ${ }^{185} \mathrm{Im}$ römischen Bereich leben zudem viele lyrische Gedichte aus der Spannung zwischen pragmatischem Vorbild und literarischer Tradition und Konstruktion. ${ }^{186}$ Einen produktiven Unterbereich stellen die Untersu-

181 Dazu nun am Beispiel des Sophokles Henrichs 2004.

182 Dies geschieht über den Komos sowie die Siegesfeier und das Symposion am Schluß. Vgl. Pappas 1987; Bierl 2001; Calame 2004; Sfyroeras 1992.

183 Zum Epos vgl. u. a. Auffarth 1991; Papadopoulou-Belmehdi 1994; Cook 1995. Zur Lyrik vgl. u. a. Contiades-Tsitsoni 1990; Krummen 1990; Yatromanolakis 2003.

$184 \mathrm{Vgl}$. Calame 2000, 169-205; Henrichs 1993c.

185 Merkelbach 1956, 115-122.

186 Catull carm. 62 übernimmt beispielsweise die traditionelle Struktur eines Hochzeitsliedes. 
chungen dar, welche die Fragestellung leitet, wie die nach Frazer lange verschmähten Formen der Magie auf die Literatur einwirken. ${ }^{187}$

\section{Kult, Orakeldeuter, Priester und Heiligtum}

Literarische Texte, beispielsweise Platonische Dialoge oder ganze Dramen, können in einem Heiligtum verortet sein, wodurch Kulthandlungen für entsprechende Gottheiten integriert werden. ${ }^{188}$ Besonders das an sie gerichtete Gebet kann ein wichtiges Handlungselement werden. Orakel und Orakeldeuter spielen eine herausragende Rolle für die Gestaltung des Plots, nicht nur in der Tragödie, sondern nahezu überall in der griechischen Literatur. Die Schriftsteller nutzen gerade das dem Orakel inhärente narrative Potential für ihre poetische Konstruktion. Sie können damit das Publikum proleptisch auf kommendes Geschehen vorbereiten oder sogar Erwartungen einer bestimmten Wendung der Ereignisse schüren, um sie dann jäh zu enttäuschen. Gerade die Autoren der Alten Komödie verstehen sich darauf, eigenartige kultische Praktiken, wie etwa die Inkubation im Asklepiostempel, oder Kultspezialisten, Heiler, Priester und neuartige Chresmologen (wie in den Vögeln) als Lachnummern auf die Bühnen zu bringen. ${ }^{189}$ Es stellt sich die Frage, ob dies als Religionskritik gemeint sei oder ob die komischen Dichter nicht wiederum entsprechend den Gattungsgesetzen auf den ersten Blick befremdliches Material der rituellen Lebenswelt, bewußte Verzerrungen und Überzeichnungen, für die poetische Struktur des grotesken Spiels nutzen. ${ }^{190}$

\section{Opfer und Opfertheorie}

Als Untergattung der die Tragödienhandlung durchdringenden Rituale spielt das Opfer seit Burkerts bahnbrechendem Aufsatz aus dem Jahre 1966 eine herausragende Rolle. ${ }^{191}$ Darin führt er die Gattung nach einer antiken Tradition auf den "Gesang beim Bocksopfer" bzw. "um den Preis eines Bockes" zurück, ${ }^{192}$ weist dessen Funktion nach und skizziert bereits

${ }^{187}$ Faraone 1985; 1993; 1994; zu Theoc. Id. 2 vgl. Faraone 1995; Graf 1996, 158183, bes. 159-171; Petrovic 2004.

188 Z. B. A. Eu.; S. OC; E. Ion, IT; Ar. Th.; Men. Dysc.

${ }^{189} \mathrm{Zu}$ diesen Orakeldeutern und abstrusen Kultspezialisten vgl. Smith 1989.

$190 \mathrm{Zu}$ den Gattungsgesetzen der Aristophanischen Poetik vgl. Bierl 2002b.

${ }^{191}$ Burkert 1966b.

192 Burkert 1966b, dt. Zitat Burkert 1990, 14. 
seine auf K. Meuli (1891-1968) und K. Lorenz (1903-1989) zurückgehende diesbezügliche evolutionistisch-universalistische Theorie, die er in Homo necans (Burkert 1972) weiter ausführen wird. "Opfer ist rituelle Tötung. Im Opferritual verursacht und erfährt der Mensch den Tod."193 Ziel sei die ostentative Zurschaustellung dieses schaudervollen Akts. Aus der schrecklichen Angst, aus dem Schock und Schuldgefühl wegen des Mordes am Tier erwachse soziale Gemeinschaft, weswegen Opferfeste dazu dienten, soziale Krisen zu überwinden. ${ }^{194}$ Auf der anderen Seite wirkt wiederum die Pariser Schule um Vernant. Diese betrachtet ausgehend von der Prometheusgeschichte (Hes. Th. 535-557) das Opfer strukturalistisch und innergriechisch als symbolisch-klassifikatorisches Ritual, das den Platz des Menschen zwischen Gott und Tier bestimmt. Die religiöse Funktion bestehe in der Etablierung einer Struktur im Kosmos qua dem Akt des Fleisch-Essens, wobei in Anschluß an Durkheim (1912) die Götter eine Projektion und Abbildung der hierarchischen Strukturen auf der Erde darstellten. ${ }^{195}$ Die einzelnen Prozeduren des Opfervorgangs seien dazu da, die gewaltsamen Aspekte zu minimieren und zu verbergen. Diese kategoriale Einordnung wird überdies in der verzerrenden Inszenierung des tragischen Opfers eines Helden thematisiert. ${ }^{196} \mathrm{Im}$ Erscheinungsjahr von Burkerts Homo necans (1972) entwirft der Romanist R. Girard, nachdem er seine Thesen zunächst am Roman des 19. Jahrhunderts entwickelt hat, ${ }^{197}$ ebenfalls ein evolutionistisches, anthropologisches und an S. Freud (18561939) orientiertes Konzept über den Zusammenhang von Aggression und ihrer gesellschaftlichen Bewältigung. ${ }^{198}$ Die einer Gemeinschaft inhärenten Rivalitätsverhältnisse, deren Gewaltpotential ihr Zusammenleben bedroht ('mimetische Krise'), könnten nur überwunden werden, indem die Masse einen Sündenbock ( $\varphi \alpha \rho \mu \alpha$ кó pharmakos) auswähle. Der kollektive Mord wirke gemeinschaftsstiftend, wobei das Opferritual mimetisch die kollektive Gründungstat wiederhole und rituell die Grausamkeit

193 Burkert 1966b, dt. Zitat Burkert 1990, 21.

194 Burkert 1977, 101-115; 1979, Kap. 2; 1982b; 1987. Kritik an Burkerts Position findet sich u. a. bei Alexiou 1990; Henrichs 1987, 29-30. Zum Ablauf des Tieropfers vgl. van Straten 1995.

195 Zur Paris-Lausanne-Schule vgl. Detienne/Vernant 1979; Vernant 1981; 1987 , 170-187. Zu Gegensätzlichkeiten und Parallelen der Thesen Burkerts resp. der Pariser Schule vgl. Peirce 1993.

196 Foley 1985, 30-46.

197 Girard 1961.

198 Girard 1972. 
kaschiere. Sobald diese Praktik in die Krise geraten sei, habe man die sozialintegrative Funktion qua Mimesis durch das Theater zu ersetzen begonnen; hierbei behandelt Girard unter anderem S. OT und E. Ba. Die Überbetonung der grausamen, auf dem Mythos, nicht auf dem Kult beruhenden Seite des Dionysos - "Dionysos est le dieu du lynchage réussi" -, ${ }^{199}$ die auch sonst in Frankreich blüht, ${ }^{200}$ stammt letztlich von Nietzsche. ${ }^{201}$ Als unhistorisches Konstrukt wird Girards Modell heftig kritisiert, ${ }^{202}$ als heuristisches Instrument zur Interpretation von Literatur und Theater bis in die Moderne ist Girard hingegen von großer Bedeutung. ${ }^{203}$ Wesentlich mehr verspricht die Methode, diese Ansätze zu verbinden und gleichzeitig die Eigengesetzlichkeit der Literatur, ihre Mittelbarkeit und ihr Abgelöstsein von der Realität sowie ihr Eingebundensein in die jeweilige Gattung zu berücksichtigen. ${ }^{204}$ Hier ist wiederum die Tragödie das hauptsächliche Anwendungsgebiet, die bekanntlich die Perspektiven ins Gewaltsame verzerrt. Daher taucht dieses Motiv hier oft als pervertiertes Opfer auf. ${ }^{205}$ Das Opfer kann vor allem einen strukturbestimmenden und einen pragmatischen Aspekt in der literarischen Verarbeitung besitzen. ${ }^{206}$ Bisweilen werden die Motive von Jagd und Opfer verbunden. ${ }^{207}$ Thematisch ist gerade das Selbstopfer bei Euripides von Bedeutung. ${ }^{208}$ Die von W. R. Smith (1846-1894) stammende Sakramentaltheorie appliziert J. Kott (1914-2001) auf die tragische Gattung. ${ }^{209}$ Die Sünden-

199 Girard 1972, 190; vgl. Girard 1982 und Burkert 1982b, 18-21 (Burkert über Girard).

200 Vgl. u. a. Detienne 1977, 149-153.

$201 \mathrm{Vgl}$. Henrichs 1984, bes. 232-234.

202 Gordon 1979; Henrichs 1984, 232-234; zu einer theologischen Kritik vgl. Herzog 1992.

203 Vgl. u. a. Hardie 1993, 19-56 (für Vergil); Fischer-Lichte 1998c, bes. 45-46 (zum Opfer und modernen Theater aus performativer Perspektive); Teuber 2000 (zur frühneuzeitlichen Tragödie); Braungart 1996, 236-241; 2001; 2005 (moderne Literatur); allgemein: Düssel/Edel/Schödlbauer 2001, 127-233 (Teil 3: "Zur Mechanik der Kultur"; Teil 4: "Opfermythologie"); Thomas 1998 (zum Vergessen).

$204 \mathrm{Vgl}$. die gute Einleitung von Foley 1985, bes. 17-64. Zur Situation im Lateinischen vgl. Feeney 2004.

205 Zeitlin 1965; 1966; Henrichs 2000; Gibert 2003.

206 Zum strukturbestimmenden Aspekt vgl. Pucci 1977; Seidensticker 1979; Tyrrell/

Brown 1991, 73-98; Henrichs 2004; zum pragmatischen Aspekt vgl. Burkert 1985.

207 Vidal-Naquet 1969.

208 O'Connor-Visser 1987; Henrichs 2000.

${ }^{209}$ Kott 1975. 
bocktheorie in Verbindung mit dem Thargelien-Ritual des $\varphi \alpha \rho \mu \alpha$ kós (pharmakos) (auch ohne Girard) ist ein weiterer Schwerpunkt. ${ }^{210}$ Das Menschenopfer wird zunehmend nicht als ritueller Reflex der Realität, sondern insbesondere als narrativ-kompositorisches Element in der Literatur erkannt; ${ }^{211}$ in der Tragödie wird in der Pervertierung das Gewaltpotential des Tieropfers dramaturgisch umgesetzt, indem Mord und Totschlag mit Opferterminologie versehen und so performativ ausgespielt werden..$^{212}$ Im Mythos wird die drohende Opferung eines Menschen oft mittels der Substitution durch ein Tier verhindert.

In der Romanforschung gibt es vor allem anhand von Lollianos eine Auseinandersetzung zwischen Henrichs (1972) und Winkler (1980) über den Realitätsgehalt von Menschenopferszenen. Im Gegensatz zu Henrichs, der brutale Opferszenen im Roman als getreues Abbild des Rituals ansieht, betrachtet Winkler dieses Material als innerliterarische Fiktion, welche die gattungstypische Spannungssteigerung durch Motivketten von dramatischen Abenteuern bewirke. ${ }^{213}$ Das Opfer und entsprechende Störungen des Ablaufs sind überdies als Strukturelemente in der Alten Komödie (z. B. Ar. Ach., Pax, $A v$.) nachweisbar. ${ }^{214}$ Durch verkehrte Gründungsopfer kann die Inversion der Ordnung ausgedrückt werden oder ein Opfer kann gegen Ende als Zeichen der Rückkehr zur Ordnung gelesen werden. ${ }^{215}$ Neuerdings zeichnet sich eine Tendenz $a b$, daß man sich von den vorherrschenden dunklen Szenarien der Gewalt, Angst und Schuld löst und das Opfer im Festkontext positiver bewertet. Man blickt vermehrt auf das Lachen, die Freude am Schmaus und die komischen Elemente in der Ikonographie von Opferszenen. ${ }^{216}$ Dies wird wohl vor allem Auswirkungen auf die Interpretation der Komödie haben, die von diesen heiteren Aspekten des

210 Allgemein Bremmer 1983b; zu Thersites als 'Sündenbock' in der llias vgl. Usener 1897, 239-259; Graf 1991, 340-341; zum Motiv in der Tragödie vgl. Cornford 1914, 129-133; Vernant 1972, 114-131, bes. 114-119 (in S. OT); Segal 1982, 36-54 (in E. Ba.); zum Motiv in der Komödie vgl. Cornford 1914, 33, 57, 131; Bennett/Tyrrell 1990; Bowie 1993a, 74-75 (in Ar. Eq.).

211 Zum Menschenopfer allgemein vgl. Henrichs 1981; Hughes 1991; Bonnechère 1994; Georgoudi 1999; Grottanelli 1999.

212 Henrichs 2000; Gibert 2003.

$213 \mathrm{Zu}$ den Räubern in der römischen Gesellschaft und bei Apuleius vgl. nun Riess 2001.

214 Sfyroeras 2004.

215 Vgl. u. a. Bowie 1993a, Index s. v.; Riu 1999, Index s. $v$.

216 Obbink 1993; Peirce 1993. 
Festes bestimmt ist. ${ }^{217}$ In einem anderen kulturwissenschaftlichen Ansatz verbindet man die Dichtung mit dem Opfer, der Gabe an die Götter. ${ }^{218} \mathrm{Im}$ Anschluß an das Konzept der Kultur als Textes ist anhand der Phalloslieder fr. $851 P M G$ ausführlich gezeigt worden, wie diese volkstümlichen Texte die Vorstellungen von Opfer, Wein und Sexualität durchdringen und wie ihre Verschmelzung gleichzeitig Auswirkungen auf die performative Produktion hat. 219

\section{Schamanen und Trickster als kulturvergleichende Modelle}

Nach einem einflußreichen Beitrag von K. Meuli zum Skythenexkurs im vierten Buch Herodots erfreut sich das Modell des Schamanismus in der Religionswissenschaft sowie in der Verbindung von Literatur und Religion einer gewissen Beliebtheit. ${ }^{220}$ Doch bald erheben sich skeptische Stimmen dagegen. J. Bremmer und F. Graf lehnen das Wirken des Konzepts aufgrund des fehlenden institutionell-pragmatischen Bezugs ab. ${ }^{221}$ Doch die erkannten strukturellen $\ddot{A}$ hnlichkeiten, wie Graf selbst betont, ${ }^{222}$ rühren daher, daß die von der rituellen Wirklichkeit abgelösten Themen als Wandermotive in Erzählungen integriert worden sind. Dies ist meines Erachtens ein zentrales Kriterium hinsichtlich der Applikation auf die Literatur. Die Forschungen, die 'schamanistisches' Gedankengut in der archaischen Dichtung aufdecken, zielen bisher jedoch wieder eher auf die Erklärung des Ursprungs als darauf, die besonderen Strukturprinzipien und die generische Funktion dieser Texte damit zu verdeutlichen. ${ }^{223}$ In der Ethnologie und Theater-Anthropologie gibt es Ansätze, die performativen Züge

${ }^{217}$ U. a. Sfyroeras 1992.

218 Svenbro 1984; vgl. Sfyroeras 1992 (für die Alte Komödie).

219 Bierl 2001, 300-346. Ähnlich Kurke 2005 zu Pindars sechstem Paian. Zur Kultur als Text vgl. Bachmann-Medick 1996.

220 Meuli 1935; Dodds 1951, 135-178; Burkert 1962a, 98-142, 324-325 (zu frühen Wanderpriestern, Sehern, Dichtern und Philosophen wie z. B. Pythagoras, Abaris, Aristeas, Epimenides, Orpheus, Parmenides, Empedokles); 1979, 88-94, 182-184 (der Schamanismus als uraltes Konzept hinter der Heraklessage); 1996, 67-69 (in Verbindung mit einem biologischen Trieb der Suche); West 1983, 3-7, 49, 143-150 (bes. Orpheus); Kingsley 1995 (zu Empedokles).

221 Bremmer 1983a, 25-48, 52; Graf 1987; Zhmud 1997, 107-116.

222 Graf 1987 , bes. 84, 99 .

223 Meuli 1935, 164-176; Graf 1991, 358 Anm. 126 (zum Epos); Kirby 1975 (Drama, vor allem Tragödie). Zu traditionellen schamanistischen Wandermotiven in der Odyssee und in den Arimaspea des Aristeas vgl. Petersmann 1981, 45-47; West 2004. 
der Schamanenséance mit dem Drama zu assoziieren.224 Auf die Komödie hat man das Modell ansatzweise übertragen. ${ }^{225}$ Es ist interessant zu fragen, wie sich anhand 'schamanistisch' gezeichneter Figuren im attischen Theater ein Spiel mit dem Anderen und dem Selbst einstellen kann, und 'Schamanismus' als ein theatralisches Gedankenexperiment zu untersuchen. Die Alte Komödie greift im komischen Rückfall in ein vorzivilisatorisches, tribales Stadium auf dieses uralte Konzept zurück, das gleichzeitig als Substrat in der Volkskultur und im einfachen Brauchtum weiterlebt. Die theatrale 'Reminiszenz' solcher atavistischer Verhältnisse stellt also ein artifizielles poetisches Konstrukt dar, womit das Barbarische der magoi in die Polis hereingeholt wird, um ihr komplementäre Welten zu eröffnen. 226

Die von nordamerikanischen Mythen stammende Vorstellung des Tricksters ist in der Gräzistik vergleichsweise akzeptiert. Brelich verbindet eine Reihe von Zügen des griechischen Helden mit dieser Figur. ${ }^{227}$ Burkert appliziert das Konzept auf Hermes und Prometheus, gerade auch in der literarischen Darstellung dieser Figuren. ${ }^{228}$ Zudem wird Odysseus gerne damit in Verbindung gebracht. ${ }^{229} \mathrm{Im}$ Bereich der Komödien-Forschung ist es üblich, den komischen Helden in seiner grotesken Körperlichkeit mit dem Trickster in einem Zusammenhang zu sehen. ${ }^{230}$

\section{Heortologische Abläufe}

Ein Autor kann sogar kalendarische, im pragmatischen Rahmen vorhandene Festkontexte einer Polis in einer Art rituellen 'Grammatik' verarbeiten und auf dieser Grundlage eigene mythopoetische Plots konstruieren. Athen und Sparta ragen hier als Orte mit gut dokumentierten Festen heraus, die zu einer kultisch-rituell gestützten Poetik verwendet werden. In Sparta integriert Alkman offensichtlich lokale Kultelemente in seine Jung-

224 Schechner 1990, 71, 101-102, 145-147.

225 Duchemin 1957, 287-295; Bowie 1993a, 112-124 deutet die Gestalt des Sokrates

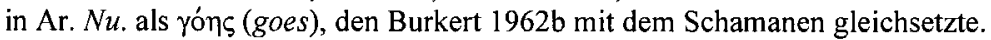

226 Vgl. Bierl (im Druck).

${ }^{227}$ Brelich 1958. Zu nordamerikanischen Vorstellungen Radin 1956.

228 Burkert 1984, 840-845.

${ }^{229} \mathrm{Vgl}$. nun Maiullari 2004.

${ }^{230}$ Brelich 1975, 114-117; Zannini Quirini 1987, 19; Riu 1999, 3, 244-245. 
frauenlieder. ${ }^{231}$ Insbesondere erweist es sich fruchtbar, ganze Abläufe als Muster für eine Handlung heranzuziehen, wie beispielsweise in Athen denjenigen von den Skiren bis zu den Panathenäen. ${ }^{232}$ Selbstverständlich können auch Einzelfeste mit verschiedenen rituellen Teilaspekten als Referenzmodelle eines Plots ausgemacht werden. ${ }^{233}$ In Athen sind besonders Kulte der eponymen Polisgöttin Athene von Bedeutung. Für das attische Drama spielen erwartungsgemäß Elemente der dionysischen Feste, wie zum Beispiel der Anthesterien, Lenäen, der Großen und der Ländlichen Dionysien, die in die Handlung projiziert werden, eine herausragende Rolle. Spezifische Jahres-, Einweihungs- und Fruchtbarkeitsfeste können entsprechend den oben dargestellten Paradigmen von den Dichtern für die Plotgestaltung herangezogen werden. Hier ist besonders an die Mysterienfeiern in Eleusis, die Thesmophorien, das Adonisfest oder die Panathenäen zu denken. Insgesamt kann wieder zwischen dem Zusammenspiel von pragmatischer Verortung und inhaltlicher Verarbeitung dieses 'Sitzes im Leben' auf der einen Seite und der situationsunabhängigen Verwendung von fremden oder sogar später literarisch gesuchten Kulten und Kultzusammenhängen unterschieden werden. ${ }^{234}$

\section{Fazit}

Jüngst wird das Paradigma der Initiation und des rite de passage massiv in Frage gestellt, nachdem es sich in den letzten vierzig Jahren nach dem Bedeutungsverlust des Fruchtbarkeits- und Neujahrmodells gerade in den Literaturwissenschaften großer Beliebtheit erfreut hat. ${ }^{235}$ Dadurch steht man plötzlich vor der absurden Situation, daß nun keines der drei grundsätzlichen Paradigmen mehr das Wohlwollen der Religionswissenschaft besitzt. Auf der anderen Seite erhält der hier vorgestellte Ansatz momentan durch den kulturwissenschaftlichen Trend in den Philologien eine wichtige Bedeutung, wie gezeigt worden ist. Die Schlußfolgerung kann wohl kaum sein, daß man sich als Literaturwissenschaftler dieses herme-

231 Calame 1977. Zum Reflex in Ar. Lys. vgl. Bierl 2007.

${ }^{232}$ Zur Lysistrate des Aristophanes ist dazu von mir ein Beitrag in Vorbereitung.

233 Bowie 1993b identifiziert z.B. das Panathenäenfest als Bezugspunkt für das Ende der Eumeniden des Aischylos.

234 Vgl. zur ersten Kategorie Papadopoulou-Belmehdi 1994; Cook 1995 (zu Homers Odyssee); Krummen 1990; Kurke 2005 (zu Pindar); zur zweiten Kategorie Wolff 1992 (zu E. $I T$ ).

$235 \mathrm{Vgl}$. Dodd/Faraone 2003. 
neutischen Instrumentariums enthalten sollte. Vielmehr zeigt die Diskussion nur, daß man sich nicht blindlings momentanen Modeströmungen und einseitigen Interpretationsmustern unter Vernachlässigung der Fakten hingeben darf. Die Konsequenz daraus kann nur sein, sich je nach Gegenstand die geeignete Methode zu suchen und stets für neue Verbindungen und Überlegungen offen zu sein, wenn man auf diesen Pfaden voranschreiten will. Die Rituale sind mit dem Text verwoben und warten darauf, für das poetische Funktionieren der Texte in adäquater Weise erkannt und analysiert zu werden. Für diese Aufgabe sind wir heute besser gerüstet denn je, zumal von religionswissenschaftlicher Seite nun für die Gräzistik das Material weitgehend aufgearbeitet ist, gerade durch Handbücher wie Thesaurus Cultus et Rituum Antiquorum und Lexicon Iconographicum Mythologiae Classicae.

\subsection{Mythische Perspektive}

In Deutschland hat sich gerade aufgrund der als Zumutungen empfundenen Thesen der Cambridge Ritualists die Tradition etabliert, die Mythenvon der Ritenforschung zu trennen, ein Verfahren, das erst mit Burkert aufgegeben worden ist. ${ }^{236}$ Mythos wird daher schon immer als Materialgrube gesehen, aus der die Dichter ihre Stoffe schöpfen. Aus dieser Perspektive ist es folglich schon immer evident, daß Mythen die Struktur von Literatur bestimmen und durchdringen. Im folgenden soll allerdings die komplexe Verbindung zum Ritual stets mitgedacht sein. Mythos ist ursprünglich ein autoritativer Sprechakt, den einerseits der Dichter mimetisch darstellt und der andererseits die Dichtung selbst hervorbringt, also essentiell die Sprache der Poesie ist. ${ }^{237}$ Der Begriff kommt von $\mu v ́ \omega(m y o)$, was in alltäglicher, unmarkierter Form so viel wie 'ich habe meine Augen oder meinen Mund geschlossen' bedeutet, in spezifischer, markierter Anwendung freilich ausdrückt, daß jemand auf besondere Weise etwas sieht oder sagt. Mythos, das heißt das autoritative 'Wort', stellt eine traditionelle, aber markierte Form des Sprechens dar, mit der man sich auf Gesellschaft und Realität bezieht, sie affirmierend preist oder kontrastiv

236 Most 1990, 10.

237 Martin 1989. 
bestätigt. ${ }^{238}$ Mythos ist traditionelle Performanz oder Erzählung, die häufig auf übernatürliche Wesen Bezug nimmt und aus einem allgemein geteilten Fundus von Glauben, Erfahrungen und Erinnerungen gespeist wird. Häufig dient er dazu, zwischen Vergangenheit und Gegenwart, Bekanntem und Unvertrautem zu vermitteln. In der Performanz stößt eine solche erzählte Geschichte auf eine dialogische Antwort von seiten des Hörers, der teilnimmt, reagiert sowie Anstoß zu neuen Versionen gibt. ${ }^{239}$ Die Form des Mythos reicht vom Lied, Tanz, Gedicht bis hin zur einfachen Erzählung in Prosa, zur romanhaften Wundergeschichte, Sage, Legende oder zur mehr oder weniger authentischen, fiktional durchsetzten Biographie. Mit dem Übergang zur Schriftlichkeit sterben solche Traditionen nicht aus, sondern verändern sich weiter und bilden die Grundlage neuer Varianten. Antiker Mythos wirkt literarisch im Sinne einer stofflichen Grundlage und als Mittel der Überlieferung der Stoffe über das Mittelalter und die Renaissance bis heute. ${ }^{240}$

\subsubsection{Mythos und Handlungsstruktur}

Mythos ist im Aristotelischen Sinne die Handlungsstruktur oder der Plot, besonders der Tragödie (z. B. Arist. Po. 1450a4-5). Als narrative Performanz oder Geschichte besitzt der Mythos keine feste und starre Form, auf die man sich bezieht, sondern jede mythische Tradition verändert laufend in einem proteischen Prozeß der "Arbeit am Mythos" seine Phänotypik. ${ }^{241}$ Das soziale Energiepotential regt zu immer neuen Varianten an; die traditionellen Narrationen stehen immer in einem Bezug zu gesellschaftlichen Ereignissen oder Faktoren. Mythopoesie kann so neue Performanzen und Erzählungen als Ausdruck einer Kultur generieren. Um exemplarisch kunstvolle Produkte zu bewahren, werden ursprünglich mündliche Formen verschriftlicht. Ein Autor kann nun wiederum diese Texte im intertextuellen Spiel mythopoetisch für neue Formen verwenden. Schließlich ent-

238 Vgl. G. Nagys Definition im Vorwort zu Martin 1989, x-xi. Nach Burkert 1979, $1-34$, bes. 23 ist Mythos traditionelle Erzählung mit sekundärer, gesellschaftsrelevanter Anwendung.

239 Dazu vgl. Alexiou 2002, 153-154; überdies Wunenburger 1994. Zum Mythos allgemein Burkert 1993.

240 Calame 1988.

241 Blumenberg 1979. 
steht daraus Literatur. ${ }^{242}$ Jedes antike Werk von der Archaik bis zur Spätantike kann auf der Handlungsebene vom Mythos determiniert sein. Dies gilt natürlich genauso für alle literarischen Werke überhaupt. Nicht nur die Rezeption antiker Mythen ist dafür verantwortlich, sondern das Prinzip der Mythopoetik, die durch eine Übertragung der Handlungsstruktur einer einheitlichen Sage oder in der Montage mythischer Motive wirken kann. ${ }^{243}$ Für das Homerische Epos und die Tragödie ist besonders die panhellenische Heldensage ausschlaggebend, während lokale Kultmythen eine eher untergeordnete Rolle spielen. ${ }^{244}$ Der Übergang zum Märchen ist fließend. Beispielsweise ist die Odyssee das epische Resultat einer langen mündlichen Tradition, hinter der man noch deutlich die einfache Geschichte eines Heimkehrermärchens erkennen kann. Dieses wird zum Großepos panhellenischen Zuschnitts ausgebaut und mit phantastischen Lebensgeschichten angereichert, ${ }^{245}$ womit wieder ein menschliches Modell der Vergangenheit in einen Bezug zur zeitgenössischen Realität des jeweiligen Publikums gestellt wird. Gerade die attische Tragödie bedeutet die paradigmatische, emotional-intellektuelle Auseinandersetzung der Polis mit mythischen Vorzeiten. Die Polis vermag über das tragische Bühnengeschehen komplexe Probleme zu reflektieren, wofür die demokratischen Organe sonst keine vergleichbaren Möglichkeiten bieten. 246 Ähnliches gilt für die Alte Komödie, wobei diese die aktuellen Verhältnisse jedoch ins Niedere verkehrt, während die Tragödie das Geschehen auf eine höhere Ebene der mythischen Vergangenheit projiziert und die dionysische Qualität sich in der Überspitzung und Perversion gültiger Normen manifestiert. ${ }^{247}$ Durch die performative Involvierung wird der Rezipient kontrastiv auf die gegenwärtigen Werte zurückgeworfen. Selbst in der sogenannten politischen Komödie kann der Mythos (z. B. derjenige der Sukzession der Göttergeschlechter, der Gigantomachie, der Herrschaft der

$242 \mathrm{Vgl}$. Wunenburger 1994. Zur modernen Literatur vgl. u. a. Frye 1957; Vickery 1966; White 1971. Vgl. den ganzen literaturwissenschaftlichen Zweig der modernen Mythentheorie und -kritik.

243 Zur griechischen Literatur vgl. Calame 2000; zur römischen Literatur vgl. Feeney 1998, 47-75.

244 Graf 1991; Calame 2000, 71-93 (zum Epos); 2000, 117-144 (zur Tragödie); Wolff 1992 liefert eine exemplarische Interpretation zu E. IT aus der Sicht der Interdependenz mit dem Ritual.

245 Hölscher 1988.

246 Meier 1988, bes. 7-13.

247 Brelich 1975. 
Amazonen) jenseits der eigentlich mythischen Stücke eine konstitutive Funktion erhalten. ${ }^{248}$ Und sogar die Geschichtsschreibung, die sich nach der antiken Literaturtheorie am deutlichsten durch den Wahrheitsanspruch vom Mythos absetzt, rekurriert in ihrer narrativen Darstellung gerne auf mythische Muster und Vorstellungen. Wie stark der Mythos die griechische Geschichte durchsetzt, zeigt bereits intensiv J. Burckhardt im ersten Kapitel ("Die Griechen und ihr Mythus") seiner Griechischen Culturgeschichte. ${ }^{249}$ Sieht man von seinen romantisierenden Tendenzen ab, erkennt man hier bereits den Ansatz seines Bestrebens, Analogien von Mythos und Geschichte herauszuarbeiten. In beiden, erkennt Burckhardt, versuche man die Vorfahren, Ursachen und Anfänge (’’ $\rho \chi \alpha i$ archai) zu erklären, Figuren, Ereignisse der Sage zu lokalisieren und mit einer Erzählung zu versehen, beziehungsweise kultische Bräuche, Feste und Riten mit Geschichten und Erklärungen zu begründen. Wo man Leerstellen zu füllen hat, tritt die mythische Fiktion ein, die sich von Aitiologien löst und produktiv anpaßt. Die genannten Muster lösen sich dann zunehmend von konkreten Vorgaben ab. In freier Anverwandlung werden sie immer neu variiert, so daß sich mythisch-rituelle Bausteine selbst in Texten wie den Biographien des Plutarch finden lassen. ${ }^{250}$ Gerade die beim Rezipienten erwünschte funktionale Verknüpfung der Vergangenheit mit der Gegenwart schafft unter anderem das Verbindungsglied zwischen Mythos und Geschichte. In der griechischen Sprache ist wie im Deutschen die Unterscheidung zwischen Geschichte als einfacher Erzählung und Geschichte im Sinne von faktenorientierter Geschichtsschreibung sprachlich nicht verankert. 'I $\sigma \tau о \rho \varepsilon ́ \omega$ (historeo) bedeutet 'erforschen' und 'betrachten', sowie 'eine Geschichte in Bildern lebendig erzählen'. Es geht also nicht darum, daß eine Geschichte wahr ist, sondern daß sie so gut erzählt ist und in der Performanz Wirkung erzielt, das heißt den Hörer fasziniert und dabei zum Denken und Verstehen in bezug auf Vergangenes animiert, das immer im Konnex mit gegenwärtigen Vorstellungen, Wünschen und Fakten steht.

248 Allgemein zu einem Mythos der Komödie vgl. Frye 1957, 163-186; Bowie 1993a findet zahlreiche Mythen (u. a. Sukzessionsmythos, Gigantomachie, Goldenes Zeitalter, Lemnische Frauen, Amazonen) als Substruktur einzelner Komödien; bes. zu Ar. Av. vgl. Hofmann 1976; Zannini Quirini 1987.

249 Burckhardt 1898, 5-35. Vgl. Wesselmann hier in Band 2.

${ }^{250}$ U. a. Braund 1993, der in Plutarchs Crassus eine dionysische Tragödie ausmacht. Der dionysische Mythos löst sich also ab und kann im intertextuellen Spiel strukturbestimmend werden. 
Mythos und Historie greifen demnach symbolisch auf ein ähnliches kulturell-symbolisches Ausdrucksreservoir zurück und zielen auf den nämlichen Effekt. ${ }^{251}$ Erst recht kann ein solches mythopoetisches Prinzip in den relativ späten Liebesroman Einzug halten, der wiederum stark von geschichtlicher Fiktionalität bestimmt ist. In dem für ihn typischen fiktionalen Konstrukt einer Biographie wird der Roman zum myth-historischen Prosanachfolger der Odyssee. ${ }^{252}$

Die Aitiologie ist der spezifische, einer bereits eher schriftlich bestimmten Kultur entstammende und gesuchte Fall eines solchen mythischen $\lambda \varepsilon \gamma o ́ \mu \varepsilon v o v$ (legomenon) in bezug auf das $\delta \rho \omega ́ \mu \varepsilon v o v$ (dromenon) des Rituals. Freilich können solche Verkettungen von $\alpha i \tau i \alpha \_$(aitiai) produktiven Anreiz für neue fiktionale Mythopoesie geben, wie Kallimachos belegt. Ebenso hat Ovid beispielsweise den aitiologischen Mythos Roms in seinen Fasti zur Literatur ausgestaltet, welche die rituellen Praktiken der römischen Lebenswelt auf eine Pluralität von gleichzeitig gültigen $\mathrm{Mu}$ stern zurückführt und dabei durch "defamiliarisation" Eigenes aus der Perspektive des Fremden erfahrbar macht.253 Mythopoesie erfährt also je nach Gattung und sozio-politischen Zeitumständen unterschiedlichste Ausprägungen. Ein anderer Bereich, der nach moderner Vorstellung gerade nicht in die Kategorie 'Literatur' fallen würde, ist die frühe Philosophie der Vorsokratiker bis hin zur Platonischen. Auch sie arbeitet mythopoetisch und stark bildlich-assoziativ. Sie produziert lkonizität und verwendet zum Teil selbst dichterische Diktion. Parmenides und Empedokles dichten sogar in Versen. Der vorsokratische philosophische Diskurs steht also zwischen Mythos und moderner, objektiv-begrifflicher Philosophie. In der Suche nach $\dot{\alpha} \rho \chi \alpha i$ (archai) und $\alpha i \tau^{\prime} \alpha \mathbf{\imath}$ (aitiai) bezieht man sich auf die Denk- und Verstehensfunktion des vorliegenden Mythos sowie zum Teil

251 Dazu Alexiou 2002, 156-157. Allgemein vgl. Brillante 1990 und nun auch Calame 2003; Candau Morón/González Ponce/Cruz Andreotti 2004. Zu Thukydides, bei dem man dies aufgrund seiner vermeintlich objektiven Geschichtsschreibung am wenigsten erwartet hätte, vgl. schon Cornford 1907; zu Herodot vgl. u. a. Rieks 1975; Sourvinou-Inwood 1991; Nesselrath 1996; Hartog 1999; Calame 2000, 145-167; Boedeker 2002; Stadter 2004; Chiasson 2005 sowie Wesselmann, die dazu gerade eine Basler Dissertation abfaßt, und Gödde hier in Band 2; zur Situation im Hellenismus vgl. Henrichs 1999; zur gesamten Annalentradition zwischen Dichtung und Geschichte vgl. Wiseman 2002; zu Livius' mythischem Substrat vgl. Miles 1995; Graf 1993b, 27; Ungern-Sternberg 1993; Wiseman 1995; 2004.

252 Zum Roman u. a. MacQueen 1990; Cueva 2004; siehe auch oben 'Mysterien und Roman' und Bierl hier in Band 2.

${ }^{253}$ Feeney 1998, 123-133. 
auf in der Orphik vorhandene mythisch-religiöse Ausdrucksformen und Wege der Reflexion. ${ }^{254}$ Selbst Platon setzt bekanntlich an zahlreichen Stellen Mythen ein und kreiert zur Verständigung in dichterischem Verfahren neue Mythen. ${ }^{255}$ Gerade das Konzept der im griechischen Mythos virulenten Metamorphose, der Verwandlung mythischer Gestalten, erweist sich als kreatives Modell und generierendes Energiefeld des mythopoetischen Transformationsprinzips von Performanz und schließlich Literatur schlechthin, die ihr textliches Geflecht über Variation, Kombination und Verschiebungen sowie mittels der Prinzipien der Ähnlichkeit und Kontiguität immer weiter fortspinnt. In Ovids Metamorphosen, der in narrative Verkettung gebrachten Enzyklopädie sagenhafter Gestalten und Geschichten von den Uranfängen bis zur eigenen augusteischen Zeit, gipfelt nun ein solches meta-mythopoetisches Bewußtsein. Gleichzeitig kann im aller Verwandlung zugrundeliegenden Prinzip des Chaos der Mensch erneut in einer lebendig handelnden Bilderflut sein ganzes Denken und Wissen in einer Gegenüberstellung von Gegenwart und Vergangenheit spielerischkunstroll abstecken. ${ }^{256}$

\subsubsection{Götter}

Mythos ist meist Götter- und Heroengeschichte. ${ }^{257}$ Die Antike ist ohne den hauptsächlich griechischen Götterhimmel undenkbar. ${ }^{258}$ In der Kunst und in der Literatur von der homerischen bis zur hellenistischen Zeit sind die Götter und Heroen allgegenwärtig. Den Dichtern Homer und Hesiod wird später nachgesagt, sie hätten diesen anthropomorphen Götterapparat geschaffen (Hdt. 2.53). Bei Homer und im Epos, wo ihre Rolle am besten

254 Vgl. u. a. Kingsley 1995; Riedweg 1995; Most 1999; Cerri 1999; Burkert 1999; Morgan 2000, bes. 46-88; Kingsley 2000; 2003; Bierl (in Vorbereitung).

255 Vgl. u. a. Zaslavsky 1981; Moors 1982; Schefer 1996; 2001; Murray 1999; Morgan 2000; Cürsgen 2002; Janka/Schäfer 2002.

256 Hierzu erhielt ich wichtige Anregungen von Rebecca Lämmle, die ein Projekt dazu in Vorbereitung hat. Richard Buxton beendet demnächst eine Monographie über die Logik des griechischen Metamorphosenmythos. Vgl. auch das Teilprojekt "Metamorphosen. Geschichte und Theorie mythopoetischer Lektüren" im von Ralf Simon (Basel) geleiteten Modul 05 im Rahmen des Nationalen Forschungsschwerpunkts der Schweiz "Eikones. Bildkritik. Macht und Bedeutung der Bilder".

257 Zum Problem des fast völligen Fehlens im Ägyptischen vgl. Assmann 1977.

258 Allgemein Detienne 1986; Henrichs 1987. 
untersucht ist, ${ }^{259}$ aber auch überall sonst besitzen sie eine doppelte Funktion: sie sind Teil eines narrativen Konstrukts und dienen der Deutung der Welt. Die Tragödie sowie die Komödie sollen aus dem Kult des Dionysos hervorgegangen sein und besitzen auf institutioneller Ebene eine enge Verbindung mit dieser Gottheit. Daher ist es legitim und lohnend, seine besondere Funktion auch in den Texten zu untersuchen. ${ }^{260}$ Einen wichtigen Erkenntnisgewinn brachte die Verbindung mit der modernen Literaturwissenschaft dadurch, ${ }^{261}$ daß man in diesem Gott auch eine metadramatische Dimension erkannte. ${ }^{262}$ Bestimmte Helden können eine spezifische dionysische Zeichnung erfahren. ${ }^{263}$ Die befremdlichen Darstellungen des Dionysos (sowie der übrigen Götter auf der Bühne, etwa der Athene im Prolog des Sophokleischen Aias) sind wiederum aus der Gattung herzuleiten und nicht, wie früher angenommen, Zeugnis von Götterkritik oder gar von religionsskeptisch-atheistischen Strömungen. ${ }^{264}$ Diese Verzerrung äußert sich als Gewalt in der Tragödie, als Verspottung und groteske Charakterisierung - oft eine übersteigerte und ins Absurde gezogene Folge des Anthropomorphismus - in der Komödie. Neben Dionysos, der in Euripides' Bakchen und Aristophanes' Fröschen freilich als verkleideter Mensch auftritt, spielen selbstverständlich auch die anderen Gottheiten und Göttergruppierungen eine Rolle im Textgewebe des Dramas. ${ }^{265}$ Zahlreiche Götter, nie zufällig gewählt, treten im Prolog und am Ende der Tragödie ex machina auf. Von ihnen gesprochene Prologe sind dann in der Neuen Komödie die Regel, ansonsten kennt die Komödie am Ende kein Eingreifen von seiten der Olympier. Oft geschieht in der Nea die Einführung mittels göttlicher Figuren, die Abstrakta verkörpern. Götterpersonifikationen, wie

$259 \mathrm{Zu}$ den homerischen Göttern vgl. den Überblick bei Burkert 1977, 191-199; Erbse 1986; Graf 1991; zum lateinischen Epos vgl. Feeney 1991.

260 Bierl 1991; Aronen 1992; Lada-Richards 1999; Riu 1999.

261 Abel 1963.

262 Segal 1982, 215-271, 369-378; Bierl 1991, 111-218 und oben Anm. 88.

263 Zur bakchischen Metapher in der Tragödie vgl. Schlesier 1993; zur dionysischen Zeichnung eines Helden, z. B. des Trygaios in Ar. Pax, vgl. Elderkin 1924, 49-75. Zu Dido als Mänade vgl. Krummen 2004.

264 Dies war die vorherrschende Meinung im 19. und frühen 20. Jahrhundert; vgl. u. a. Hild 1880; Pascal 1911. Ein übliches Mittel war zudem, die derbe Volksreligion (Fruchtbarkeitsriten im Kontext von Dionysos und Demeter) von rationaler Polisreligion zu scheiden; vgl. Keller 1931. Zu den komischen Gattungsgesetzen vgl. Bierl 2002b. Ähnliches gilt für die Götterburleske; vgl, Burkert 1982a.

265 Vgl. u. a. Rosenmeyer 1982, 259-283 (bei Aischylos); Winnington-Ingram 1980, 317-329 (bei Sophokles); Schlesier 1983; Kullmann 1987 (bei Euripides). 
Eirene, Polemos, Demos oder Plutos, kommen bereits bei Aristophanes in der Handlung vor. Manche werden in dieser Phase tatsächlich kultisch verehrt und sind somit wirkliche, wenn auch kleinere Götter. Innerhalb der Handlung können Götter ebenso auftreten, aber nur selten bestimmen sie den Plot von ganzen Stücken, wie in Aischylos' Eumeniden und Prometheus. In den Rittern des Aristophanes dient etwa der mythische Kampf zwischen Athene und Poseidon um die Vorherrschaft in Athen als Mittel, dem komischen Gefecht zwischen dem Paphlagonier-Kleon und dem Wursthändler höhere Bedeutung zu verleihen. ${ }^{266}$ Beide Götter prägen desgleichen die Auseinandersetzung der Euripideischen Troades und der Homerischen Odyssee. Je nach Kontext können Götter und ihr Gefolge entsprechend ihren Funktionen und Zuständigkeiten für spezifische Motive und Situationen handlungsbestimmend werden, etwa Aphrodite für Liebe und Erotik, Apollon und Artemis für Initiation, Demeter für Mysterienweihe und Fruchtbarkeit, Athene für Klugheit und Weisheit. ${ }^{267}$ So sind beispielsweise Aischylos' Eumeniden vom Kampf zwischen den Erinyen auf der einen Seite und Apollon sowie der zuletzt ausgleichenden Athene auf der anderen Seite bestimmt. Der Prometheus ist ganz vom Konflikt zwischen Zeus und Prometheus, der Euripideische Hippolytos von der Auseinandersetzung zwischen Aphrodite und Artemis gekennzeichnet. Nicht zuletzt wird die Präsenz der Götter auch theologische Fragen beim Publikum ausgelöst haben. ${ }^{268}$

Insgesamt kann neben Einzelfiguren auch das komplexe funktionale Beziehungsgeflecht der polytheistischen Ordnung auf die Texte übertragen poetologisch wirksam werden. ${ }^{269} \mathrm{C}$. Calame stellt den Götterapparat als symbolisches System hinsichtlich der Raum-Zeitachse in Attika dar und zeigt, wie an den rituellen Festen des attischen Kalenders der strukturierte Raum durch Prozessionen auf zentralen Achsenwegen jährlich neu abgesteckt und der Prozeß der Zivilisation durch die verschiedenen Reifungsund Zubereitungsstufen der Natur in Form von Nahrung symbolisch vergegenwärtigt wird. ${ }^{270}$ Dabei sollten aber hinter den abstrakten strukturalisti-

266 Bowie 1993a, 66-74.

${ }^{267}$ Es gibt nur wenige Studien zur Rolle von Einzelgottheiten über Dionysos hinaus. Vgl. z. B. zu Apollon Solomon 1994 (in der antiken Literatur im diachronen Querschnitt); Bierl 1994b (in der Tragödie). Zu Zeus in der Tragödie vgl. Lloyd-Jones 1971.

$268 \mathrm{Vgl}$. nun Sourvinou-Inwood 2003.

269 Z. B. Vernant 1987, 94-112; Detienne 1986; 1997; Henrichs 2001.

${ }^{270}$ Calame 1990, bes. 289-396. 
schen Zusammenhängen nicht die Götter als Wesen aus den Augen verloren werden, die ein spezifisches Spektrum sie konstituierender Zeichen mitführen. Insgesamt geht es bei der Betrachtung in diesem Kontext nicht mehr darum, die Religiosität eines Autors, das heißt seinen Götterglauben, zu behandeln, sondern die poetische Konstruktion von Gottheiten und ihr performatives Agieren im Text zu beleuchten. Durch das Offenlegen von Ähnlichkeiten und Differenzen innerhalb literarischer Traditionen gilt es zu zeigen, wie diese poetischen Mittel ein Epos, ein lyrisches Gedicht, ein Drama oder einen Prosatext jeweils bestimmen können. ${ }^{271}$ So können Götter, beispielsweise Athene in der Odyssee oder Dionysos in den Bakchen, zu Drahtziehern der Handlung, ja fast Regisseuren werden, wodurch sie im Text teilweise den Autor vertreten. ${ }^{272}$ Götter zeichnen sich zudem durch eine besondere Präsenz aus, besonders natürlich im Moment ihrer Epiphanie. ${ }^{273}$ Dadurch ist es beispielsweise möglich, die Bakchen als Inszenierung einer Parousie des Dionysos zu lesen. Im Zusammenhang einer Epiphanie kann zudem die ikonische Präsenz des Götterkultbildes poetologisch vereinnahmt werden. Bilder werden bisweilen als lebendig und agierend vorgestellt, wodurch eine Spannung zwischen Urbild und Abbild entsteht. ${ }^{274}$ Außerdem wird nach der Definition des Mythos als eines sekundären semiologischen Systems immer deutlicher, ${ }^{275}$ wie über inszenatorische Darbietungen von Mythen und Riten in Verbindung mit der Instrumentalisierung von Göttern politische Propaganda im archaischen, klassischen und hellenistischen Athen sowie im Rom der Kaiserzeit gemacht wurde. ${ }^{276}$ Aus diesem Blickwinkel ist die alte These zu revidieren, daß im frühen Griechenland der Mythos noch lebendig gewesen, im Hellenismus und in Rom hingegen erstarrt sei. ${ }^{277}$ Beispielsweise sind auch im kaiserzeitlichen Roman die Götter omnipräsent und gehen mit den Protagonisten eine spezifische Bindung ein, ja verschwimmen fast mit

271 Zu Kallimachos' Hymnen vgl. u. a. Henrichs 1993c; Calame 2000, 169-205.

272 Vgl. zur Odyssee Murnaghan 1995; zu den Bakchen vgl. Bierl 1991, 181-218.

273 Zur Anwendung des Motivs in Hom. Od. vgl. Bierl 2004; im Plot des Romans vgl. Hägg 2002.

274 Elsner 1996; Too 1996.

275 Barthes 1957, 221. 1993.

276 Z. B. Connor 1987; Tyrrell/Brown 1991, bes. 133-157; Henrichs 1999; Hölscher

277 Graf 1991 , bes. 359. 
diesen. ${ }^{278}$ Das neue Wirken der Götter kommt besonders gut im Herrscherkult der römischen Kaiser zum Tragen. Hier interagieren Elemente der alten römischen Gottesvorstellungen dynamisch mit importierten griechischen. ${ }^{279}$ Anhand Senecas Apocolocyntosis kann man die Praxis der Apotheose in der literarischen Verarbeitung und Verzerrung der Menippeischen Satire betrachten, während für die Kaiser der Nimbus göttlicher Macht in anderen Gattungen, wie etwa in Horazens carmina, zum Teil von den Dichtern mitgeschaffen wird. ${ }^{280}$

\subsubsection{Heroen}

Die griechischen Helden stellen neben den Göttern das Personal fast jeglicher Performanz und Erzählung. In der anthropomorphen Vorstellung bilden sie das Bindeglied zwischen den Göttern und den Menschen des Hier und Jetzt. Einzelne Helden können mit Göttern in eine besonders enge Beziehung treten. Der rituell angelegte Antagonismus zwischen einer Gottheit und einer heroischen Figur, die als ihr Doppelgänger fungiert, wird in der darauf aufbauenden Erzählung des Mythos ausagiert und zuletzt in Literatur umgesetzt. ${ }^{281}$ Sehr häufig stehen Heroen aber in einem besonderen Schutz- und Freundschaftsverhältnis zu einer Gottheit, etwa Odysseus zu Athene. Ein zentrales Thema ist die Zeichnung eines Helden mit Merkmalen einer göttlichen Epiphanie, um seine Bedeutung herauszustreichen. Odysseus' Heimkehr in der Odyssee ist bewußt nach dem traditionellen und mythischen Schema der Abwesenheit und Rückkehr eines Gottes gestaltet, der Protagonist einer sich langsam offenbarenden Gottheit angenähert. ${ }^{282}$ Damit kann die Ranghöhe sowie der außergewöhnliche Anspruch der Tradition und des Sängers ausgedrückt werden, mit einem solchen Lied den Helden unsterblich zu machen und vor allem für sich selbst unvergänglichen Ruhm zu erwerben. ${ }^{283}$ Die Aristokratie hypostasiert

278 Alperowitz 1992; Baier 1999.

279 Feeney $1998,76-114$.

280 Feeney 1998, 108-114.

281 Nagy 1979, 143-145 zu den Paaren Apollon-Achilles und Athene-Hektor in der Ilias. Vgl. auch Athene-Aias in Sophokles' Aias. Im Kult kann der Held indessen sogar neben der Gottheit verehrt werden (z. B. Poseidon-Erechtheus).

282 Vgl. Lord 1960, 186-197, der Achilles' Rückzug und Wiedereintritt ins Kampfgeschehen in der Ilias damit verbindet. Zum Schema in der Odyssee vgl. Murnaghan 1987, 11-19, 56-117; Reece 1993, 181-187; Bierl 2004.

$283 \mathrm{Vgl}$. Bierl 2004. 
ihre Normen und Werte in heroischen Gestalten, die zum einen als direkte Nachkommen der Götter gedacht werden, zum anderen als sagenumwobene Vorfahren den aktuellen Zustand der Menschheit überhöhen. Die traditionellen Geschichten über solche übermenschlichen Figuren werden in Sagenkreisen, wie zum Beispiel dem troianischen und thebanischen, zusammengefaßt. Die Mythen können in immer neuen Konstellationen weitergesponnen werden. Entscheidend für eine solch produktive Weiterentwicklung ist die Anpassung an gesellschaftliche Veränderungen. Die soziale Referenz der traditionellen Erzählung muß jeweils funktionieren. Dies kann affirmativ oder kontrastiv geschehen. Gerade im Mythos pflegt man häufig in freier Kombination Helden und Götter in vom Standard abweichenden Verhaltensformen auftreten zu lassen. Mord, Gewaltexzesse, Untreue und phantastische Szenerien aus der Warte des Anderen und Fremden sind an der Tagesordnung, während man im Kult aus der vertrauten Innensicht des lokalen Hier und Jetzt die nämlichen Figuren weitgehend positiv zeichnet. Die heroischen Geschichten um Troia und Theben bilden als kulturelles Arsenal im Dort und Damals die Basis von Epos und attischer Tragödie, also von den künstlerischen Produktionen, die man später als hohe Literatur bezeichnet. Diese wirken wiederum auf spätere Literaturformen. Freilich sind in der griechischen Kultur auch niedere, verzerrende und unterhaltsame Formen des Mythos vorhanden. Die Alte Komödie kann bisweilen von ganzen Chören grotesker Heroentrupps, wie zum Beispiel der Amazonen, Kyklopen, Kentauren und Amazonen, bestimmt sein. ${ }^{284}$ Gerade die volkstümliche Tradition rückt bizarre Abenteuer und Verwandlungssagen ins Zentrum, welche die Protagonisten mit Körperlichkeit und Sexualität konfrontieren.

Kurzum, Heldinnen und Helden verkörpern in ihrer Interaktion mit den Göttern sämtliche Verwicklungen und Krisen des menschlichen Lebens. Die Geschichten dienen auf lokaler, panhellenischer und später, im Kaiserreich, auf universaler Ebene dazu, den Kosmos, die Werte und Normen einer Gesellschaft zu stärken. In den traditionellen Erzählungen strukturiert man mental seine Lebenswelt im Kräftedreieck von Gott, Held und Mensch. Räume werden abgesteckt, zentrale Riten und Kulte mit Narrationen bekräftigt sowie Genealogien überliefert und vermittelt. Ferner spielen die Menschen sämtliche anthropologisch zentralen Themen - unter anderem Sexualität, Hochzeit, Tod - in phantastischen Geschichten durch.

284 Bierl 2001, 97. 
Nach J. Campbell besitzen die Heldensagen des Abenteuertypus die dreigliedrige Struktur des rite de passage, Initiations- und Neujahrsrituals, die offenbar allen menschlichen Erzählungen zugrunde liegt und sich nach Burkert auf biologische Programme zurückführen läßt. ${ }^{285}$

Ferner wirken Heroen wirken häufig über ihren Kult auf Literatur ein. Im Homerischen Epos fehlt dieses Element jedoch, da eine panhellenische Perspektive lokale Heldenverehrung verdecken mußte. ${ }^{286}$ In einigen Tragödien, zum Beispiel im Aias des Sophokles, wird freilich entsprechend dem typischen Erzählschema des Heroenmythos nach dem Tode des Helden die Gründung seines Kults in Szene gesetzt. ${ }^{287}$ Interessante Perspektiven ergeben sich aus der Erkenntnis, daß die Stimme des Dichters, beispielsweise die des Archilochos, in rituellen Zusammenhängen mit Charakteren, Helden und Göttern in Verbindung stehen kann. ${ }^{288}$ Gerade im Iambos des Archilochos dürfen die Attacken gegen Lykambes und seine Töchter wohl nicht im Sinne einer autobiographischen Äußerung als real gelesen werden, sondern diese Figuren stellen unter Umständen mythische 'stock-characters' in einer traditionellen Unterhaltung mit rituellem Hintergrund im Kontext von Dionysos oder Demeter dar. ${ }^{289}$ Archaischen und klassischen Dichtern, die ihre Handlungen so stark auf der Heldensage gründen, kommt nicht zuletzt selbst bisweilen Heroenstatus zu. 290

\section{Zusammenschau und abschließende Bemerkungen}

Das dynamische Zusammenspiel aller möglichen, hier im einzelnen vorgestellten Faktoren führt zu einem neuen, umfassenden Verständnis einer mythisch-rituellen Poetik in Texten der griechischen Kultur sowie anderer früher Gesellschaften. Ursprünglich kann man noch gar nicht von 'Literatur' sprechen. In einer mündlich geprägten, traditionellen Gesellschaft, wie es das archaische Griechenland zum Teil noch darstellt, bilden Mythos und Ritual die zentralen Äußerungssysteme. Mythos als autorita-

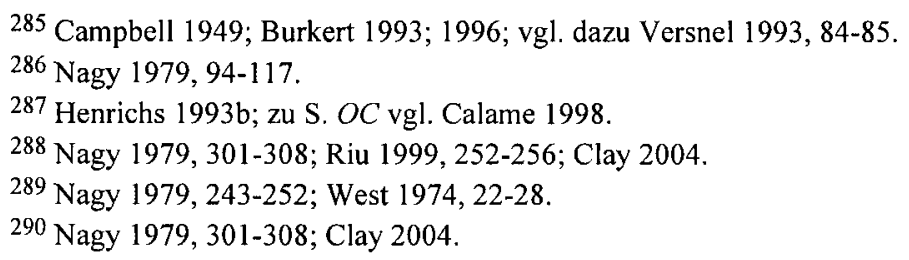


tive Rede vermittelt den Menschen die wichtigsten Themen, im Ritual werden diese performativ ausagiert. In solchen Handlungen, Performanzen und Erzählungen, in denen die Welt im großen wie im kleinen in allen Schattierungen durchgespielt wird, sind Götter, Helden, Menschen, Monster, Gespenster und Tiere die Träger der Handlung. Bestimmte Sagen- und Performanzstränge kristallisieren sich als Kanon heraus. Allerdings sind sie nie starres, immergleiches kulturelles Material, vielmehr zeichnen sich diese Diskurse durch permanente Anpassungs- und Wandlungsfähigkeit aus. Aufgrund ihres sozialen Energiepotentials stehen Mythen und Riten ständig im Austausch mit allen anderen Diskursen; sie nehmen parasitär daran teil, übernehmen Inhalte und Formen in hybrider Weise; schließlich kreieren sie Neues. Vor allem schöpfen sie gemeinsam aus kulturell grundlegenden Bildvorstellungen, die mittels Verschiebung, Kombination und Wiederholung sich in einem Geflecht von 'Texten' immer weiter fortentwickeln. Im Übergang zur Schriftlichkeit werden aus solchen kulturellen Geweben schließlich Texte. Die markierte Sprechweise von Mythos und Ritual geht direkt über in Literatur. Und selbst jetzt sind die zentralen Themen, die Götter- und Heroengeschichten, nicht einfach totes Gut, das weitergetragen wird, sondern sie werden im intertextuellen Verweisspiel für stets neue Situationen funktionalisiert. Ein Autor oder Dichter schreibt weiterhin auf der Basis einer rituell-mythischen Poetik, sein Werk wird zur Mythopoesie.

In der von der Aufklärung geprägten Moderne waren solche Ideen lange Zeit verpönt, selbst wenn sich hinter der dominanten Kultur immer wieder Ansätze einer solchen Poetik und mythischen Denkweise finden, gerade in der Romantik. Der neuzeitliche Diskurs zeichnet sich, auch unter dem Einfluß des Protestantismus, durch eine Konzentration auf das Wort und den objektiven Begriff aus. In der Performanz legt man auf die Abbildhaftigkeit und Natürlichkeit Wert. Bildlichkeit, Mythos und Rituale gelten hingegen als unseriös und volkstümlich. In der heutigen Gegenwart, in der Bilder omnipräsent sind, kann nun eine Rückbesinnung auf Mythen und Riten beobachtet werden. In einer einförmig und technokratisch empfundenen Welt rekurriert man, auch in Aufnahme von Gedanken Freuds, auf solche Erzähl- und Darstellungsformen in der Kunst, Poesie und im Film. ${ }^{291}$

${ }^{291}$ Heinrichs 2005. 
Zur Veranschaulichung, wie Vormodernes mit dem zeitgenössischen Diskurs verwoben ist, führe ich folgendes Beispiel an: Im gegenwärtigen Theater konvergieren bekanntlich Prä- und Postdramatik. Das aktuelle postdramatische Theater zeichnet sich nach H.-T. Lehmann (1999) wie folgt aus: es ist anti-aristotelisch, nicht-thetisch und ebensowenig mimetisch-referentiell. Es ahmt also keine Handlung nach. Die Spannung steht nicht im Vordergrund, vielmehr geht es um das theatrale Spiel, die Betrachtung und Selbstreflexion. Es entzieht sich einer klaren Synthese, produziert ein synästhetisches Spektakel metonymisch sich im Raum bewegender Bilder; es ist als umfassende Performance verständlich, die sich ähnlich wie das Ritual auszeichnet durch Parataxis und mangelnde Hierarchisierung, Simultaneität, Dichte und Überfülle der Zeichen, Musikalisierung, Visualisierung, Multimedialität und Körperlichkeit sowie durch eine Vorliebe für das Chorische.

Wird man beispielsweise dem antiken Theater eines Aischylos, dessen Tragödien gerade in den extensiven Chorpartien in großem Ausmaß von Ritualen und kultischen Praktiken bestimmt sind, mit solchen Kriterien nicht eher gerecht als mit naturalistischen Vorurteilen und intentionalistischen Vorannahmen in bezug auf einen angeblich ausschließlich der ratio gehorchenden Autor?

Eine umfassende kulturwissenschaftliche Gräzistik steht heute ganz am Anfang einer neuerlichen Rekonstruktion des Verständnisses kanonischer Texte aufgrund der im Kontext des Primärrezipienten vollzogenen turns in den Geisteswissenschaften. Nach den hier dargestellten Prämissen ist es ein sehr lohnendes Unterfangen, die zahlreichen Gattungen der griechischen Literatur auf ihre mythisch-rituelle Poetik hin zu untersuchen.

Anton Bierl, Seminar für Klassische Philologie, Universität Basel 


\section{Bibliographie}

Abel 1963, L.: Metatheatre. A New View of Dramatic Form, New York 1963.

Ackerman 1987, R.: J. G. Frazer. His Life and Work, Cambridge 1987.

Ackerman 1991, R.: The Myth and Ritual School. J. G. Frazer and the Cambridge Ritualists, New York/London 1991.

Alexiou 1974, M.: The Ritual Lament in Greek Tradition, 2nd edition revised by D. Yatromanolakis and P. Roilos, Lanham, MD $2002^{2}$ (Cambridge 1974 ${ }^{1}$ ).

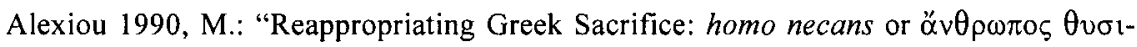

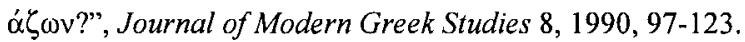

Alexiou 2002, M.: After Antiquity. Greek Language, Myth, and Metaphor, Ithaca/London 2002.

Aloni 1998, A.: Cantare glorie di eroi. Comunicazione e performance poetica nella Grecia arcaica, Turin 1998.

Alperowitz 1992, M.: Das Wirken und Walten der Götter im griechischen Roman, Heidelberg 1992.

Apte 1985, M. L.: Humor and Laughter. An Anthropological Approach, Ithaca/London 1985.

Arlen 1990, S.: The Cambridge Ritualists. An Annotated Bibliography of the Works by and about Jane Ellen Harrison, Gilbert Murray, Francis M. Cornford and Arthur Bernard Cook, Metuchen, NJ 1990.

Aronen 1992, J.: "Notes on Athenian Drama as Ritual Myth-Telling within the Cult of Dionysos", Arctos 26, 1992, 19-37.

Assmann 1977, J.: "Die Verborgenheit des Mythos in Ägypten", Göttinger Miszellen 25, $1977,7-43$.

Auerochs 2002, B.: "Literatur und Religion", in: H. D. Betz, D. S. Browing, B. Janowski und E. Jüngel (Hrsg.), $R G G, \mathrm{~V}$, Tübingen 2002 4 , 391-403.

Auffarth 1991, C.: Der drohende Untergang. 'Schöpfung' in Mythos und Ritual im Alten Orient und in Griechenland am Beispiel der Odyssee und des Ezechielbuches, Berlin/New York 1991.

Auffarth 1994, C.: "Der Opferstreik: Ein altorientalisches 'Motiv' bei Aristophanes und im homerischen Hymnus", $G B$ 20, 1994, 59-86.

Auffarth 1999, C.: "Ein seltsamer Priester und seine Jünger. Typisches und Charakteristisches im Bühnen-Sokrates des Aristophanes", in: K. Pestalozzi (Hrsg.), Der fragende Sokrates, Stuttgart/Leipzig 1999, 77-97.

Austin 1972, J. L.: Zur Theorie der Sprechakte (How to Do Things with Words), deutsche Bearbeitung von E. von Savigny, Stuttgart $1994^{2}\left(1972^{1}\right)$ (engl. Originalfassung Cambridge, MA $1962^{1}, 1975^{2}$ ).

Babcock 1978, B. (Hrsg.): The Reversible World. Symbolic Inversion in Art and Society, Ithaca 1978. 
Bachmann-Medick 1996, D.: "Einleitung", in: D. Bachmann-Medick (Hrsg.), Kultur als Text. Die anthropologische Wende in der Literaturwissenschaft, Frankfurt a. M. 1996, 7-64.

Baier 1999, T.: "Zur Funktion der Götter bei Chariton", WJA 23, 1999, 101-113.

Baines 1996, J.: "Myth and Literature", in: A. Loprieno (Hrsg.), Ancient Egyptian Literature. History and Forms, Leiden et al., 1996, 361-377.

Barchiesi/Rüpke/Stephens 2004, A./J./S. (Hrsg.): Rituals in Ink, Stuttgart 2004.

Barthes 1957, R.: Mythologies, Paris 1957 (dt. Mythen des Alltags, Frankfurt a. M. 1972', $2000^{20}$ ).

Baudy 1986, G. J.: Adonisgärten. Studien zur antiken Samensymbolik, Frankfurt a. M. 1986.

Baudy 1991, G. J.: "Das alexandrinische Erntefest. Ein Rekonstruktionsversuch", Mitteilungen für Anthropologie und Religionsgeschichte 6, 1991, 5-110.

Baudy 1992, G. J.: "Der Heros in der Kiste. Der Erichthoniosmythos als Aition athenischer Erntefeste", $A \& A$ 38, 1992, 1-47.

Baudy 1993a, G. J.: “Die Herrschaft des Wolfes. Das Thema der 'verkehrten Welt' in Euripides' Herakles", Hermes 121, 1993, 159-180.

Baudy 1993b, G. J.: "Hirtenmythos und Hirtenlied. Zu den rituellen Aspekten der bukolischen Dichtung", Poetica 25, 1993, 282-318.

Baudy 1996, G. J.: "Der Thesauros des Rhampsinit. Ein religionswissenschaftlicher Deutungsversuch zu Herodot 2.121-123", in: C. Mueller-Goldingen und K. Sier (Hrsg.), LHNAIKA. Festschrift für Carl Werner Müller zum 65. Geburtstag, Stuttgart/Leipzig 1996, 1-20.

Baudy 2004, G.: "Der Kampf um das siebentorige Theben. Zu den verschollenen Anfängen frühgriechischer Heldenepik und ihrer antiken Rezeption", in: A. Assmann und M. C. Frank (Hrsg.), Vergessene Texte, Konstanz 2004, 23-62.

Beard 1993, M.: "Looking (Harder) for Roman Myth: Dumézil, Declamation and the Problems of Definition", in: Graf 1993a, 44-64.

Beard 2000, M.: The Invention of Jane Harrison, Cambridge, MA 2000.

Beck 1982, R.: "Soteriology, the Mysteries, and the Ancient Novel: Iamblichus Babyloniaca as a Test-Case", in: U. Bianchi und M. J. Vermaseren (Hrsg.), La soteriologia dei culti orientali nell'impero romano, Leiden 1982, 527-537.

Beck 1996, R.: "Mystery Religions, Aretalogy and the Ancient Novel", in: G. Schmeling (Hrsg.), The Novel in the Ancient World, Leiden 1996, 131-150.

Bell 1992, C.: Ritual Theory, Ritual Practice, Oxford 1992.

Bennett/Tyrrell 1990, L. J./W. B.: "Making Sense of Aristophanes' Knights", Arethusa 23, 1990, 235-254.

Berti 1967, M.: "Sulla interpretazione mistica del romanzo di Longo", SCO 16, 1967, 343-358.

Bertrand 1988, J.-M.: "Les Boucôloi ou le monde à l'envers”, $R E A$ 90, 1988, 139-149. 
Bierl 1991, A. F. H.: Dionysos und die griechische Tragödie. Politische und 'metatheatralische' Aspekte im Text, Tübingen 1991.

Bierl 1994a, A.: "Karion, die Karer und der Plutos des Aristophanes als Inszenierung eines anthesterienartigen Ausnahmefestes", in: Bierl/Möllendorff 1994, 30-43.

Bierl 1994b, A.: "Apollo in Greek Tragedy: Orestes and the God of Initiation", in: Solomon 1994, 81-96 und 149-159.

Bierl 1999, A.: Rezension von Seaford 1996, Gnomon 71, 1999, 582-592.

Bierl 2001, A.: Der Chor in der Alten Komödie. Ritual und Performativität (unter besonderer Berücksichtigung von Aristophanes' Thesmophoriazusen und der Phalloslieder fr. 851 PMG), München/Leipzig 2001.

Bierl 2002a, A.: "Religion und Literatur", DNP 15/2, 2002, 669-677.

Bierl 2002b, A.: "Experimentelle Innovation und ihre rituell-pragmatischen Grenzen in der Alten Komödie", QUCC n. s. 72.3 (101), 2002, 7-21.

Bierl 2002c, A.: Rezension von Riu 1999, Gnomon 74, 2002, 196-203.

Bierl 2003, A.: "'Ich aber (sage), das Schönste ist, was einer liebt!' Eine pragmatische Deutung von Sappho Fr. 16 LP/V", QUCC n. s. 74.2 (103), 2003, 91-124.

Bierl 2004, A.: “'Turn on the Light!': Epiphany, the God-Like Hero Odysseus, and the Golden Lamp of Athena in Homer's Odyssey (Especially 19.1-43)", ICS 29, 2004, 43-61.

Bierl 2006, A.: "Tragödie als Spiel und das Satyrspiel. Die Geburt des griechischen Theaters aus dem Geiste des Chortanzes und seines Gottes Dionysos", in: J. Sánchez de Murillo und M. Thurner (Hrsg.), Kind und Spiel (Aufgang. Jahrbuch für Denken, Dichten, Musik 3), Stuttgart 2006, 111-138.

Bierl 2007, A.: "L'uso intertestuale di Alcmane nel finale della Lisistrata di Aristofane. Coro e rito nel contesto performativo", in: F. Perusino und M. Colantonio (Hrsg.), Dalla lirica corale alla poesia drammatica. Forme e funzioni del canto corale nella tragedia e nella commedia greca, Pisa 2007, 259-290.

Bierl (im Druck), A.: "'Schamanismus' und die Alte Komödie. Generischer Rückgriff auf einen Atavismus und Heilung (mit einer Anwendung am Beispiel von Aristophanes' Frieden)", in: Religion: Lehre und Praxis (Akten des Kolloquiums, Basel, 22. Oktober 2004) (Beiheft Archaiognosia 6), Athen (wahrscheinlich 2007) (im Druck).

Bierl (in Vorbereitung), A.: "Empedokles: Philosoph, Arzt, Dichter und religiöser Prophet. Vom Mythos zum Logos?" Antrittsvorlesung, Basel 13.5.2003.

Bierl/Calder/Fowler 1991, A./III, W. M./R. L. (Hrsg.): The Prussian and the Poet. The Letters of U. v. Wilamowitz-Moellendorff to G. Murray (1894-1930), Hildesheim 1991.

Bierl/Möllendorff 1994, A./P. von (unter Mitwirkung von S. Vogt) (Hrsg.): Orchestra. Drama - Mythos - Bühne. Festschrift für Hellmut Flashar anläßlich seines 65. Geburtstages, Stuttgart/Leipzig 1994.

Blumenberg 1979, H.: Arbeit am Mythos, Frankfurt a. M. $1996^{5}\left(1979^{1}\right)$. 
Boedeker 2002, D.: "Epic Heritage and Mythical Patterns in Herodotus", in: E. J. Bakker, I. J. F. de Jong und H, van Wees (Hrsg.), Brill's Companion to Herodotus, Leiden 2002, 97-116.

Bonnechère 1994, P.: Le sacrifice humain en Grèce ancienne (Kernos, Suppl. 3), Athen/Liège 1994.

Bowersock 1994, G. W.: Fiction as History. Nero to Julian, Berkeley, CA 1994.

Bowie 1993a, A. M.: Aristophanes. Myth, Ritual and Comedy, Cambridge 1993.

Bowie 1993b, A. M.: "Religion and Politics in Aeschylus' Oresteia", CQ 43, 1993, 1031.

Braund 1993, D.: "Dionysiac Tragedy in Plutarch, Crassus", CQ 43, 1993, 468-474.

Braungart 1996, W.: Ritual und Literatur, Tübingen 1996.

Braungart 1998, W.: "Einleitung", in: W. Braungart (Hrsg.), Literatur und Religion, 1998, 3-6.

Braungart 2001, W.: "Ills Krankheit, Ills Opfer. Einige Thesen zu Friedrich Dürrenmatts Der Besuch der alten Dame (1956) im Ausgang von René Girards Theorie des Sündenbocks", in: Düssel/Edel/Schödlbauer 2001, 213-224.

Braungart 2004, W.: "Tabu, Tabus. Anmerkungen zum Tabu 'ästhetischer Affirmation"”, in: W. Braungart, K. Ridder und F. Apel (Hrsg.), Wahrnehmen und Handeln. Perspektiven einer Literaturanthropologie, Bielefeld 2004, 297-327.

Braungart 2005, W.: "Warum es die Tragödie gibt und was sie mit Recht und Gerechtigkeit zu tun hat", in: S. Kaul und R. Bittner (Hrsg.), Fiktionen der Gerechtigkeit. Literatur-Film - Philosophie - Recht, Baden-Baden 2005, 93-116.

Brelich 1958, A.: Gli eroi greci, Rom 1958.

Brelich 1975, A.: "Aristofane: commedia e religione", in: M. Detienne (Hrsg.), Il mito. Guida storica e critica, Roma/Bari $1982^{3}\left(1975^{1}\right), 103-118$ (ursprünglich in: $A C D$ 5, 1969, 21-30).

Bremmer 1978, J.: "Heroes, Rituals and the Trojan War", SSR 2, 1978, 5-38.

Bremmer 1980, J.: “An Enigmatic Indo-European Rite: Paederasty”, Arethusa 13, 1980 , 279-298.

Bremmer 1983a, J.: The Early Greek Concept of the Soul, Princeton, NJ 1983.

Bremmer 1983b, J.: "Scapegoat Rituals in Ancient Greece", HSPh 87, 1983, 299-320.

Bremmer 1992, J.: "Dionysos travesti”, in: Moreau 1992, I, 189-198.

Brillante 1990, C.: "History and the Historical Interpretation of Myth", in: L. Edmunds (Hrsg.), Approaches to Greek Myth, Baltimore 1990, 93-138.

Burckhardt 1898, J.: Griechische Culturgeschichte, I, aus dem Nachlaß hrsg. von L. Burckhardt, B. von Reibnitz und J. von Ungern-Sternberg, München/Basel 2002.

Burian 1972, P.: "Supplication and Hero Cult in Sophocles' Ajax", GRBS 13, 1972, 151156.

Burkard/Thissen 2003, G./H. J.: Einführung in die altägyptische Literaturgeschichte, I, Münster 2003. 
Burkert 1962a, W.: Weisheit und Wissenschaft. Studien zu Pythagoras, Philolaos und Platon, Nürnberg 1962 (engl. Lore and Science in Ancient Pythagoreanism, Cambridge, MA 1972).

Burkert 1962b, W.: "Гóns. Zum griechischen 'Schamanismus", RhM 105, 1962, 36-55.

Burkert 1966a, W.: "Kekropidensage und Arrhephoria. Vom Initiationsritus zum Panathenäenfest", Hermes 94, 1966, 1-25 (Nachdruck in: Burkert 1990, 40-59).

Burkert 1966b, W.: "Greek Tragedy and Sacrificial Ritual", GRBS 7, 1966, 87-121 (dt. Fassung in: Burkert 1990, 13-39).

Burkert 1970, W.: "Iason, Hypsipyle, and New Fire at Lemnos. A Study in Myth and Ritual", CQ 20, 1970, 1-16 (dt. Fassung in: Burkert 1990, 60-76).

Burkert 1972, W.: Homo Necans. Interpretationen altgriechischer Opferriten und Mythen, Berlin/New York 1972.

Burkert 1977, W.: Griechische Religion der archaischen und klassischen Epoche, Stuttgart et al. 1977.

Burkert 1979, W.: Structure and History in Greek Mythology and Ritual, Berkeley/Los Angeles/London 1979.

Burkert 1982a, W.: "Götterspiel und Götterburleske in altorientalischen und griechischen Mythen", Eranos-Jb 51, 1982, 335-367.

Burkert 1982b, W.: Anthropologie des religiösen Opfers. Die Sakralisierung der Gewalt (Privatdruck: Carl Friedrich von Siemens Stiftung - Themen 40), München $1987^{2}$ $\left(1982^{\prime}\right)$.

Burkert 1984, W.: "Sacrificio-sacrilegio: Il 'trickster' fondatore", StudStor 25, 1984, 835845.

Burkert 1985, W.: "Opferritual bei Sophokles. Pragmatik-Symbolik-Theater", $A U$ 28/2, $1985,5-20$.

Burkert 1987, W.: "The Problem of Ritual Killing", in: R. G. Hamerton-Kelly (Hrsg.), Violent Origins. Walter Burkert, René Girard, and Jonathan Z. Smith on Ritual Killing and Cultural Formation, Stanford 1987, 149-176.

Burkert 1990, W.: Wilder Ursprung. Opferritual und Mythos bei den Griechen, Berlin 1990.

Burkert 1993, W.: "Mythos - Begriff, Struktur, Funktionen", in: Graf 1993a, 9-24.

Burkert 1996, W.: Creation of the Sacred. Tracks of Biology in Early Religions, Cambridge MA/London 1996 (dt. Fassung: Kulte des Altertums. Biologische Grundlagen der Religion, München 1998).

Burkert 1999, W.: "The Logic of Cosmogony", in: Buxton 1999, 87-106.

Buxton 1999, R. (Hrsg.): From Myth to Reason? Studies in the Development of Greek Thought, Oxford 1999.

Calame 1977, C.: Les chours de jeunes filles en Grèce archaïque, I-II; I: Morphologie, fonction religieuse et sociale; II: Alcman, Rom 1977 (Bd. I in engl. aktualisierter Fassung: Choruses of Young Women in Ancient Greece. Their Morphology, 
Religious Role, and Social Function, translated by D. Collins and J. Orion, Lanham et al. 1997).

Calame 1988, C. (Hrsg.): Métamorphoses du mythe en Grèce antique, Genf 1988.

Calame 1990, C.: Thésée et l'imaginaire athénien. Légende et culte en Grèce antique, Lausanne 1990.

Calame 1995, C.: The Craft of Poetic Speech in Ancient Greece, übers. von J. Orion, Ithaca/London 1995 (aktualisierte Fassung vom frz. Original Le récit en Grèce ancienne: énonciations et représentations de poètes, Paris 1986).

Calame 1998, C.: "Mort hérö̈que et culte à mystère dans l'Edipe à Colone de Sophocle", in: F. Graf (Hrsg.), Ansichten griechischer Rituale. Geburtstags-Symposium für Walter Burkert, Stuttgart/Leipzig 1998, 326-356.

Calame 2000, C.: Poétique des mythes dans la Grèce antique, Paris 2000.

Calame 2003, C.: Myth and History in Ancient Greece. The Symbolic Creation of a Colony, Princeton, NJ/Oxford 2003.

Calame 2004, C.: "Choral Forms in Aristophanic Comedy. Musical Mimesis and Dramatic Performance in Classical Athens", in: P. Murray und P. Wilson (Hrsg.), Music and the Muses. The Culture of 'Mousikê' in the Classical Athenian City, Oxford 2004, 157-184.

Calame 2005, C.: Masks of Authority. Fiction and Pragmatics in Ancient Greek Poetics, Ithaca/London 2005.

Calder 1991, III, W. M. (Hrsg.): The Cambridge Ritualists Reconsidered, Atlanta, GA 1991.

Calder/Schlesier 1998, III, W. M./R. (Hrsg.): Zwischen Rationalismus und Romantik. Karl Otfried Müller und die antike Kultur, Hildesheim 1998.

Candau Morón/González Ponce/Cruz Andreotti 2004, J. M./F. J./G. (Hrsg.): Historia y mito. El pasado legendario como fuente de autoridad, Malaga 2004.

Campbell 1949, J.: The Hero With a Thousand Faces, Princeton, NJ 2004 (commemorative edition, New York 1949 ${ }^{1}$ ) (dt. Fassung: Der Heros in tausend Gestalten, Frankfurt a. M. $1953^{1}, 1989^{3}$ ).

Cartledge 1997, P.: "Deep Plays': Theatre as Process in Greek Civic Life", in: P. E. Easterling (Hrsg.), The Cambridge Companion to Greek Tragedy, Cambridge 1997, 3-35.

Cerri 1999, G.: "La poesia di Parmenide”, QUCC n. s. 63.3 (92), 1999, 7-27.

Chiasson 2005, C. C.: "Myth, Ritual, and Authorial Control in Herodotus' Story of Cleobis and Biton (Hist. 1.31), AJPh 126, 2005, 41-64.

Clay 2004, D.: Archilochos Heros. The Cult of Poets in the Greek Polis, Cambridge, MA 2004.

Connor 1987, W. R.: "Tribes, Festivals and Processions: Civic Ceremonial and Political Manipulation in Archaic Greece", JHS 107, 1987, 40-50.

Connor 1988, W. R.: "“Sacred' and 'Secular'. 'I $\varepsilon \rho \grave{\alpha} \kappa \alpha i$ ö $\sigma \iota \alpha$ and the Classical Athenian Concept of the State", AncSoc 19, 1988, 161-188. 
Contiades-Tsitsoni 1990, E.: Hymenaios und Epithalamion. Das Hochzeitslied in der frühgriechischen Lyrik, Stuttgart 1990.

Cook 1995, E. F.: The Odyssey in Athens. Myths of Cultural Origins, Ithaca/London 1995.

Cornford 1907, F. M.: Thucydides Mythistoricus, London 1907 (Nachdruck 1965).

Cornford 1912, F. M.: From Religion to Philosophy. A Study in the Origins of Western Speculation, Princeton, NJ 1991 (Cambridge 1912 ${ }^{1}$ ).

Cornford 1914, F. M.: The Origin of Attic Comedy, ed. by J. Henderson, Ann Arbor, MI 1993 (Cambridge 1914', Garden City, NY 1961²).

Cornford 1952, F. M.: Principium Sapientiae. The Origins of Greek Philosophical Thought, Cambridge 1952.

Craik 1987, E. M.: “'One for the Pot': Aristophanes' Birds and the Anthesteria", Eranos $85,1987,25-34$.

Csapo 2005, E.: Theories of Mythology, Malden, MA 2005.

Cueva 2004, E. C.: The Myths of Fiction. Studies in the Canonical Greek Novels, Ann Arbor, MI 2004.

Cürsgen 2002, D.: Die Rationalität des Mythischen. Der philosophische Mythos bei Platon und seine Exegese im Neuplatonismus, Berlin 2002.

Degani 1987, E.: "Insulto ed escrologia in Aristofane", Dioniso 57, 1987, $31-47$.

des Bouvrie 1993, S.: "Creative Euphoria. Dionysos and the Theatre", Kernos 6, 1993 , 79-112.

Detienne 1977, M.: Dionysos mis à mort, Paris 1977.

Detienne 1986, M.: "Du polythéisme en général", $C P h$ 81, 1986, 47-55.

Detienne 1997, M.: "Expérimenter dans le champ des polythéismes", Kernos 10, 1997, 57-72.

Detienne/Vernant 1979, M./J.-P. (Hrsg.): La cuisine du sacrifice en pays grec, Paris 1979.

Dobrov 2001, G. W.: Figures of Play. Greek Drama and Metafictional Poetics, Oxford 2001.

Dodd/Faraone 2003, D. B./C. A. (Hrsg.): Initiation in Ancient Greek Rituals and Narratives. New Critical Perspectives, London/New York 2003.

Dodds 1944, E. R.: Euripides. Bacchae, edited with introduction and commentary, Oxford $1960^{2}\left(1944^{1}\right)$.

Dodds 1951, E. R.: The Greeks and the Irrational, Berkeley 1951 (dt. Fassung: Die Griechen und das Irrationale, übers. von H.-J. Dirksen, Darmstadt $1991^{2}$ ).

Döpp 1993a, S. (Hrsg.): Karnevaleske Phänomene in antiker und nachantiker Kulturen und Literaturen, Trier 1993.

Döpp 1993b, S.: "Saturnalien und lateinische Literatur", in: Döpp 1993a, 145-177.

Dowden 1999, K.: “Fluctuating Meanings: 'Passage Rites' in Ritual, Myth, Odyssey, and the Greek Romance", in: Padilla 1999, 221-243. 
Duchemin 1957, J.: "Recherche sur un thème aristophanien et ses sources religieuses: les voyages dans l'autre monde", LEC 25, 1957, 273-295.

Durkheim 1912, E.: Les formes élémentaires de la vie religieuse, Paris 1912 (Nachdruck $1960)$.

Düssel/Edel/Schödlbauer 2001, R./G./U. (Hrsg.): Die Macht der Differenzen. Beiträge zur Hermeneutik der Kultur, Heidelberg 2001.

Easterling 1988, P. E.: "Tragedy and Ritual. 'Cry 'Woe, woe', but may the good prevail'", Mètis 3, 1988, 87-109.

Easterling 1997, P. E.: “A Show for Dionysus", in: P. E. Easterling (Hrsg.), The Cambridge Companion to Greek Tragedy, Cambridge 1997, 36-53.

Elderkin 1924, G. W.: Kantharos. Studies in Dionysiac and Kindred Cult, Princeton/London 1924.

Elsbree 1991, L.: Ritual Passages and Narrative Structures, New York/Bern 1991.

Elsner 1996, J.: "Image and Ritual. Reflections on the Religious Appreciation of Classical Art”, CQ 46, 1996, 515-531.

Erbse 1986, H.: Untersuchungen zur Funktion der Götter im homerischen Epos, Berlin/New York 1986.

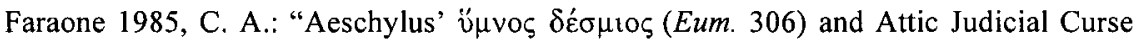
Tablets", JHS 105, 1985, 150-154.

Faraone 1993, C. A.: "Molten Wax, Spilt Wine and Mutilated Animals: Sympathetic Magic in Near Eastern and Early Greek Oath Ceremonies", JHS 113, 1993, 60-80.

Faraone 1994, C. A.: "Deianira's Mistake and the Demise of Heracles. Erotic Magic in Sophocles' Trachiniae", Helios 21, 1994, 115-135.

Faraone 1995, C. A.: "The 'Performative Future' in Three Hellenistic Incantations and Theocritus' Second Idyll", CPh 90, 1995, 1-15.

Faraone 1997, C. A.: "Salvation and Female Heroics in the Parodos of Aristophanes' Lysistrata", JHS 117, 1997, 38-59.

Farioli 2001, M.: Mundus alter. Utopie e distopie nella commedia greca antica, Mailand 2001.

Feeney 1991, D. C.: The Gods in Epic. Poets and Critics of the Classical Tradition, Oxford 1991 .

Feeney 1998, D. C.: Literature and Religion at Rome. Cultures, Contexts, and Beliefs, Cambridge 1998.

Feeney 2004, D. C.: "Interpreting Sacrificial Ritual in Roman Poetry: Disciplines and Their Models", in: Barchiesi/Rüpke/Stephens 2004, 1-21.

Fernandez 1977, J. W.: "The Performance of Ritual Metaphors", in: J. D. Sapir und J. C. Crocker (Hrsg.), The Social Use of Metaphor. Essays on the Anthropology of Rhetoric, Philadelphia 1977, 100-131.

Fernandez 1986, J. W. (Hrsg.): Persuasions and Performances. The Play of Tropes in Culture, Bloomington 1986. 
Fernandez 1991, J. W. (Hrsg.): Beyond Metaphor. The Theory of Tropes in Anthropology, Stanford 1991.

Ferrari 1997, G.: "Figures in the Text. Metaphors and Riddles in the Agamemnon", CPh 92, 1997, 1-45.

Ferrari 2002, G.: Figures of Speech. Men and Maidens in Ancient Greece, Chicago/London 2002.

Fischer-Lichte 1998a, E.: "Grenzgänge und Tauschhandel. Auf dem Wege zu einer performativen Kultur", in: Fischer-Lichte/Kreuder/Pflug 1998, 1-20.

Fischer-Lichte 1998b, E.: "Verwandlung als ästhetische Kategorie. Zur Entwicklung einer neuen Ästhetik des Performativen”, in: Fischer-Lichte/Kreuder/Pflug 1998, 2191.

Fischer-Lichte 1998c, E.: "Das theatralische Opfer", Forum Modernes Theater 13/1, $1998,42-57$.

Fischer-Lichte 1999, E.: "Für eine Ästhetik des Performativen", in: E. Goebel und W. Klein (Hrsg.), Literaturforschung heute, Berlin 1999, 221-228.

Fischer-Lichte 2004, E.: Ästhetik des Performativen, Frankfurt a. M. 2004.

Fischer-Lichte/Kreuder/Pflug 1998, E./F./I. (Hrsg.): Theater seit den 60er Jahren. Grenzgänge der Neo-Avantgarde, Tübingen/Basel 1998.

Fischer-Lichte/Wulf 2001, E./C. (Hrsg.): Theorien des Performativen, Berlin 2001.

Foley 1985, H. P.: Ritual Irony. Poetry and Sacrifice in Euripides, Ithaca 1985.

Foley 1993, H. P.: "The Politics of Tragic Lamentation", in: Sommerstein/Halliwell/ Henderson/Zimmermann 1993, 101-143.

Frazer 1890, J. G.: The Golden Bough, London 1890 (2 Bände); 1911-1915 (12 Bände).

Friedrich 1983, R.: "Drama and Ritual", in: J. Redmond (Hrsg.), Drama and Religion, Cambridge 1983, 159-223.

Friedrich 1996, R.: "Everything to Do with Dionysos? Ritualism, the Dionysiac, and Tragedy", in: M. S. Silk (Hrsg.), Tragedy and the Tragic. Greek Theatre and Beyond, Oxford 1996, 257-283.

Friedrich 2000, R.: "Dionysos Among the Dons: The New Ritualism in Richard Seaford's Commentary on the Bacchae", Arion $3^{\text {rd }}$ series 7.3, Winter 2000, 115-152.

Friedrich 2001, R.: "Don Quixote Responds to the Windmill: A Riposte to Richard Seaford on the New Ritualism", Arion $3^{\text {rd }}$ series 9.1, Spring/Summer 2001, 57-72.

Frye 1957, N.: The Anatomy of Criticism. Four Essays, Princeton 1957.

García Gual 1992, C.: "L’initiation de Daphnis et Chloé", in: Moreau 1992, II, 157-166.

Gaster 1950, T.: Thespis: Ritual, Myth and Drama in the Ancient Near East, New York $1950\left(1961^{2}\right)$.

Georgoudi 1999, S.: “A propos du sacrifice humain en Grèce ancienne: remarques critiques", $A R G 1 / 1,1999,61-82$.

Geyer 1977, A.: "Roman und Mysterienritual. Zum Problem eines Bezugs zum dionysischen Mysterienritual im Roman des Longos", WJA N. F. 3, 1977, 179-196. 
Gibert 2003, J.: “Apollo's Sacrifice. The Limits of a Metaphor in Greek Tragedy", HSPh 101, 2003, 159-206.

Girard 1961, R.: Mensonge romantique et vérité romanesque, Paris 1961.

Girard 1972, R.: La violence et le sacré, Paris 1972.

Girard 1982, R.: Le bouc émissaire, Paris 1982.

Girshausen 1999, T.: Ursprungszeiten des Theaters. Das Theater der Antike, Berlin 1999.

Gödde 2000a, S.: "Zu einer Poetik des Rituals in Aischylos' Persern", in: S. Gödde und T. Heinze (Hrsg.), Skenika. Beiträge zum antiken Theater und seiner Rezeption. Festschrift zum 65. Geburtstag von Horst-Dieter Blume, Darmstadt 2000, 31-47.

Gödde 2000b, S.: Das Drama der Hikesie. Ritual und Rhetorik in Aischylos' Hiketiden, Münster 2000.

Goldhill 1987, S.: "The Great Dionysia and Civic Ideology", JHS 107, 1987, 58-76.

Goldhill 1991, S.: The Poet's Voice. Essays on Poetics and Greek Literature, Cambridge 1991.

Goldhill 1997, S.: "Modern Critical Approaches to Greek Tragedy", in: P. E. Easterling (Hrsg.), The Cambridge Companion to Greek Tragedy, Cambridge 1997, 324-347.

Gordon 1979, R. L.: "Reason and Ritual in Greek Tragedy. On René Girard Violence and the Sacred and Marcel Detienne The Garden of Adonis", Comparative Criticism Yearbook 1, 1979, 279-310.

Graf 1987, F.: "Orpheus: A Poet Among Men", in: J. Bremmer (Hrsg.), Interpretations of Greek Mythology, London/Sydney 1987, 80-106.

Graf 1991, F.: "Religion und Mythologie im Zusammenhang mit Homer: Forschung und Ausblick", in: J. Latacz (Hrsg.), Zweihundert Jahre Homer-Forschung. Rückblick und Ausblick, Stuttgart/Leipzig 1991, 331-362.

Graf 1993a, F. (Hrsg.): Mythos in mythenloser Gesellschaft. Das Paradigma Roms, Stuttgart/Leipzig 1993.

Graf 1993b, F.: "Der Mythos bei den Römern. Forschungs- und Problemgeschichte", in: Graf 1993a, 25-43.

Graf 1996, F.: Gottesnähe und Schadenzauber. Die Magie in der griechisch-römischen Antike, München 1996.

Graf 1998, F.: "Die kultischen Wurzeln des antiken Schauspiels", in: G. Binder und B. Effe (Hrsg.), Das antike Theater. Aspekte seiner Geschichte, Rezeption und Aktualität, Trier 1998, 11-32.

Graf 2007, F.: "Religion and Drama", in: M. McDonald und M. Walton (Hrsg.), The Cambridge Companion to Greek and Roman Theatre, Cambridge (erscheint voraussichtlich 2007).

Grottanelli 1999, C.: "Ideologie del sacrificio umano: Roma e Cartagine", $A R G$ 1/1, 1999, 41-59.

Guépin 1968, J.-P.: The Tragic Paradox. Myth and Ritual in Greek Tragedy, Amsterdam 1968. 
Habinek 1990, T. N.: "Lucius' Rite of Passage", MD 25, 1990, 49-69.

Hägg 2002, T.: "Epiphany in the Greek Novels: The Emplotment of a Metaphor", Eranos $100,2002,51-61$.

Halliwell 1991, S.: "The Uses of Laughter in Greek Culture", CQ 41, 1991, 279-296.

Hame 2004, K. J.: "All in the Family: Funeral Rites and the Health of the Oikos in Aischylos' Oresteia", AJPh 125, 2004, 513-538.

Hardie 1993, P.: The Epic Successors of Virgil. A Study in the Dynamics of a Tradition, Cambridge 1993.

Harrison 1912, J. E.: Themis. A Study of the Social Origins of Greek Religion, Cambridge $1927^{2}\left(1912^{1}\right)$ (Nachdruck 1962).

Harrison 1996, S. J.: "Apuleius' Metamorphoses", in: G. Schmeling (Hrsg.), The Novel in the Ancient World, Leiden 1996, 491-516.

Harrison 1999, S. J.: "Introduction", in: S. J. Harrison (Hrsg.), Oxford Readings in the Roman Novel, Oxford 1999, xi-xxxix.

Hartog 1999, F.: "Myth into Logos': The Case of Croesus, or the Historian at Work", in: Buxton 1999, 183-195.

Heinrichs 2005, H.-J.: Expeditionen ins innere Ausland. Freud, Morgenthaler, LéviStrauss, Kerényi. Das Unbewußte im modernen Denken, Gießen 2005.

Henderson 1993, J. (Hrsg.): "Introduction", in: F. M. Cornford, The Origin of Attic Comedy, Ann Arbor, MI 1993 (1914'), xi-xxxiii.

Henrichs 1972, A.: Die Phoinikika des Lollianos. Fragmente eines neuen griechischen Romans, Bonn 1972.

Henrichs 1981, A.: "Human Sacrifice in Greek Religion: Three Case Studies", in: J. Rudhardt und $\mathrm{O}$. Reverdin (Hrsg.), Le sacrifice dans l'antiquité, Genf-Vandœuvres 1981, 195-235.

Henrichs 1984, A.: "Loss of Self, Suffering, Violence: The Modern View of Dionysus from Nietzsche to Girard", HSPh 88, 1984, 205-240.

Henrichs 1986, A.: "The Last of the Detractors. Friedrich Nietzsche's Condemnation of Euripides", GRBS 27, 1986, 369-397.

Henrichs 1987, A.: Die Götter Griechenlands. Ihr Bild im Wandel der Religionswissenschaft, Bamberg 1987.

Henrichs 1993a, A.: "'He Has a God in Him': Human and Divine in the Modern Perception of Dionysus", in: T. H. Carpenter und C. A. Faraone (Hrsg.), Masks of Dionysus, Ithaca/London 1993, 13-43.

Henrichs 1993b, A.: "The Tomb of Aias and the Prospect of Hero Cult in Sophokles", ClAnt 12, 1993, 165-180.

Henrichs 1993c, A.: "Gods in Action: The Poetics of Divine Performance in the Hymns of Callimachus", in: M. A. Harder, R. F. Regtuit und G. C. Wakker (Hrsg.), Callimachus, Groningen 1993, 127-147.

Henrichs 1994/95, A.: “'Why Should I Dance?': Choral Self-Referentiality in Greek Tragedy", Arion $3^{\text {rd }}$ series 3.1, Fall 1994/Winter 1995, 56-111. 
Henrichs 1996a, A.: 'Warum soll ich denn tanzen?'. Dionysisches im Chor der griechischen Tragödie, Stuttgart/Leipzig 1996.

Henrichs 1996b, A.: "Dancing in Athens, Dancing on Delos: Some Patterns of Choral Projection in Euripides", Philologus 140, 1996, 48-62.

Henrichs 1999, A.: "Demythologizing the Past, Mythicizing the Present: Myth, History, and the Supernatural at the Dawn of the Hellenistic Period", in: Buxton 1999, 223248.

Henrichs 2000, A.: "Drama and Dromena: Bloodshed, Violence, and Sacrificial Metaphor in Euripides", $H S P h$ 100, 2000, 173-188.

Henrichs 2001, A.: "Götterdämmerung und Götterglanz: Griechischer Polytheismus seit 1872", in: B. Seidensticker und M. Vöhler (Hrsg.), Urgeschichten der Moderne. Die Antike im 20. Jahrhundert, Stuttgart/Weimar 2001, 1-19.

Henrichs 2004, A.: "Let the Good Prevail': Perversions of the Ritual Process in Greek Tragedy", in: Yatromanolakis/Roilos 2004, 189-198.

Herzog 1992, M.: "Religionstheorie und Theologie René Girards", Kerygma und Dogma 38, 1992, 105-137.

Hild 1880, J.-A.: Aristophanes impietatis reus, Diss. Paris 1880.

Hoffman 1989, R. J.: "Ritual License and the Cult of Dionysus", Athenaeum n. s. 67, 1989, 91-115.

Hofmann 1976, H.: Mythos und Komödie. Untersuchungen zu den Vögeln des Aristophanes, Hildesheim/New York 1976.

Hölscher 1993, T.: "Mythen als Exempel der Geschichte", in: Graf 1993a, 67-87.

Hölscher 1965, U.: "Selbstgespräch", in: U. Hölscher, Die Chance des Unbehagens. Zur Situation der klassischen Studien, Göttingen 1965, 53-86.

Hölscher 1988, U.: Die Odyssee. Epos zwischen Märchen und Roman, München $1989^{2}$ $\left(1988^{l}\right)$.

Hooke 1933, S. H. (Hrsg.): Myth and Ritual. Essays on the Myth and Ritual of the Hebrews in Relation to the Culture Pattern of the Ancient East, Oxford 1933.

Hughes 1991, D. D.: Human Sacrifice in Ancient Greece, Ann Arbor, MI 1991.

Hunter 1988, R. L.: “'Short on Heroics'. Jason in the Argonautica”, CQ 38, 1988, 436453.

Hüttler 1999, M.: "Aspekte des Rituals und seine Beziehung zum Theater", Maske und Kothurn 40, 1999, 85-97.

Isler-Kerényi 2001, C.: Dionysos nella Grecia arcaica. Il contributo delle immagini, Pisa/Rom 2001.

Janka/Schäfer 2002, M./C. (Hrsg.): Platon als Mythologe. Neue Interpretationen zu den Mythen in Platons Dialogen, Darmstadt 2002.

Jeanmaire 1939, H.: Couroi et Courètes. Essai sur l'éducation spartiate et sur les rites d'adolescence dans l'antiquité hellénique, Lille 1939. 
Jeanmaire 1951, H.: Dionysos. Histoire du culte de Bacchus, Paris 1951 (Nachdruck 1978).

Jouanna 1992, J.: "Libations et sacrifices dans la tragédie grecque", $R E G$ 105, 1992, 406434.

Kaimio et al. 2001, M.: "Metatheatricality in the Greek Satyr-Play", Arctos 35, 2001, $35-$ 78.

Keller 1931, G.: Die Komödien des Aristophanes und die athenische Volksreligion seiner Zeit, Diss. Zürich, Tübingen 1931.

Kenner 1970, H.: Das Phänomen der verkehrten Welt in der griechisch-römischen Antike, Klagenfurt 1970.

Kerényi 1927, K.: Die griechisch-orientalische Romanliteratur in religionsgeschichtlicher Beleuchtung, Darmstadt $1973^{3}$ (Tübingen 1927').

Kingsley 1995, P.: Ancient Philosophy, Mystery, and Magic. Empedocles and Pythagorean Tradition, Oxford 1995.

Kingsley 2000, P.: Die Traumfahrt des Parmenides. Die mystischen Wurzeln der westlichen Zivilisation, übers. von K. Rausch, Frankfurt a. M. 2000 (engl. Originalfassung: In the Dark Places of Wisdom, Inverness, CA 1999).

Kingsley 2003, P.: Reality, Inverness, CA 2003.

Kirby 1975, E. T.: Ur-Drama. The Origins of Theatre, New York 1975.

Kohl 1988, K.-H.: "Geschichte der Religionswissenschaft", in: H. Cancik, B. Gladigow und K.-H. Kohl (Hrsg.), Handbuch religionswissenschaftlicher Grundbegriffe, I, Stuttgart 1988, 217-262.

Köpping 2003, H.-P.: "Ritual and Theatre", in: D. Kennedy (Hrsg.), The Oxford Encyclopedia of Theatre and Performance, Oxford 2003, 1139-1141.

Köpping (im Druck), H.-P.: “Theatre and Ritual - A Tandem?”, in: P. Kennedy (Hrsg.), Encyclopedia of Performance Studies, Oxford (im Druck).

Kott 1975, J.: Gott-Essen. Interpretationen griechischer Tragödien, München/Zürich 1975.

Kranz 1933, W.: Stasimon. Untersuchungen zu Form und Gehalt der griechischen Tragödie, Berlin 1933.

Krummen 1990, E.: Pyrsos Hymnon. Festliche Gegenwart und mythisch-rituelle Tradition als Voraussetzung einer Pindarinterpretation (Isthmie 4, Pythie 5, Olympie 1 und 3), Berlin/New York 1990.

Krummen 1993, E.: "Athens and Attica. Polis and Countryside in Greek Tragedy", in: Sommerstein/Halliwell/Henderson/Zimmermann 1993, 191-217.

Krummen 1998, E.: "Ritual und Katastrophe: Rituelle Handlung und Bildersprache bei Sophokles und Euripides", in: F. Graf (Hrsg.), Ansichten griechischer Rituale. Geburtstags-Symposium für Walter Burkert, Stuttgart/Leipzig 1998, 296-325.

Krummen 2004, E.: "Dido als Mänade und tragische Heroine. Dionysische Thematik und Tragödientradition in Vergils Didoerzählung", Poetica 36, 2004, 25-69. 
Kulenkampff 1993, J.: "Mythos oder Logos?", in: L. Bornscheuer, H. Kaiser und J. Kulenkampff (Hrsg.), Glaube - Kritik - Phantasie. Europäische Aufklärung in Religion und Politik, Wissenschaft und Literatur, Frankfurt a. M. et al. 1993, 151-168.

Kullmann 1987, W.: "Deutung und Bedeutung der Götter bei Euripides", in: Mythos. Deutung und Bedeutung, Innsbruck 1987, 7-22.

Kurke 2005, L.: “Choral Lyric as 'Ritualization': Poetic Sacrifice and Poetic Ego on Pindar's Sixth Paian", ClAnt 24, 2005, 81-132.

Kuschel 1997, K.-J.: "Literatur und Religion", in: W. Kasper et al. (Hrsg.), Lexikon für Theologie und Kirche, VI, Freiburg et al. 19973 , 965-966.

Lada-Richards 1997, I.: "Neoptolemus and the Bow: Ritual thea and Theatrical Vision in Sophocles' Philoctetes", JHS 117, 1997, 179-183.

Lada-Richards 1999, I.: Initiating Dionysus. Ritual and Theatre in Aristophanes' Frogs, Oxford 1999.

Lakoff/Johnson 1980, G./M.: Metaphors We Live By, Chicago 1980.

Lakoff/Turner 1989, G./M.: More Than Cool Reason. A Field Guide to Poetic Metaphor, Chicago/London 1989.

Lalanne 2006, S.: Une éducation grecque. Rites de passage et construction des genres dans le roman grec ancien, Paris 2006.

Leach 1982, E.: "Introduction", in: M. I. Steblin-Kamenskij (Hrsg.), Myth, Ann Arbor, MI 1982, 1-20.

Lefèvre 1988, E.: "Saturnalien und Palliata", Poetica 20, 1988, 32-46.

Lehmann 1999, H.-T.: Postdramatisches Theater, Frankfurt a. M. $2001^{2}\left(1999^{\prime}\right)$.

Leitao 1995, D. D.: "The Perils of Leukippos: Initiatory Transvestism and Male Gender Ideology in the Ekdusia at Phaistos", ClAnt 14, 1995, 130-163.

Lloyd-Jones 1971, H.: The Justice of Zeus, Berkeley/Los Angeles/London $1983^{2}\left(1971^{1}\right)$.

Lloyd-Jones 1998, H.: "Ritual and Tragedy", in: F. Graf (Hrsg.), Ansichten griechischer Rituale. Geburtstags-Symposium für Walter Burkert, Stuttgart/Leipzig 1998, 271295.

Lonsdale 1993, S. H.: Dance and Ritual Play in Greek Religion, Baltimore/London 1993.

Loprieno 1996, A.: "Defining Egyptian Literature: Ancient Texts and Modern Theories", in: A. Loprieno (Hrsg.), Ancient Egyptian Literature. History and Forms, Leiden/ New York/Köln 1996, 39-58.

Lord 1960, A. B.: The Singer of Tales, Cambridge, MA 1960.

MacQueen 1990, B. D.: Myth, Rhetoric and Fiction. A Reading of Longus's Daphnis and Chloe, Lincoln, NE 1990.

Maiullari 2004, F.: Omero anti-Omero. Le incredibili storie di un trickster giullare alla corte micenea, Rom 2004.

Mannhardt 1865, W.: Roggenwolf und Roggenhund. Beitrag zur germanischen Sittenkunde, Danzig 1865. 
Mannhardt 1868, W.: Die Korndämonen. Beitrag zur germanischen Sittenkunde, Berlin 1868.

Mannhardt 1875/1877, W.: Wald- und Feldkulte, I-II; I: Der Baumkultus der Germanen und ihrer Nachbarstämme: Mythologische Untersuchungen; II: Antike Wald- und Feldkulte aus nordeuropäischer Überlieferung erläutert, Berlin 1875-1877 (1904$1905^{2}$ ).

Mannhardt 1884, W.: Mythologische Forschungen, Straßburg 1884.

Martin 1987, R. P.: "Fire on the Mountain: Lysistrata and the Lemnian Women", ClAnt $6,1987,77-105$.

Martin 1989, R. P.: The Language of Heroes. Speech and Performance in the Iliad, Ithaca/London 1989.

Mazzoli 1982, G.: "L'Apocolocyntosis di Seneca. Un 'monde à l'envers"', Vichiana 11, $1982,193-211$.

Meier 1988, C.: Die politische Kunst der griechischen Tragödie, München 1988.

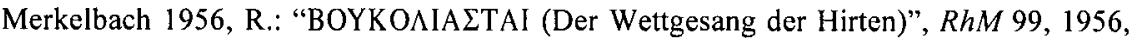
97-133 (Nachdruck in: R. Merkelbach, Hestia und Erigone. Vorträge und Aufsätze, hrsg. von W. Blümel, B. Kramer, J. Kramer und C. E. Römer, Stuttgart/Leipzig 1996, 129-161).

Merkelbach 1957, R.: "Sappho und ihr Kreis", Philologus 101, 1957, 1-29 (Nachdruck in: R. Merkelbach, Hestia und Erigone. Vorträge und Aufsätze, hrsg. von W. Blümel, B. Kramer, J. Kramer, C. E. Römer, Stuttgart/Leipzig 1996, 87-114).

Merkelbach 1962, R.: Roman und Mysterium in der Antike, München 1962.

Merkelbach 1988, R.: Die Hirten des Dionysos. Die Dionysos-Mysterien der römischen Kaiserzeit und der bukolische Roman des Longus, Stuttgart 1988.

Merkelbach 1994, R.: "Novel and Aretalogy", in: J. Tatum (Hrsg.), The Search for the Ancient Novel, Baltimore 1994, 283-295 (Nachdruck in: R. Merkelbach, Philologica, hrsg. von W. Blümel, H. Engelmann, B. Kramer, J. Kramer und C. E. Römer, Stuttgart / Leipzig 1997, 130-142).

Merkelbach 1995, R.: Isis Regina - Zeus Sarapis. Die griechisch-ägyptische Religion nach den Quellen dargestellt, Stuttgart/Leipzig $2001^{2}\left(1995^{1}\right)$.

Meuli 1935, K.: "Scythica", Hermes 70, 1935, $121-176$ (Nachdruck mit Ergänzungen in: Gesammelte Schriften, hrsg. von T. Gelzer, II, Basel/Stuttgart 1975, 817-879).

Meuthen 1993, E.: "Säkularisationsformen religiös fundierter Subjektivitätsstrukturen im Roman des 18. Jahrhunderts (Rousseau/Goethe)", in: L. Bornscheuer, H. Kaiser und J. Kulenkampff (Hrsg.), Glaube - Kritik - Phantasie. Europäische Aufklärung in Religion und Politik, Wissenschaft und Literatur, Frankfurt a. M. et al. 1993, 169-180.

Miles 1995, G. M.: Livy. Reconstructing Early Rome, Ithaca 1995.

Möllendorff 1995, P. von: Grundlagen einer Ästhetik der Alten Komödie. Untersuchungen zu Aristophanes und Michail Bachtin, Tübingen 1995.

Moors 1982, K. F.: Platonic Myth. An Introductory Study, Washington DC 1982. 
Moreau 1992, A. (Hrsg.): L'initiation, I-II; I: Les rites d'adolescence et les mystères; II: $L$ 'acquisition d'un savoir ou d'un pouvoir: Le lieu initiatique: parodies et perspectives (Actes du colloque international de Montpellier, 11-14 avril 1991), Montpellier 1992.

Morgan 2000, K. A.: Myth and Philosophy from the Presocratics to Plato, Cambridge 2000.

Most 1990, G.: "Strenge Erforschung wilder Ursprünge. Walter Burkert über Mythos und Ritus", Vorwort zu Burkert 1990, 7-12.

Most 1999, G. W.: "From Logos to Mythos", in: Buxton 1999, 25-47.

Müller 1825, K. O.: Prolegomena zu einer wissenschaftlichen Mythologie, Göttingen 1825.

Münstermann 1995, H.: Apuleius. Metamorphosen literarischer Vorlagen. Untersuchung dreier Episoden des Romans unter Berücksichtigung der Philosophie und Theologie des Apuleius, Stuttgart/Leipzig 1995.

Münz 1998, R.: Theatralität und Theater. Zur Historiographie von Theatralitätsgefügen, hrsg. von G. Amm, Berlin 1998.

Murnaghan 1987, S.: Disguise and Recognition in the Odyssey, Princeton 1987.

Murnaghan 1995, S.: "The Plan of Athena", in: B. Cohen (Hrsg.), The Distaff Side. Representing the Female in Homer's Odyssey, New York/Oxford 1995, 61-80.

Murray 1912, G.: "Excursus on the Ritual Forms Preserved in Greek Tragedy", in: Harrison 1912, 341-369.

Murray 1999, P.: "What Is a Mythos for Plato", in: Buxton 1999, 251-262.

Nagy 1979, G.: The Best of the Achaeans. Concepts of the Hero in Archaic Greek Poetry, revised edition, Baltimore/London $1999^{2}\left(1979^{1}\right)$.

Nagy 1990, G.: Pindar's Homer. The Lyric Possession of an Epic Past, Baltimore/London 1990.

Nagy 1994/95, G.: "Genre and Occasion", Mètis 9-10, 1994/95, 11-25.

Nauta 1987, R. R.: "Seneca's Apocolocyntosis as Saturnalian Literature", Mnemosyne 40, 1987, 69-96.

Nesselrath 1996, H.-G.: "Herodot und der griechische Mythos", Poetica 28, 1996, 275296.

Nesselrath 1999, H.-G.: "Mythos - Logos - Mytho-logos: Zum Mythos-Begriff der Griechen und ihrem Umgang mit ihm", in: P. Rusterholz und R. Moser (Hrsg.), Form und Funktion des Mythos in archaischen und modernen Gesellschaften, Bern/Stuttgart 1999, 1-26.

Nestle 1940, W.: Vom Mythos zum Logos. Die Selbstentfaltung des griechischen Denkens von Homer bis auf die Sophistik und Sokrates, Stuttgart $1975^{2}\left(1940^{1}\right)$.

Neumann 2000, G.: "Begriff und Funktion des Rituals im Feld der Literaturwissenschaft", in: Neumann/Weigel 2000, 19-52.

Neumann/Weigel 2000, G./S. (Hrsg.): Lesbarkeit der Kultur. Literaturwissenschaften zwischen Kulturtechnik und Ethnographie, München 2000. 
Nietzsche 1872, F.: "Die Geburt der Tragödie aus dem Geiste der Musik, 1872", in: G. Colli und M. Montinari (Hrsg.), Nietzsche Werke. Kritische Gesamtausgabe, III.1, Berlin/New York 1972, 17-152.

Obbink 1993, D.: "Dionysus Poured Out. Ancient and Modern Theories of Sacrifice and Cultural Formation", in: T. H. Carpenter und C. A. Faraone (Hrsg.), Masks of Dionysus, Ithaca/London 1993, 65-86.

O'Connor-Visser 1987, E. A. M. E.: Aspects of Human Sacrifice in the Tragedies of Euripides, Amsterdam 1987.

Padilla 1992, M.: "The Heraclean Dionysus: Theatrical and Social Renewal in Aristophanes' Frogs", Arethusa 25, 1992, 359-384.

Padilla 1999, M. W. (Hrsg.): Rites of Passage in Ancient Greece: Literature, Religion, Society, Lewisburg 1999.

Papadopoulou-Belmehdi 1994, I.: Le chant de Pénélope. Poétique du tissage féminin dans l'Odyssée, Paris 1994.

Pappas 1987, T.: "Contributo a uno studio antropologico della commedia attica antica: struttura e funzione degli exodoi nelle commedie di Aristofane", Dioniso 57, 1987, 191-202.

Paradiso 1987, A.: "Le rite de passage du Ploutos d'Aristophane", Mètis 2, 1987, 249267.

Pascal 1911, C.: Dioniso. Saggio sulla religione e la parodia religiosa in Aristofane, Catania 1911.

Peirce 1993, S.: "Death, Revelry, and Thysia", ClAnt 12, 1993, 219-266 und Abb. 1-18.

Petersmann 1981, H.: "Homer und das Märchen", WS 94, 1981, 43-68.

Petrovic 2004, I.: “ФАРМАKЕYТPIA ohne ФAPMAKON. Überlegungen zur Komposition des zweiten Idylls von Theokrit", Mnemosyne 57, 2004, 421-444.

Pickard-Cambridge 1927, A. W.: Dithyramb, Tragedy and Comedy, Oxford 1927 (rev. $\left.1962^{2}\right)$.

Propp 1972, V.: Morphologie des Märchens, München 1972 (russische Erstauflage 1928).

Pucci 1977, P.: "Euripides. The Monument and the Sacrifice", Arethusa 10, 1977, 165195.

Pulleyn 1997, S.: Prayer in Greek Religion, Oxford 1997.

Radin 1956, P.: The Trickster. A Study in American Indian Mythology, London 1956.

Radke 2003, G.: Tragik und Metatragik. Euripides' Bakchen und die moderne Literaturwissenschaft, Berlin/New York 2003.

Reece 1993, S.: The Stranger's Welcome. Oral Theory and the Aesthetics of the Homeric Hospitality Scene, Ann Arbor, MI 1993.

Reinhold 1984, M.: Classica Americana. The Greek and Roman Heritage in the United States, Detroit 1984. 
Reitzenstein 1893, R.: Epigramm und Skolion. Ein Beitrag zur Geschichte der alexandrinischen Dichtung, Gießen 1893.

Richardson 1978, R. D. Jr.: Myth and Literature in the American Renaissance, Bloomington 1978.

Riedweg 1987, C.: Mysterienterminologie bei Platon, Philon und Klemens von Alexandrien, Berlin/New York 1987.

Riedweg 1995, C.: "Orphisches bei Empedokles", $A \& A$ 41, 1995, 34-59.

Riedweg 1998, C.: "Initiation - Tod - Unterwelt", in: F. Graf (Hrsg.), Ansichten griechischer Rituale. Geburtstags-Symposium für Walter Burkert, Stuttgart/Leipzig 1998, 359-398.

Rieks 1975, R.: "Eine tragische Erzählung bei Herodot (Hist. 1.34-45)", Poetica 7, 1975 , 23-44.

Riess 2001, W.: Apuleius und die Räuber. Ein Beitrag zur historischen Kriminalitätsforschung, Stuttgart 2001.

Riu 1999, X.: Dionysism and Comedy, Lanham et al. 1999.

Robinson 2002, A.: The Life and Work of Jane Ellen Harrison, Oxford 2002.

Rosenmeyer 1982, T. G.: The Art of Aeschylus, Berkeley/Los Angeles/London 1982.

Rösler 1986, W.: "Michail Bachtin und die Karnevalskultur im antiken Griechenland", QUCC n. s. 23 (52), 1986, 25-44.

Rösler 1993, W.: "Über Aischrologie im archaischen und klassischen Griechenland", in: Döpp 1993a, 75-97.

Ruh 1980, U.: Säkularisierung als Interpretationskategorie. Zur Bedeutung des christlichen Erbes in der modernen Geistesgeschichte, Freiburg i. Br. 1980.

Ruh 1998, U.: "Literatur und Säkularisierungsprozeß", Deutschunterricht 50/5, 1998, 713.

Ruiz-Montero 1988, C.: La estructura del la novela griega. Análisis funcional, Salamanca 1988.

Schauer 2002, M.: Tragisches Klagen. Form und Funktion der Klagedarstellung bei Aischylos, Sophokles und Euripides, Tübingen 2002.

Schechner 1990, R.: Theater-Anthropologie. Spiel und Ritual im Kulturvergleich, übers. von S. Winnacker, Reinbek bei Hamburg 1990.

Schefer 1996, C.: Platon und Apollon. Vom Logos zurück zum Mythos, Sankt Augustin 1996.

Schefer 2000, C.: “'Nur für Eingeweihte!' Heraklit und die Mysterien”, $A \& A 46,2000$, 46-75.

Schefer 2001, C.: Platons unsagbare Erfahrung. Ein anderer Zugang zu Platon, Basel 2001.

Schlesier 1983, R.: "Daimon und Daimones bei Euripides", Saeculum 34, 1983, 267-279.

Schlesier 1993, R.: "Mixture of Masks: Maenads as Tragic Models", in: T. H. Carpenter und C. A. Faraone (Hrsg.), Masks of Dionysus, Ithaca/London 1993, 89-114. 
Schlesier 1994, R.: Kulte, Mythen und Gelehrte. Anthropologie der Antike seit 1800, Frankfurt a. M. 1994.

Schlesier 1995, R.: "Lust durch Leid: Aristoteles' Tragödientheorie und die Mysterien", in: W. Eder (Hrsg.), Die athenische Demokratie im 4. Jahrhundert v. Chr. - Krise oder Vollendung einer Verfassungsform?, Stuttgart 1995, 389-415.

Schlesier 1998, R.: “'Dieser mystische Gott'. Dionysos im Spiegel von Karl Otfried Müllers Religionstheorie", in: Calder/Schlesier 1998, 397-421.

Schmitt Pantel 1992, P.: La cité au banquet. Histoire des repas publics dans les cités grecques, Rom 1992.

Scullion 2002, S.: "Nothing to Do With Dionysus': Tragedy Misconceived as Ritual", CQ 52, 2002, 102-137.

Seaford 1981, R.: "Dionysiac Drama and the Dionysiac Mysteries", CQ 31, 1981, 252275.

Seaford 1984, R. A. S.: Euripides. Cyclops, edited with introduction and commentary, Oxford $1988^{2}\left(1984^{1}\right)$.

Seaford 1986, R.: "Immortality, Salvation, and the Elements", $H S P h$ 90, 1986, 1-26.

Seaford 1987, R.: "The Tragic Wedding", JHS 107, 1987, 106-130.

Seaford 1993, R.: "Dionysus as Destroyer of the Houeshold: Homer, Tragedy, and the Polis", in: T. H. Carpenter und C. A. Faraone (Hrsg.), Masks of Dionysus, Ithaca/ London 1993, 115-146.

Seaford 1994a, R.: Reciprocity and Ritual. Homer and Tragedy in the Developing CityState, Oxford 1994.

Seaford 1994b, R.: "Sophokles and the Mysteries", Hermes 122, 1994, 275-288.

Seaford 1996, R.: Euripides. Bacchae, with an introduction, translation and commentary, Warminster 1996.

Segal 1981, C.: Tragedy and Civilization. An Interpretation of Sophocles, Cambridge MA/London 1981.

Segal 1982, C.: Dionysiac Poetics and Euripides' Bacchae, expanded edition with a new afterword by the author, Princeton, NJ $1997^{2}\left(1982^{1}\right)$.

Segal 1994a, C.: "Female Mourning and Dionysiac Lament in Euripides' Bacchae", in: Bierl/Möllendorff 1994, 12-18.

Segal 1994b, C.: Singers, Heroes, and Gods in the Odyssey, Ithaca/London 1994.

Seidensticker 1979, B.: "Sacrificial Ritual in the Bacchae", in: G. W. Bowersock, W. Burkert und M. C. J. Putnam (Hrsg.), Arktouros. Hellenic Studies Presented to Bernard M.W. Knox on the Occasion of his 65th Birthday, Berlin/New York 1979, 181-190.

Sfyroeras 1992, P. V.: The Feast of Poetry: Sacrifice, Foundation, and Performance in Aristophanic Comedy, Diss. Princeton, NJ 1992.

Sfyroeras 2004, P.: "From Sacrifice to Feast. A Ritual Pattern in Aristophanic Comedy", in: D. L. Cairns und R. A. Knox (Hrsg.), Law, Rhetoric, and Comedy in Classical 
Athens. Essays in Honour of Douglas M. MacDowell, London/Swansea 2004, 251268.

Smith 1989, N. D.: "Diviners and Divination in Aristophanic Comedy", ClAnt 8, 1989, 140-158.

Solomon 1994, J. (Hrsg.): Apollo. Origins and Influences, Tucson/London 1994.

Sommerstein/Halliwell/Henderson/Zimmermann 1993, A. H./S./J./B. (Hrsg.): Tragedy, Comedy and the Polis. Papers from the Greek Drama Conference, Nottingham, 18 20 July 1990, Bari 1993.

Sourvinou-Inwood 1988, C.: Studies in Girls' Transitions. Aspects of the Arkteia and Age Representation in Attic Inconography, Athen 1988.

Sourvinou-Inwood 1990, C.: "What is Polis Religion?", in: O. Murray und S. Price (Hrsg.), The Greek City. From Homer to Alexander, Oxford 1990, 295-322.

Sourvinou-Inwood 1991, C.: "'Myth' and History: On Herodotus 3.48 and 3.50-53", in: C. Sourvinou-Inwood, 'Reading' Greek Culture. Texts and Images, Rituals and Myths, Oxford 1991, 244-284.

Sourvinou-Inwood 2003, C.: Tragedy and Athenian Religion, Lanham, MD 2003.

Stadter 2004, P. A.: "From the Mythical to the Historical Paradigm. The Transformation of Myth in Herodotus", in: Candau Morón/González Ponce/Cruz Andreotti 2004, 3146.

Stehle 2004, E.: "Choral Prayer in Greek Tragedy. Euphemia or Aischrologia?", in: P. Murray und P. Wilson (Hrsg.), Music and the Muses. The Culture of 'Mousikê' in the Classical Athenian City, Oxford 2004, 121-155.

Stehle 2005, E.: "Prayer and Curse in Aeschylus' Seven Against Thebes", CPh 100, 2005, 101-122.

Svenbro 1984, J.: "La découpe du poème. Notes sur les origines sacrificielles de la poétique grecque", Poétique 15, 1984, 215-232.

Tambiah 1985, S. J.: "A Performative Approach to Ritual", in: S. J. Tambiah, Culture, Thought, and Social Action. An Anthropological Perspective, Cambridge, MA/ London 1985, 123-166, 364-368, 382-389.

Tervooren 1993, H.: "Säkularisierungen und Sakralisierungen in der deutschen Liebeslyrik des Mittelalters", in: L. Bornscheuer, H. Kaiser und J. Kulenkampff (Hrsg.), Glaube - Kritik - Phantasie. Europäische Aufklärung in Religion und Politik, Wissenschaft und Literatur, Frankfurt a. M. et al. 1993, 213-231.

Teuber 1993, B.: "Zur Schreibkunst eines Zirkusreiters: Karnevaleskes Erzählen im Goldenen Esel des Apuleius und die Sorge um sich in der antiken Ethik", in: Döpp 1993a, 179-238.

Teuber 2000, B.: "Die frühneuzeitliche Tragödie als Opfer auf dem Theater? Inszenierungsformen ritueller Gewalt im spanischen Barock und in der französischen Klassik", in: Neumann/Weigel 2000, 79-99.

Thiercy 1986, P.: Aristophane. Fiction et dramaturgie, Paris 1986. 
Thomas 1989, J.: “De l'ordalie à l'initiation. Le voyage d'Enée", Latomus 48, 1989, 3645.

Thomas 1998, K.: "Ritual und Vergessen. Zu René Girards Theorem der méconnaissance", in: A. Schäfer und M. Wimmer (Hrsg.), Rituale und Ritualisierungen, Opladen 1998, 109-115.

Thomson 1953, G.: "From Religion to Philosophy", JHS 73, 1953, 77-83.

Thomson 1957, G.: Aischylos und Athen. Eine Untersuchung der gesellschaftlichen Ursprünge des Dramas, übers. von H.-G. Heidenreich, Berlin $1985^{3}\left(1957^{1}\right.$ ) (engl. Originalfassung: Aeschylus and Athens, London 1941, 1946 ${ }^{2}$ ).

Thomson 1968, G.: Die ersten Philosophen, Berlin $1980^{4}\left(1968^{\prime}\right)$ (engl. Originalfassung: The First Philosophers. Studies in Ancient Greek Society, London 1955').

Todorov 1978, T.: Les genres du discours, Paris 1978.

Too 1996, Y. L.: "Statues, Mirrors, Gods: Controlling Images in Apuleius", in: J. Elsner (Hrsg.), Art and Text in Roman Culture, Cambridge 1996, 133-152.

Treu 1999, M.: Undici cori comici. Aggressività, derisione e tecniche drammatiche in Aristofane, Genua 1999.

Turcan 1963, R.: “Le roman 'initiatique': A propos d'un livre récent", $R H R$ 163, 1963, 149-199 (Rezension von Merkelbach 1962).

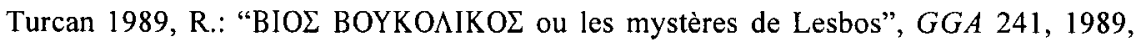
169-192 (Rezension von Merkelbach 1988).

Turner 1967, V.: The Forest of Symbols. Aspects of Ndembu Ritual, Ithaca/London 1967.

Turner 1974, V.: Dramas, Fields, and Metaphors. Symbolic Action in Human Society, Ithaca/London 1974.

Turner 1989, V.: Vom Ritual zum Theater. Der Ernst des menschlichen Spiels, übers. von S. M. Schomburg-Scherff, Frankfurt a. M./New York 1989 (engl, Originalfassung: From Ritual to Theatre. The Human Seriousness of Play, New York 1982).

Tyrrell/Brown 1991, W. B./F. S.: Athenian Myths and Institutions. Words in Action, New York/Oxford 1991.

Ungern-Sternberg 1993, J. von: "Romulus-Bilder. Die Begründung der Republik im Mythos", in: Graf 1993a, 88-108.

Usener 1897, H.: "Der Stoff des griechischen Epos", Sitzungsberichte der Kaiserlichen Akademie der Wissenschaften in Wien, Philosophisch-Historische Classe, 137/3, 1897, 1-63 (zitiert nach Kleine Schriften, IV, Leipzig/Berlin 1913, 199-259).

Usener 1904, H.: "Heilige Handlung", $A R W$ 7, 1904, 281-339 (zitiert nach Kleine Schriften, IV, Leipzig/Berlin 1913, 422-467).

van Gennep 1909, A.: Les rites de passage. Etude systématique des rites, Paris 1909 (dt. Übergangsriten, übers. von K. Schomburg und S. M. Schomburg-Scherff. Mit einem Nachwort von S. M. Schomburg-Scherff, Frankfurt a. M. 1986).

van Straten 1995, F. T. W.: 'I $\varepsilon \rho \dot{\alpha} \kappa \alpha \lambda \alpha$ : Images of Animal Sacrifice in Archaic and Classical Greece, Leiden 1995. 
Vernant 1972, J.-P.: "Ambiguité et renversement. Sur la structure énigmatique d' Edipe Rol", in: Vernant/Vidal-Naquet I 1972/1986, 99-131.

Vernant 1981, J.-P.: "Théorie générale du sacrifice et mise à mort dans la $\Theta Y \Sigma I A$ grecque", in: J. Rudhardt und O. Reverdin (Hrsg.), Le sacrifice dans l'antiquité, GenfVandœuvres 1981, 1-21.

Vernant 1987, J.-P.: Mythos und Gesellschaft im alten Griechenland, übers. von G. Roßler, Frankfurt a. M. 1987 (franz. Originalfassung: Mythe et société en Grèce ancienne, 1974).

Vernant/Vidal-Naquet 1972/1986, J.-P./P. (Hrsg.): Mythe et tragédie en Grèce ancienne, I-II, Paris $1972\left(1986^{3}\right)-1986$.

Versnel 1993, H. S.: Inconsistencies in Greek and Roman Religion, II: Transition and Reversal in Myth and Ritual, Leiden/New York/Köln 1993.

Versnel 1998, H. S.: "Komödie, Utopie und verkehrte Welt", in: G. Binder und B. Effe (Hrsg.), Das antike Theater. Aspekte seiner Geschichte, Rezeption und Aktualität, Trier 1998, 93-114.

Vickery 1966, J. B. (Hrsg.): Myth and Literature. Contemporary Theory and Practice, Lincoln $1973^{3}\left(1966^{1}\right)$.

Vidal-Naquet 1968, P.: "Le chasseur noir et l'origine de l'éphébie athénienne", Annales (Économie, Sociétés, Civilisations) 23, 1968, $947-964$ (dt. in: P. Vidal-Naquet, Der Schwarze Jäger. Denkformen und Gesellschaftsformen in der griechischen Antike, übers. von A. Wittenburg, Frankfurt a. M./New York 1989, 105-122 und 294-299).

Vidal-Naquet 1969, P.: "Chasse et sacrifice dans l'Orestie d'Eschyle", PP 129, 1969, 401-425 (Nachdruck in: Vernant/Vidal-Naquet I 1972/1986, 133-158).

Waldner 2000, K.: Geburt und Hochzeit des Kriegers. Geschlechterdifferenz und Initiation in Mythos und Ritual der griechischen Polis, Berlin/New York 2000.

Warning 1976, R.: "Elemente einer Pragmasemiotik der Komödie", in: W. Preisendanz und R. Warning (Hrsg.), Das Komische, München 1976, 279-333.

West 1974, M. L.: Studies in Greek Elegy and Iambus, Berlin/New York 1974.

West 1983, M. L.: The Orphic Poems, Oxford 1983.

West 2004, S.: "Herodotus on Aristeas", in: C. J. Tuplin (Hrsg.), Pontus and the Outside World. Studies in Black Sea History, Historiography, and Archaeology, Leiden 2004, 43-67.

White 1971, J. J.: Mythology in the Modern Novel. A Study of Prefigurative Techniques, Princeton, NJ 1971.

Wilamowitz-Moellendorff 1884 , U. von: Homerische Untersuchungen, Hildesheim $1991^{3}$ (Berlin 1884').

Winkler 1980, J. J.: "Lollianos and the Desperadoes", JHS 100, 1980, 155-181.

Winkler 1985, J. J.: Auctor and Actor. A Narratological Reading of Apuleius's Golden Ass, Berkeley/Los Angeles/Oxford 1985. 
Winkler 1990, J. J.: "The Ephebes' Song: Tragôidia and Polis", in: J. J. Winkler und F. I. Zeitlin (Hrsg.), Nothing to Do with Dionysos? Athenian Drama in Its Social Context, Princeton, NJ 1990, 20-62 (ursprünglich in: Representations 11, 1985, 26-62).

Winnington-Ingram 1980, R. P.: Sophocles. An Interpretation, Cambridge 1980.

Wirth 2002, U.(Hrsg.): Performanz. Zwischen Sprachphilosophie und Kulturwissenschaften, Frankfurt a. M. 2002.

Wiseman 1995, T. P.: Remus. A Roman Myth, Cambridge 1995.

Wiseman 2002, T. P.: "History, Poetry, and Annales", in: D. S. Levene und D. P. Nelis (Hrsg.), Clio and the Poets. Augustan Poetry and the Traditions of Ancient Historiography, Leiden/Boston/Köln 2002, 331-362.

Wiseman 2004, T. P.: The Myths of Rome, Exeter 2004.

Wojaczek 1969, G.: Daphnis. Untersuchungen zur griechischen Bukolik, Meisenheim am Glan 1969.

Wolff 1992, C.: "Euripides' Iphigenia among the Taurians: Aetiology, Ritual, and Myth", ClAnt 11, 1992, 308-334.

Wunenburger 1994, J.-J.: "Mytho-phorie: formes et transformations du mythe", Religiologiques 10, automne 1994, 49-70.

Yatromanolakis 2003, D.: "Ritual Poetics in Archaic Lesbos. Contextualizing Genre in Sappho", in: Yatromanolakis/Roilos 2003, 43-59.

Yatromanolakis/Roilos 2003, D./P.: Towards a Ritual Poetics, Athen 2003.

Yatromanolakis/Roilos 2004, D./P. (Hrsg.): Greek Ritual Poetics, Cambridge, MA 2004.

Zannini Quirini 1987, B.: Nephelokokkygia. La prospettiva mitica degli Uccelli di Aristofane, Rom 1987.

Zaslavsky 1981, R.: Platonic Myth and Platonic Writing, Washington DC 1981.

Zeitlin 1965, F. I.: "The Motif of the Corrupted Sacrifice in Aeschylus' Oresteia", TAPhA 96, 1965, 463-508.

Zeitlin 1966, F. I.: "Postscript to Sacrificial Imaginary in the Oresteia (Ag. 1235-37)", TAPhA 97, 1966, 645-653.

Zeitlin 1978, F. I.: "The Dynamics of Misogyny: Myth and Mythmaking in the Oresteia", Arethusa 11, 1978, 149-184.

Zeitlin 1989, F. I.: "Mysteries of Identity and Designs of the Self in Euripides' Ion", PCPhS 215, 1989, 144-197.

Zeitlin 1991, F. I.: "Introduction", in: J.-P. Vernant, Mortals and Immortals. Collected Essays, ed. by F. I. Zeitlin, Princeton, NJ 1991, 3-24.

Zhmud 1997, L.: Wissenschaft, Philosophie und Religion im frühen Pythagoreismus, Berlin 1997. 